\title{
Dendrimers and derivatives as a potential therapeutic tool in regenerative medicine strategies $-\mathrm{A}$ review
}

\author{
Joaquim Miguel Oliveira ${ }^{a, b}$, António José Salgado ${ }^{c}$, Nuno Sousa $^{c}$, João Filipe Mano ${ }^{a, b}$, \\ Rui Luís Reis ${ }^{\mathrm{a}, \mathrm{b}, *}$ \\ a 3B's Research Group - Biomaterials, Biodegradables and Biomimetics, University Minho, Headquarters of the European Institute of Excellence on Tissue \\ Engineering and Regenerative Medicine, AvePark, S. Cláudio de Barco, 4806-909 Taipas, Guimarães, Portugal \\ b IBB - Institute for Biotechnology and Bioengineering, PT Government Associated Laboratory, Guimarães, Portugal \\ ${ }^{c}$ Life and Health Sciences Research Institute (ICVS), School of Health Sciences, University of Minho, Braga, Portugal
}

\section{A R T I C L E I N F O}

\section{Article history:}

Received 24 September 2009

Received in revised form 14 January 2010

Accepted 14 April 2010

Available online 22 April 2010

\begin{abstract}
A B S T R A C T
Since the pioneering work dealing with the synthesis and physicochemical aspects of dendrimers, a predictable and tunable set of compositions for therapeutic, scaffolding and imaging systems has been reported. These are well documented, but many hot issues should be examined and reviewed. Herein, a review is given on dendritic nanopolymers and their applications that show promise in the field of regenerative medicine. This review begins
\end{abstract}

Abbreviations: 2-AS, 12-(9-anthroyloxy) stearic acid; 2-D, two-dimensional; 3-D, three-dimensional; 3-TC, lamivudine; 5-ASA, 5-aminosalicylic acid; Ac, acetylated; AChE, acetylcholinesterase; AF, alexaFluor; AFM, atomic force microscopy; ATRP, atom transfer radical polymerization; b-FGF, basic fibroblast growth factor; BAPTA-AM, 1,2-bis-(o-aminophenoxy) ethane-N,N,N',N',-tetraacetic acid-acetoxymethyl ester; $\beta$-CD, $\beta$-cyclodextrin; BBB, blood brain barrier; BMVEC, brain micro-vessel endothelial cells; BNTC, boron neutron capture therapy; BSA, bovine serum albumin; CLB, chlorambucil; CD, cyclodextrins; CED, convection enhanced delivery; CMCht, carboxymethylchitosan; CMCht/PAMAM, carboxymethylchitosan/poly(amidoamine); CNS, central nervous system; DCC, dicyclohexylcarbodiimide; Dex, dexamethasone; DDS, drug delivery system; di-BOC, di-tert-butyl dicarbonate; DNA, deoxyribonucleic acid; DOPE, 1,2-dioleyl-3-phosphatidylethanolamine; DOTAP, N-(1-(2,3-dio-leoyloxy) propyl)-N,N,N-trimethyl ammonium methylsulfate; Dox, doxorubicin; EBV, Epstein Barr virus; ECM, extracellular matrix; EG, ethylene glycol; EGF, epidermal growth factor; EGFP, green fluorescent protein; ELISA, enzyme-linked immunosorbent assay; ENFET, enzyme field-effect transistor; EPR, electron paramagnetic resonance; FA, folic acid; FITC, fluorescein isothiocyanate; FTIR, Fourier transformed infra-red spectroscopy; G, generation number; GAGs, glycosaminoglycans; GLUT 1, glucose transporter; GOX, glucose oxidase; HA, Hyaluronic acid; HAp, hydroxyapatite; HAS, human serum albumin; HBP, hyperbranched polymer; HER-2, human growth receptor; HIV, human immunodeficiency virus; HIV-1, human immunodeficiency virus type 1; HMGB1, high mobility group box 1 plasmid; HPLC, high performance liquid chromatography; HSGP, heparin or heparan sulfate proteoglycan; i.p., intraperitoneal; i.t., intratumoral; LCST, lower critical solution temperature; LH, light-harvesting; MA, methacrylate; MAPs, multiple antigen peptides; Man, mannose; Mn, number-average molecular weight; Mo/Mac, monocyte/macrophages; MPPI, poly(propyleneimine); MRI, magnetic resonance imaging; mRNA, messenger ribonucleic acid; MS, multiple sclerosis; MTX, methotrexate; $M_{\mathrm{w}}$, weight-average molecular weight, $M_{\mathrm{w}} / M_{\mathrm{n}}$ polydispersity index; NaHA, sodium hyaluronate; NMR, nuclear magnetic resonance; NSAIDs, non-steroidal anti-inflammatory drugs; OEI, oligoethylenimine; OG, oregon green; ONs, antisense oligonucleotides; PABA, p-aminobenzoic acid; PAMAM, poly(amidoamine); PAH, $p$-aminohippuric acid; PCI, photochemical-internalization; PDMA, poly( $N, N$-dimethylaminoethyl methacrylate); PEG, poly(ethylene glycol); PEG-DA, poly(ethylene glycol)-dialdehyde; PEI, poly(ethyleneimine); PEPE, polyether-copolyester; PETIM, poly(propyl ether imine); PLGA, poly(lactide-co-glycolide); PLGSA, poly(glycerol-succinic acid); PLL, poly-(L-lysine); PNIPAAM, poly(N-isopropylacrylamide); PP, primaquine phosphate; PPI, poly(propyleneimine); PrPSc, protease-resistant isoform of the prion protein; PSMA, prostrate specific membrane antigen; PTX, paclitaxel; RAFT, reversible addition-fragmentation transfer; RGD, Arg-Gly-Asp peptides; RNA, ribonucleic acid; ROS, reactive oxygen species; SA, sulfasalazine; SEM, scanning electron microscopy; siRNA, small interfering RNA; shRNA, small hairpin RNA; t-BOC, N-tert-butoxycarbonyl; TEM, transmission electron microscopy; TE, tissue engineering; ThT, thioflavin T; TIMP, tissue inhibitors of metalloproteinases; TMA-DPH, 1-(trimethylammoniumphenyl)-6-phenyl-1,3,5 hexatriene $p$-toluenesulfonate; UV, ultraviolet; VEGF, vascular endothelial growth factor.

* Corresponding author at: 3B's Research Group - Biomaterials, Biodegradables and Biomimetics, University Minho, Headquarters of the European Institute of Excellence on Tissue Engineering and Regenerative Medicine, AvePark, S. Cláudio de Barco, 4806-909 Taipas, Guimarães, Portugal. Tel.: +351253510 902; fax: +351253510909.

E-mail address: rgreis@dep.uminho.pt (R.L. Reis). 


\section{Keywords:}

Central nervous system

Dendrimers

Drug delivery systems

Regenerative medicine

Tissue engineering

Theranostics with a brief overview on research merging nanotechnology and regenerative medicine. Fundamentals of the synthesis and macromolecular structure of dendritic polymers are provided. Dendrimers fulfill the requirements as carriers for gene, nucleic acids, bioactive molecules and peptide/protein delivery aimed at modulate the cells functions, in vitro and in vivo. However, to make use of this potential, toxicological, drug-loading capacity, surface engineering and host-guest chemistries in dendrimers must be addressed and thus are also discussed. We focus on recent work involving dendrimers with applications in tissue engineering and the central nervous system. Due to their innovative character, applications beyond drug delivery systems became possible, namely as scaffolding and chemoattractants for tissue regeneration, and implantable biodegradable nanomaterialbased medical devices integrated with drug delivery functions (theranostics). Finally, we highlight promising areas for further research and comment on how and why dendrimer and dendron technology should be viewed as the next generation of biomaterials for the 21st century.

(c) 2010 Elsevier Ltd. All rights reserved.

\section{Contents}

1. Introduction

2. Dendritic polymers-dendrimers and dendrons: fundamentals and biotechnological applications $\ldots \ldots \ldots \ldots \ldots \ldots \ldots \ldots \ldots$

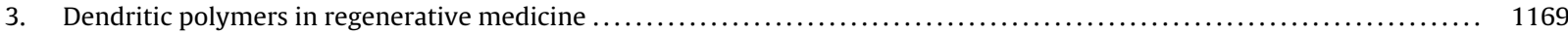

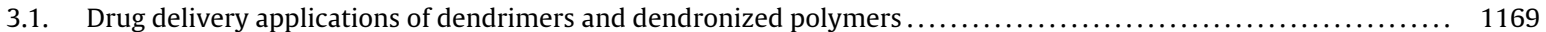

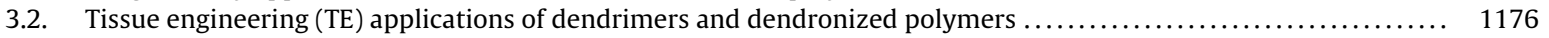

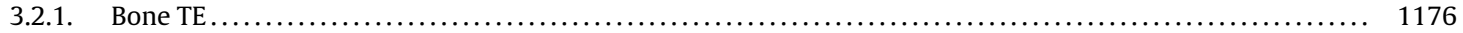

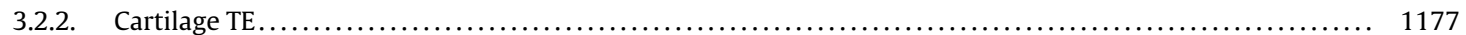

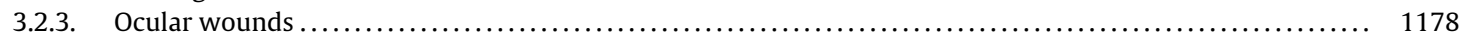

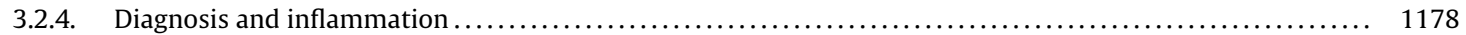

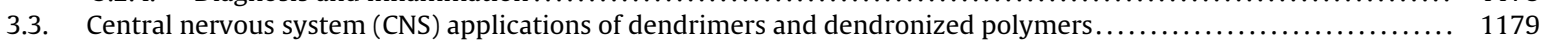

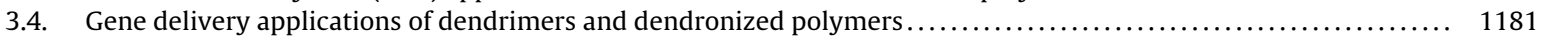

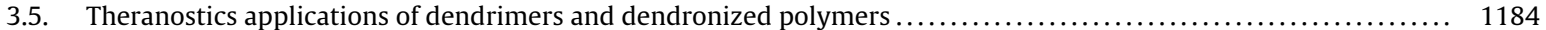

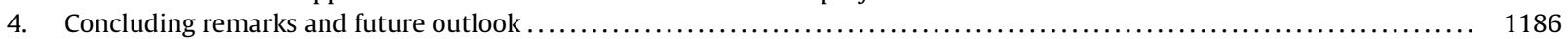

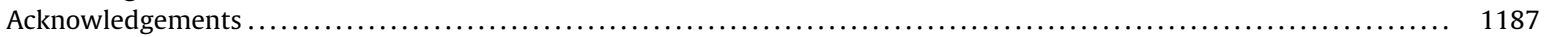

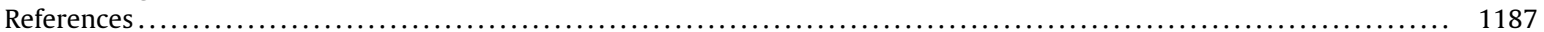

\section{Introduction}

The 20th century has witnessed impressive innovations in polymer synthesis and advances in the design of biodegradable chemistries. These achievements permit the synthesis of macromolecules with multiple compositions and novel architectures possessing unique physicochemical and biological properties. Synthetic polymers can be divided into four key architectural classes: linear, cross-linked, branched, and dendritic structures. The first three types have been studied extensively in the past. The fourth comprises the more recently developed, nature-inspired dendrimers, and derivatives thereof are reviewed here. These are highly branched and nanospherical macromolecules, and are a prominent example of nano-polymer revolution. The first reports on dendrimers synthesis are attributed to Vögtle group [1] in the late 1970s, followed by the work of Tomalia et al. [2] in the early 1980s. These novel structures differ from those of typical linear polymers, since their architecture is extremely precise and controlled, conferring them with tunable and predictable molecular weights, biodegradability and biocompatibility. This chemistry revolution ignited many possibilities, and it is not surprising that we now witness their exploitation in a variety of medical applications.
In this review, we report on the noteworthy scientific advances and most recent literature, dealing with the dendritic polymers nanotechnology, and briefly discuss the convergence of nanotechnology and regenerative medicine. Discussion of the fundamental dendrimers will include the numerous synthetic strategies reported for the preparation of dendrimer-based materials. Recent advances in dendrimer surface engineering are described, leading to novel and promising complexities (architectures and chemical functionalities), such as dendronized polymers. Interesting features reported for dendronized polymers are also discussed, as well as suggestions for potential applications, such as tissue engineering (TE), central nervous system (CNS), gene delivery and theranostics.

In 1959, Feynman [3] coined nanotechnology as a futuristic approach to the development of materials atom by atom. The ultimate goal of nanotechnology can be described as the ability to apply the nanoscale principles and work at the atomic, molecular and supramolecular levels (on the range of $1-100 \mathrm{~nm}$ ) to understand, and create material systems by assembling molecules into objects. Nanotechnology provides solutions for the transformation of biosystems and provides a broad collection of technologies, techniques and processes for real life purposes. Current and potential applications of nanotechnology in medicine include research involving diagnostic 


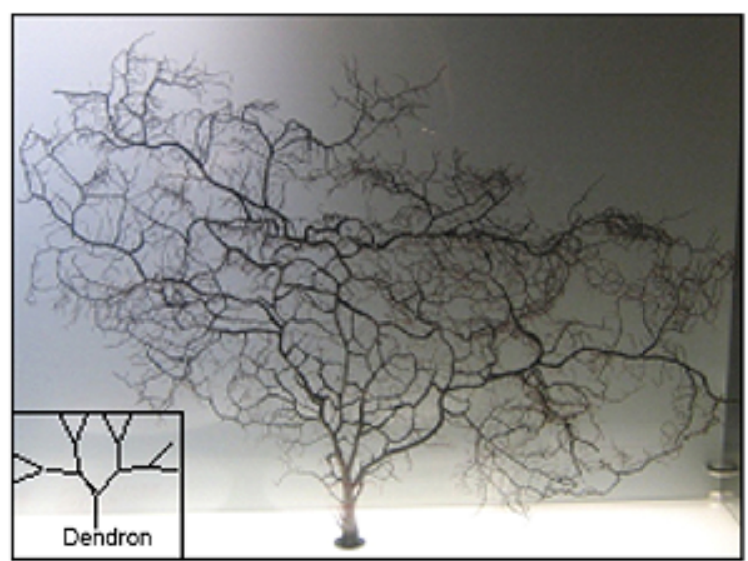

Fig. 1. A typical dendron structure resembles the architecture of a tree, and provides figurative meaning to Tomalia inspiration from nature and a poetic analogy of the dendrimers to nature's architecture and geometric forms (photo obtained from Casa Milà also known as La Pedrera-Barcelona).

devices, drug delivery vehicles, nanoscale surgery, biosensors and body part repair/regeneration and cancer therapy. In turn, regenerative medicine uncovers fundamental biological processes, self-repairing, self-replicating, and tissue regeneration mechanisms and offers inspiration models to nanotechnology [4-6]. Several examples of applications of nanotechnology in regenerative medicine will be provided further, but the currently undergoing explosive developments are summarized in Table 1, including examples from references [7-77]. As may be seen by the examples in Table 1, exploratory research in nanotechnology is considered to be emerging, disruptive and multidisciplinary [78]. Since it offers ever more exciting promises of new diagnoses and treatment routes, it can greatly impact every aspect of society. Consequently, there have been tremendous investments in this area [6].

\section{Dendritic polymers-dendrimers and dendrons: fundamentals and biotechnological applications}

Dendrimers are a unique class of synthetic polymers which play an important role in emerging nanotechnology $[79,80]$. The term "dendrimer" (from Greek: dendra, tree and meros, part of) describes the architecture of this emerging class of polymeric macromolecules which possess 3-D features that resemble a tree (Fig. 1).

Presently, the dendritic architectural class can be divided into four subclasses: random hyperbranched polymers, dendrigraft polymers, dendrons, and dendrimers [80]. More than 100 different dendrimers and 1000 surface chemistries are currently known.

A typical dendrimer structure consists of three basic components (Fig. 2): a multi-functional central core $(\bigcirc)$ where other molecules can be trapped [81], branched units $(Y)$ that emanates from the central core and external capping-groups (E). The highly regular branching units are organized in layers called "generations", and represent the repeating monomer unit of these synthetic macromolecules [80]. Therefore, dendrimers can be synthesized from simple branched monomer units, in a precise and con-

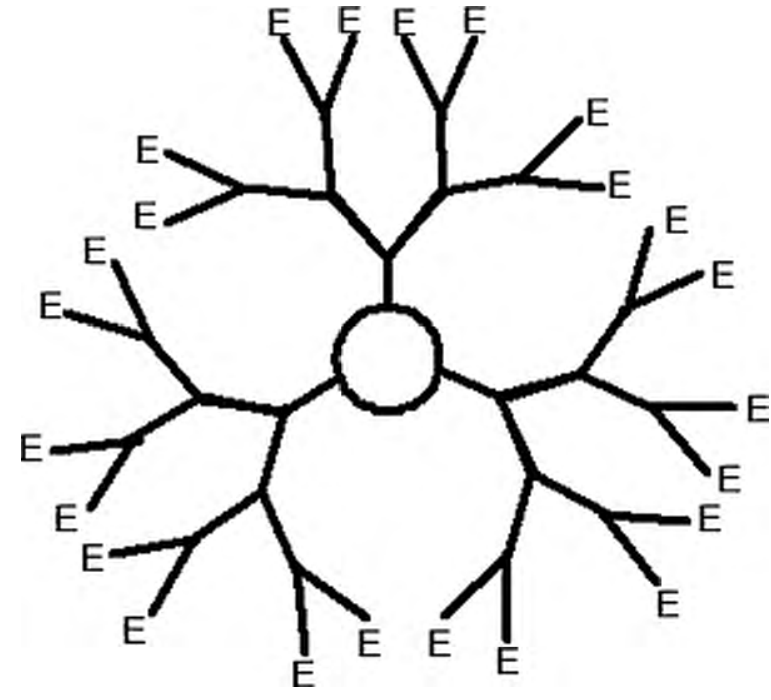

Fig. 2. Schematic representation of the dendrimer typical structure.

trolled fashion from trunk to branch and to leaf "surface groups".

Dendrimers may be designed to provide a quite versatile choice of external functional groups [74] in order to reduce cytotoxicity, enhance transepithelial transport $[81,82]$, promote interaction with coupling molecules such as natural-based polymers [83] and create fluorescentprobes [84]. The surface groups may also act as passive or reactive gates controlling entry or departure of molecules from the dendrimer interior. Surface properties may also allow control clearance and biodistribution in the body. Their size, shape, and topology, as well as flexibility and surface functionality, may be controlled at the molecular level (all three architectural components), which makes them not only useful building blocks and carrier molecules at the nanometer level, but also able to precisely manipulate both molecular weight and chemical composition. This new class of synthetic [85-87], highly branched, nanospherical macromolecules presents unique features in comparison to the traditional linear, cross-linked and branched polymers $[80,88]$, thus many researchers have explored their potential in many biological applications. An advantage is related with the fact that the narrow molecular weight distributions $\left(M_{\mathrm{w}} / M_{\mathrm{n}}=1.0000-1.05\right)$ can provide reproducible pharmacokinetic behavior [80].

There are various classes of dendrimers, but the ones that have attracted a great deal of attention are: (i) glycodendrimers and (ii) peptide dendrimers. Glycodendrimers have exhibited great potential as drug carriers. The term 'glycodendrimer' has been used to describe dendrimers that include carbohydrates in their architecture. The vast majority of glycodendrimers have saccharide residues on their outer surface, but glycodendrimers containing a sugar unit as the central core, from which all branches emanate, have also been described. Generally, glycodendrimers can be classified as: (i) carbohydrate-centered, (ii) carbohydrate-based and (iii) carbohydrate-coated dendrimers. The later will be further discussed in Section 3, the so-called dendronized polymers. 
Table 1

Nanotechnology applications in regenerative medicine.

\begin{tabular}{|c|c|c|}
\hline Application(s) & Examples of material structures, devices and systems at nanoscale & Reference(s) \\
\hline \multirow[t]{5}{*}{$\begin{array}{l}\text { Targeted and controlled } \\
\text { drug delivery }\end{array}$} & $\begin{array}{l}\text { Nanoshells (layered colloids with a non-conducting nanoparticle core covered by a thin metal shell) } \\
\text { and nanorods (e.g., copolymers, gold) are used in combination with specific wavelengths of lights and } \\
\text { heat technology for cancer therapy }\end{array}$ & {$[7-10]$} \\
\hline & $\begin{array}{l}\text { Dendrimer-antibody or peptide-major histocompatibility complex ligand constructs for sensitive } \\
\text { detection and drug delivery (e.g., doxorubicin) to T cells. Using this type of strategy guided therapy is } \\
\text { possible }\end{array}$ & {$[11,12]$} \\
\hline & $\begin{array}{l}\text { Quantum dots (central core of elements of groups II- or III-VI of the periodic table, i.e. CdSe, CdTe, } \\
\text { PbSe, ZnSe, GaAs, InP, GaN capped with ZnS) cross-linked to antibody conjugates (e.g., monoclonal } \\
\text { antibodies, biotin, avidin), oligonucleotides molecule ligands to render them specific to biological } \\
\text { targets }\end{array}$ & {$[13-15]$} \\
\hline & $\begin{array}{l}\text { Liposomes (lipid-based vesicles with size ranging from } 50 \text { to } 100 \mathrm{~nm} \text { ) and surface modified-liposomes } \\
\text { (e.g., PEGylated lipids trademarked as QuSomes }{ }^{\mathrm{TM}} \text { ) for drug delivery and treatment of several diseases } \\
\text { (e.g., cancer therapy and inflammatory arthritis). Surface modified sialyl Lewis X-liposomes } \\
\text { demonstrate their efficiency as a targeted drug delivery system for preventing stenosis after } \\
\text { angioplasty }\end{array}$ & {$[16-20]$} \\
\hline & $\begin{array}{l}\text { Fullerenes (i.e. clusters of } 60 \text { carbon atoms) for intracellular drug delivery, as their structure mimic } \\
\text { that of clathrin known to mediate endocytosis }\end{array}$ & {$[21-23]$} \\
\hline \multirow[t]{4}{*}{ Medical devices } & $\begin{array}{l}\text { Contrast agents as the superparamagnetic nanoparticles (e.g., FePt, iron oxide, PLGA coated iron oxide } \\
\text { with size ranging from } 10 \text { to } 20 \mathrm{~nm} \text { ) and quantum-dot-based nanoparticles (e.g., biotinylated } \\
\text { gadolinium-annexin A5-streptavidin) for use in magnetic resonance imaging (MRI). Radiopaque } \\
\text { iodinated polymeric nanoparticles for X-ray imaging applications have also been developed }\end{array}$ & [24-28] \\
\hline & $\begin{array}{l}\text { T1 agents to target folate receptors using dendrimer-based agent that can be decorated with both } \\
\text { ligands and gadolinium }\end{array}$ & {$[29]$} \\
\hline & $\begin{array}{l}\text { Proteins such as antibodies, antigens, and enzymes can be immobilized on protein chips for } \\
\text { application in early diagnosis of disease, tailored drug therapy, and detection of various pathogens }\end{array}$ & {$[30-34]$} \\
\hline & Silicon nanopore membranes for find applications in haemodialysis and haemofiltration & {$[35]$} \\
\hline \multirow[t]{4}{*}{ Cell/tissue engineering } & Carbon single-wall nanotube (size $<100 \mathrm{~nm}$ ) sheets to develop artificial muscle & {$[36,37]$} \\
\hline & Systems to determine or reduce immune rejection of organs. & {$[38,39]$} \\
\hline & Nanostructured materials for nerve, bone, and cartilage regeneration & {$[40-42]$} \\
\hline & Collagen-dendrimer hydrogels for ocular tissue engineering & {$[43]$} \\
\hline \multirow[t]{2}{*}{ Gene delivery } & $\begin{array}{l}\text { Polycationic polymers (e.g., SuperFect }{ }^{\circledR} \text { dendrimers, poly-(L-lysine)) as synthetic non-viral vectors } \\
\text { with decrease cytotoxicity }\end{array}$ & {$[44-46]$} \\
\hline & $\begin{array}{l}\text { Cationic liposomes and formulations (e.g., lipid-coated magnetic nanoparticles, liposomal bubbles) for } \\
\text { the delivery of oligonucleotides to different cells. Liposomal formulations for triggered release of } \\
\text { siRNA have also been developed }\end{array}$ & {$[47-52]$} \\
\hline \multirow[t]{5}{*}{$\begin{array}{l}\text { Molecular-tags } \\
\text { (in vitro and in vivo } \\
\text { imaging) }\end{array}$} & $\begin{array}{l}\text { Semi-conductor nanocrystals quantum dots (e.g., CdSe, ZnS), nanocrystals that fluoresce in different } \\
\text { colours depending on their sizes and may find application for targeting multiple types of cells in living } \\
\text { organisms. The quantum dots may be also linked with ligand molecules for receptor labeling and } \\
\text { visualization }\end{array}$ & {$[53-56]$} \\
\hline & Metal-chelate-dendrimer coupled to monoclonal antibody for radiotherapy and imaging & [12] \\
\hline & $\begin{array}{l}\text { Fluorescent labelled-nanoparticles (e.g., fluorescein isothiocyanate (FITC)-labeled PAMAM } \\
\text { dendrimer-drug conjugate) for assessing cellular uptake }\end{array}$ & {$[57]$} \\
\hline & Gold and silver nanoparticles (size $<50 \mathrm{~nm}$ ) for molecular detection and separation & {$[58-60]$} \\
\hline & Gold nanorods for cancer-cell imaging & {$[10]$} \\
\hline \multirow{5}{*}{$\begin{array}{l}\text { Biosensors, bioanalysis and } \\
\text { microfluidics }\end{array}$} & Carbon-nanotubes arrays as immunosensors for detection of antigen-antibody binding & {$[61]$} \\
\hline & $\begin{array}{l}\text { Electrochemical immunosensor based on dendrimer-assisted self-assembled monolayers } \\
\text { functionalized with enzyme-tagged antibody }\end{array}$ & {$[62,63]$} \\
\hline & $\begin{array}{l}\text { Dendrimer-modified electrodes for application as biosensors. PAMAM-CdS nanocomposites for } \\
\text { biological assays }\end{array}$ & {$[64-67]$} \\
\hline & Nanowire field-effect transistors for detection of biomolecules & {$[68,69]$} \\
\hline & $\begin{array}{l}\text { High-throughput (e.g., extracellular matrix microarray, high-throughput screening of gene functions) } \\
\text { analysis as a tool for evaluating cell fate and drug discovery }\end{array}$ & [70-72] \\
\hline \multirow{3}{*}{$\begin{array}{l}\text { Theranostics } \\
\text { (i.e. combined } \\
\text { therapeutics and } \\
\text { diagnostic) }\end{array}$} & Polymer-based nanosystems for therapeutic and diagnostic of several diseases & {$[73,74]$} \\
\hline & $\begin{array}{l}\text { Liposomes (e.g., polyethylene glycol (PEG)-coated liposomes-doxorubicin, } \\
{ }^{111} \text { Indium-vinorelbine-liposomes) for imaging, therapy and diagnosis of variety of cancers }\end{array}$ & {$[75,76]$} \\
\hline & $\begin{array}{l}\text { Fullerenes (e.g., PEG-coated fullerenes containing gadolinium ions) for MRI and efficient } \\
\text { photodynamic therapy of tumors }\end{array}$ & [77] \\
\hline
\end{tabular}

Sadler and Tam [89] broadly defined peptide dendrimers as "radial or wedge-like branched macromolecules consisting of a peptidyl branching core and/or covalently attached surface functional units". Thus, this definition includes any dendrimer with an amino acid core, branching units, surface functional groups or any combination of the three as a peptide dendrimer. In dendrimer synthesis, aminoacids are also appealing building blocks because 
peptide-coupling techniques can be used. Despite this, most research on dendritic polymers has been conducted with glycodendrimers.

The synthesis and applications of glycodendrimers and peptide dendrimers have been reviewed [89-92]. Two different synthetic strategies are currently explored for synthesizing structurally well-defined dendritic polymers, namely the divergent $[88,93]$ and convergent growth [94-96] approaches. Most commercially available dendrimers, such as the Tomalia's poly(amidoamine) (PAMAM) dendrimers from Dendritech Inc. (Midland, MI, USA) and poly(propyleneimine) (PPI) dendrimers from DSM (Geleen, Netherlands) are produced by the divergent method. This method involves in situ branch-component construction in step-wise and iterative stages around a desired core to produce core-shell structures. In the convergent method (Fréchet approach) [97], dendrons are synthesized and then are anchored to a multi-functional core. This strategy can provide the best structural control, e.g., purification of low molecular dendrons at interim stages of the growth, while dendrons can be decorated step-bystep at the periphery and core $[98,99]$ (e.g., by phosphines at the end of the branches, then by amines at the core). This method affords the so-called "Christmas tree"-like compounds. Moreover, Fréchet-type dendrimers can be designed to obtain various (un)symmetrical dendrimers [100], such as amphiphilic dendrimers. Both strategies offer advantages and disadvantages, and the appropriate route depends mainly on the type of monomer used, or "building blocks", and the desired structure. Although there are different routes to synthesize dendrimers, their maximum size is typically in the order of $\sim 10-20 \mathrm{~nm}[79,101]$. Recently, a novel synthetic route has been proposed for new low-cost Priostar dendrimers [102,103].

The unique characteristics of dendritic polymers make possible their use in a wide range of applications. Among the myriad of possibilities, dendritic polymers can find applications as a delivery carrier of drugs [81,104,105], and on the development of synthetic vaccines [106,107], anti-tumor systems $[108,109]$ and immunology $[110,111]$. Other applications in the bioscience field include blood anticoagulant [112] and microbicidal [113-116] activities. For example, Jiang at al. [117] reported on a poly-(L-lysine) (PLL) dendrimer with a polyanionic outer surface consisting of 32 naphthalene disulfonate units, also known as Vivagel (Starpharma Ltd., Melbourne, Australia), found to be safe and prevent HIV-1 infection by binding to receptors on the viral coat. The promising results support the investigation of VivaGel in phase II clinical trials in humans [118]. In another study, Saha and Roy [119] synthesized HIV-1 protease inhibitors analogs consisting of a $\mathrm{N}$-substituted oligoglycine peptoids bearing $\mathrm{N}$-acetylglucosamine residues. The resultant glycosilated peptoids were synthesized by an iterative strategy involving mono $\mathrm{N}$-alkylation and bromoacetylation. Dendrimer-based DDS have also proved to effectively enhance anti-viral activity in vitro, by reducing the viral load $[120,121]$. Dendrimers have also been useful in prion research [122-124] since cationic dendrimers are shown to perturb peptide fibrillation in a process dependent on the nature of the charged groups on the dendrimer surface.
Dendrimers mimicking the surface structure of proteins involved in angiogenesis inhibition have been developed for use in anti-tumor systems [125,126]. Angiogenesis, an important process for tumor growth, is initiated by angiogenic factors, such as vascular endothelial growth factor (VEGF) and basic fibroblast growth factor (b-FGF). These growth factors bind to their receptors on endothelial cells with the dependence of heparin or heparan sulfate proteoglycan (HSPG) in extracellular matrix (ECM). The participation of binding to heparin or HSPG leads to potential targets for anti-angiogenic activity. Endostatin, a well-known endogenous angiogenic protein binds to heparin or HSPG and inhibits some functions of endothelial cells, resulting in potent suppression of angiogenesis. To find new potent angiogenic inhibitors, Shimamura at al. [126] focused their attention on the characteristic positive-charge-rich surface of endostatin and the interaction between its arginine residues and either heparin or HSPG. This group designed novel arginine-rich dendrimers, TX-1943 (8 Arg residues) and TX-1944 (16 Arg residues), which mimic the surface structure of endostatin, and evaluated their anti-angiogenic ability, in vitro and in vivo. In vitro studies demonstrated that both dendrimers bound to heparin [126]. During this study, it was also observed that angiogenesis inhibition of b-FGF stimulated proliferation and tube formation of endothelial cells. However, in vitro the anti-angiogenic activity of TX-1944 was stronger than that of TX-1943. Moreover, both types of dendrimers exhibited potent anti-angiogenic activity in the chicken embryo chorioallantoic membrane assay, in vivo. These data suggest that arginine dendrimer can be used to suppress or prevent the growth and metastasis of solid tumors.

Innovative synthetic procedures have increased accessibility to the functionalization of dendrimers with transition metals in the core, finding interesting applications in catalysis [127-130]. Several authors have proposed the use of dendrimers to develop complexes with metals, including Pt [131], Ag [132,133], Fe [134], Cu and Ni [135]. Most metallodendrimers are built from organic skeletons, in particular from PAMAM or PPI type dendrimers. Despite the impressive properties of metallodendrimers, special attention to this topic is not presented here, as several good reviews summarize aspects dealing with the synthesis and properties [136-138], as well as characterization techniques $[139,140]$. A number of examples are also known for fluorinated [141] and phosphorus-containing dendrimers and dendrons [142-144].

Applications of dendrimers in more traditional technologies such as coatings and inks have also been explored, as the spherical shape of dendrimers can promote special rheological characteristics [145]. The versatility of dendrimer also explains their importance in optic, electronics and magnetic applications [146-148]. A recent work [149] proposed the use of PAMAM dendrimers adsorbed onto native oxide surfaces of silicon wafers as a strategy to direct the integration of metal electrodeposition with silicon microfabrication processes, and selective deposition by dendrimer patterning.

Alonso et al. [150] described the development of an amperometric enzyme electrode for glucose monitoring. 
This high sensitive electrode consisted of the electrostatic immobilization of the enzyme glucose oxidase onto $\mathrm{C}$ and $\mathrm{Pt}$ electrodes modified with mixed ferrocenecobaltocenium dendrimers. This work showed that higher generation dendrimers can be more efficient electron transfer mediators, and can find applications as sensors. In another study [151], PPI dendrimer cores functionalized with octamethylferrocenyl units were deposited onto a Pt electrode. Amperometric biosensors for glucose were prepared by immobilization of glucose oxidase (GOX) on the electrodes and their applications as hydrogen peroxide and glucose sensor were investigated. It was also shown that electrodes modified with polymethylferrocenyl dendrimer promote the redox reactions of hydrogen peroxide with an efficiency affected by structural characteristics of the dendrimers when low working potentials are used. The biosensors developed possess a good linear response region, and superior sensitivity and reproducibility as compared with other ferrocene-mediated glucose sensors.

Yao et al. [65] reported an enzyme field-effect transistor (ENFET) for determining glucose. This biosensor was produced with dendrimer encapsulated Pt nanoparticles and GOX via a layer-by-layer self-assembly method. This work demonstrated that the developed biosensor possesses good stability, enhanced sensitivity and extended lifetime as compared to conventional ones. Buschbeck and Lang [152] have proposed the surface-modification of low generation dendrimers with triethylene glycol methyl ether units to develop ionophores for chemical sensors.

Another work [153] using erythrocyte ghosts demonstrated that the addition of fourth-generation PAMAM dendrimer and PAMAM-OH has a dual effect on the activity of human erythrocyte membrane acetylcholinesterase (AChE). Low dendrimer $(25 \mu \mathrm{M})$ concentrations caused a statistically significant increase of the enzyme activity. Inhibition of AChE was observed for dendrimer concentrations higher than $100 \mu \mathrm{M}$. The efficiency of the inhibition was similar for both amine- and hydroxyl-terminated PAMAM dendrimers; however, the maximum activation occurred for a different range of dendrimer concentration; $25 \mu \mathrm{M}$ for PAMAM-OH (G4) and $100 \mu \mathrm{M}$ for PAMAM (G4). The initical explanation attributed the changes of AChE activity upon addition of dendrimers to alteration in protein structure, but the effect may be associated with the structural changes in the whole membrane. A study reported by Shcharbin et al. [154] aimed to clarify whether AChE inhibition was a result of direct action of dendrimers on the enzyme or indirect changes in lipid bilayer of membrane. By performing fluorescence analysis it was demonstrated that anionic and cationic dendrimers changed AChE conformation and the strongest effect was induced by carboxylic-terminated PAMAM dendrimers (G3.5). It was also demonstrated that change in the AChE conformation and catalytic activity depended on type and concentration of the dendrimer.

Kubát et al. [155], investigated the interaction of porphyrins in aqueous solution with PAMAM dendrimers of different generations and external groups. In that work, the binding of porphyrins to PAMAM dendrimers was controlled mainly by electrostatic interactions between porphyrins and terminal groups of PAMAM dendrimers (amine or carboxylic groups), and depended on both porphyrin peripheral functionalization and $\mathrm{pH}$ of the solution. Both low and high-generation dendrimers formed complexes with porphyrins.

Shcharbin et al. [156,157] have studied the interaction of serum albumins with cationic dendrimers. In their first study [156], they investigated the interaction of a fourth-generation PAMAM dendrimer and serum albumins from human (HAS) and bovine (BSA) origin. This study demonstrated that serum albumins and PAMAM G4 dendrimer form complexes with stoichiometry of 4-6:1 for PAMAM:HSA and 4-5:1 for PAMAM:BSA molar ratio. Results obtained from circular dichroism, fluorescence polarization and zeta-potential experiments have shown that dendrimers did not significantly change the secondary structure of proteins, and interactions between protein and dendrimer were weak. Based on the 3-D crystal structures of HSA and BSA, they identified five non-specific anionic regions for binding of cationic dendrimers. Another study [157] investigated the effect of the generation of PAMAM dendrimers (G2 and G6) on the binding to bovine serum albumin (fatty acids free and loaded with different fatty acids). This comprehensive work showed that although proteins loaded with fatty acids have more stable structures and were less sensitive to the action of dendrimers, BSA-fatty acid complexes bound to PAMAM dendrimers. These results suggested that the efficiency of the interaction depends on the fatty acids loaded on the protein, e.g., PAMAM dendrimers were able to compete with BSA for fatty acids if two or three fatty acids were loaded per protein.

An important characteristic of dendritic molecules is their improved solubility in a large number of organic solvents [158,159]. An understanding of the interfacial interactions is important to the biomedical applications of these polymers. In this respect, it has been shown that dendrimers are able to change their conformation on different alkanethiol surfaces due to their flexibility. Abdelhady et al. [160] conducted an atomic force microscopy (AFM) study to understand the factors affecting the interactions of fourth-generation PAMAM dendrimers with substrates of defined surface chemistry. Their results also suggest that the surface conformation of such dendrimer molecules can depend upon the nature of the functionalized substrates.

Recently, Allabashi at al. [161] reported an easy method for manufacturing composite filters cross-linked with silylated dendritic polymers and cyclodextrins (CD). Triethoxysilylated derivatives of PPI dendrimer, PPI and polyglycerol hyperbranched polymers and $\beta$-cyclodextrin $\left(\beta\right.$-CD) were impregnated into $\mathrm{Al}_{2} \mathrm{O}_{3}, \mathrm{SiC}$ and $\mathrm{TiO}_{2}$ membranes and tested for the removal of a variety of organic pollutants from water. The data proved their efficiency on removing up to $99 \%$ polycyclic aromatic hydrocarbons, $93 \%$ of the monocyclic aromatic hydrocarbons, and up to $43 \%$ of pesticides, among others.

Cromer et al. [162] have proposed the use of functionalized dendrimers as endotoxin sponges. Using in vitro and in vivo models of septic shock, they demonstrated that PAMAM dendrimers partially modified by hydrophobic groups effectively bind and sequester bacterial lipopolysaccharides. Therefore, these systems may be 
useful for the therapy of gram-negative sepsis. The studies of Labieniec et al. [163] provided the first evidence of the therapeutic effect of fourth-generation PAMAM dendrimers. These were found to lower plasma glucose and suppress long-term markers of diabetic hyperglycaemia, in vivo.

Despite the many advantages and superior performance of the dendrimers highlighted herein, with the exception of PAMAM, PPI, polyphosphane, and triallyl phenol, few can be obtained with high generations. Synthesis of highgeneration dendrimers, useful for exploring the nature of the dendritic architecture, depends critically on the nature of the constituent monomers, their reactivities, and on the method of their preparation. Krishna et al. [164] showed that poly(propyl ether imine) (PETIM) dendrimers (G3) possessing alcohol, amine, nitrile, ester or carboxylic acid groups at the peripheries can be obtained. Moreover, during their studies it was demonstrated that PETIM dendrimers with carboxylic acid groups were non-toxic over two different cell lines: human breast cancer T47D and African green monkey kidney (CV-1) cells. Jayamurugan and Jayaraman [165] also reported the synthesis of high-generation PETIM dendrimers, obtaining PETIM dendrimers up to G6 by carrying out simple iterative steps consisting of two alternate Michael additions and two reduction reactions. The disadvantage is that the procedure is long, but the overall yields are quite good for lower generations. They have shown that it is possible to tailor the peripheries of these dendrimers by introducing different groups such as alcohols, amines, carboxylic acids, esters, or nitriles, and up to 128 external groups, thereby opening up new properties and possibilities for several applications.

The well-defined hyperbranched structure of dendrimers has motivated chemists to explore the possibility for mimicking protein functions with dendritic macromolecules [166], such as $\mathrm{O}_{2}$-carrying haemoproteins [167] and coenzyme $\mathrm{B}_{12}$ [168]. In the next section, this issue will be explored further.

\section{Dendritic polymers in regenerative medicine}

\subsection{Drug delivery applications of dendrimers and dendronized polymers}

The development of nanotechnology-based efficient drug delivery systems for small molecules, proteins and DNA has attracted a great deal of attention over the last few years. Unlike traditional polymers, dendrimers can be obtained in precise molecular weights even at high generations, which as previously highlighted can provide a reproducible pharmacokinetic behavior. This feature makes them ideal candidates for drug delivery applications. However, an efficient drug delivery systems should meet other criteria, such as: (i) structural control over the size and shape of drug or imaging-agent cargo-space; (ii) biocompatibility, non-toxic polymer/pendant functionality; (iii) precise, nanoscale-container and/or scaffolding properties with high drug-loading capacity; (iv) well-defined scaffolding and/or surface modifiable functionality for cellspecific targeting moieties; (v) lack of immunogenicity; (vi) appropriate cellular adhesion and internalization, (vii) ade- quate bio-elimination or biodegradation; (viii) controlled or stimuli-responsive drug release features; (ix) molecular level isolation and protection of the drug against inactivation during transit to target cells; $(\mathrm{x})$ minimal non-specific cellular and blood-protein binding properties; (xi) ease of consistent, reproducible, clinical grade synthesis.

In regenerative medicine, the control of cells' behavior at the nanoscale is addressed via cell-adhesion receptors. The surface of eukaryotic cells is covered with an array of glycoconjugates (e.g., glycoprotein's and glycolipids). Extracellularly, carbohydrates in some of the glycoconjugates play a key role in the process of cell-cell and cell-pathogen adhesion. Furthermore, they also participate in such fundamental processes as glycan cross-linking in the ECM. Intracellularly, carbohydrate receptors are involved in such key biological processes as protein folding and sorting of proteins (e.g., the degradative lysosomal enzymes). It is the weak binding of most carbohydrate ligands for their protein receptors, that require these carbohydrates to be clustered to attain biologically meaningful affinities towards their receptors (e.g., lectin type) [169]. In order to refine the biological activities and drug delivery by dendritic polymers, efficient carbohydrate ligands of the glycodendrimer-type are emerging as potent ligands for carbohydrate-binding proteins. Such type of molecules can be obtained through surface engineering using a carbohydrate coating on the dendrimeric system, the so-called dendronized polymers (Fig. 3). Dendrimers modified with terminal carbohydrate polymers constitute a new class of biopolymers with many interesting applications. Such type of dendrimers have been proposed by the Roy and co-workers [170], and can be synthesized for example, by functionalization of the dendrimers with lactogroups, the so-called lactodendrimers. Thus, dendronized polymers can be conveniently synthesized with good yield using both divergent and convergent approaches, or by chemoenzymatic approaches [171]. Another advantage of these systems is related with the chemical nature of the synthetic linker and the possibility of tailoring the type of glycosidic linkages in these compounds, which gives us additional flexibility to meet demands from the point of view of hydrophobicity, and biodegradability [169]. Moreover, these compounds can grow to considerable size by successive cycles of branching, which give them a unique possibility to vary the degree of carbohydrate clustering required by the carbohydrate receptors. Potentially, such molecules can be used for the treatment and control of metabolic disorders involving carbohydrates, and protection against certain types of infections.

Dendronized polymers with a variety of shapes, core molecules, carbohydrate residues and valences have been made available for the biological evaluation. This new class of materials is expected to exhibit entirely new properties since the structures might have sizes larger than $10 \mathrm{~nm}$ and different surface properties [86]. In fact, the linking of terminal sugar residues, such as heparin, on dendrimers can create a multivalent display that mimic cell-surface glycans [172]. This strategy showed that heparin dendrimers promote FGF-2-mediated mitogen-activated kinase activation in L6 myoblasts. Thus, these glycodendrimers can modulate heparin-protein interactions. 
(A)

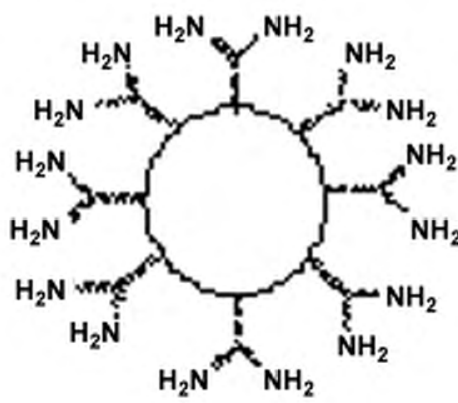
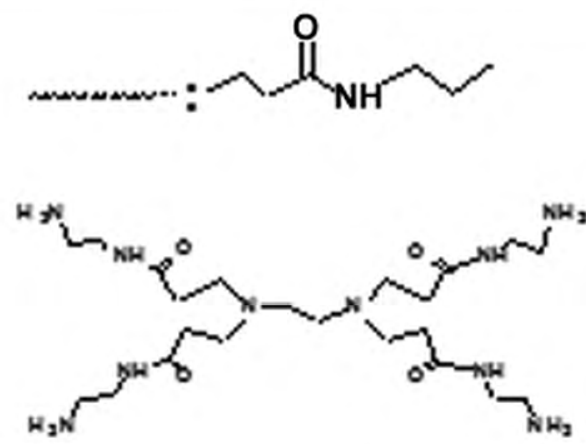

Core structure

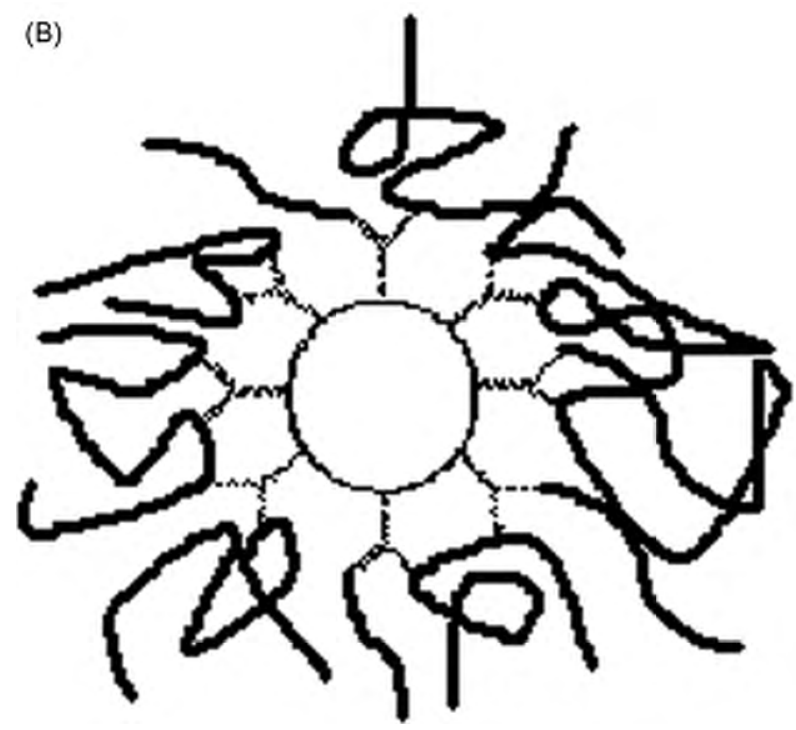

Fig. 3. Comparison of the structure of (A) PAMAM dendrimer (G2), and (B) PAMAM dendrimer bearing carbohydrate end groups (dendronized polymer).

It has been found [173] that high-generation dendrimers (G7) with amine capping-groups causes haemolysis and changes the morphology of red cells, since they bind to membranes of cells (negatively charged) in a non-specific manner and can cause toxicity in vitro and in vivo. Similar findings were reported by Domanski et al. [174], who investigated the effect of PAMAM dendrimers' concentration and generation (G2, G3 and G4) on human red blood cells. This paper demonstrated that erythrocyte shape changed and was accompanied by dendrimer-induced haemolysis when these cells were exposed to nanoparticles concentrations ranging between $1 \mathrm{nM}$ and $1 \mu \mathrm{M}$. Moreover, it was conclusive that when higher dendrimer generation was used, a lower concentration of PAMAM dendrimer was needed to cause haemolysis. These observations were supported by the work of Jevprasesphant et al. [175]. The cytotoxicity of unmodified PAMAM dendrimers towards Caco-2 cells was appreciably higher for cationic (whole generation) compared with anionic (half generation) dendrimers and for both types increased with increasing size (generation) and concentration. King Heiden et al. [176] also demonstrated that PAMAM dendrimers amine-terminated (G4) are toxic and attenuated growth and development of zebrafish embryos at sub-lethal concentrations. However, PAMAM dendrimers carboxylic-terminated (G3.5) were not toxic to zebrafish embryos. Dutta et al. [177] study corroborated previous findings that demonstrated the cytotoxic behavior of PPI dendrimer amine-terminated (G5), in vitro. Recently, Libieniec et al. [163] showed cytotoxic effects of PAMAM dendrimers (G4), in vivo. It was found that PAMAM dendrimers increased mortality of streptozotocindiabetic rats. Neerman et al. [178] reported melamine dendrimers were developed, and their potential as a vehicle for drug delivery applications was investigated. The preliminary in vitro study showed a decrease in Clone 9 cells viability at $0.1 \mathrm{mg} \mathrm{mL}^{-1}$ as compared to that of cells cultured in the presence of dextran. For the in vivo study, mice were administered with increasing concentrations of dendrimer via intraperitoneal (i.p.) injection. 
At a higher concentration ( $160 \mathrm{mg} \mathrm{kg}^{-1}$ ), 100\% mortality was observed and histopathological data revealed hepatoxicity. At low concentrations (2.5-40 $\mathrm{mg} \mathrm{kg}^{-1}$ ) of the dendrimers, no mortality was seen, and no hepatic damage was found. These data suggest that the toxicity of the melamine-based dendrimer is comparable to the cationic PAMAM dendrimers, and further studies need to be carried out to evaluate their potential as DDS.

Surface engineered dendrimers with carbohydrates should make it also possible to avoid the cytotoxic effects of cationic and high-generation dendrimers and reduce the haemolytic toxicity by reduction/shielding of the positive charge on the dendrimer surface, while enhancing the peripheral congestion to improve container properties. The development of strategies for the synthesis of dendrimers based on novel cores and branches [179] continues to be one of the important aspects of dendrimer chemistry due to the need for tailoring rigidity and density to refine drug release kinetics. Sashiwa and co-workers $[83,180-182]$ have established the synthesis of a variety of chitosan-dendrimer dendronized polymers mainly by two procedures: (i) dendrimers bearing aldehyde and a spacer are synthesized, and then these are reacted with chitosan by reductive $\mathrm{N}$-alkylation, and (ii) linking of chitosan to the dendrimer surface. The first approach has the advantage of no cross-linking during the reaction. The second allows the use of commercially available amino-dendrimers, such as PAMAM and poly(ethyleneimine) (PEI) dendrimers. At least two binding points are available; however, this can be a drawback as it can cause an undesired cross-linking. Following these studies, Oliveira et al. [183] proposed to surface engineer PAMAM dendrimers with water-soluble carboxymethylchitosan (CMCht), to develop novel spherelike nanoparticles for possible application as carriers to deliver intracellularly bioactive molecules. These are aimed at control of the behavior of stem cells, namely their proliferation and differentiation. Dubber and Lindhorst [184] reported the synthesis of a carbohydrate-centered PAMAM dendrimers. First, D-glucose was converted into its per-aminoethyl-functionalized derivative, which was then submitted to the multi-step reaction to obtain the PAMAM branches. Domanski et al. [185] also showed that thiophosphate dendrimers (G5) were neither haemotoxic nor cytotoxic within the concentration range $100 \mathrm{pM}$ to $10 \mu \mathrm{M}$, thus being good candidates for drug delivery. A marked decrease in the cytotoxicity of amine-terminated PAMAM dendrimers was noted when the surface was modified with the addition of six lauroyl or four PEG chains [175]. Dutta et al. [177] demonstrated that the surface modification of PPI (G5) dendrimers with mannose and N-tert-butoxycarbonyl (t-Boc) decreases haemolitic toxicity and cytotoxicity over HepG2 and COS-7 cell lines, in vitro. Moreover, an in vivo study [186] in Wistar rats showed that administration of PPI dendrimers (G5) caused haemolysis and tissue degeneration, after $24 \mathrm{~h}$. On the contrary, no signs of toxicity were observed in animals to which surface-modified PPI dendrimers were administered, suggesting that functionalization of dendrimers leads to drastic reduction of toxicity and increases biocompatibility. Makimura et al. [187] investigated glycodendrimers with a lysine core and with different carbohydrates on the exterior. Compared to
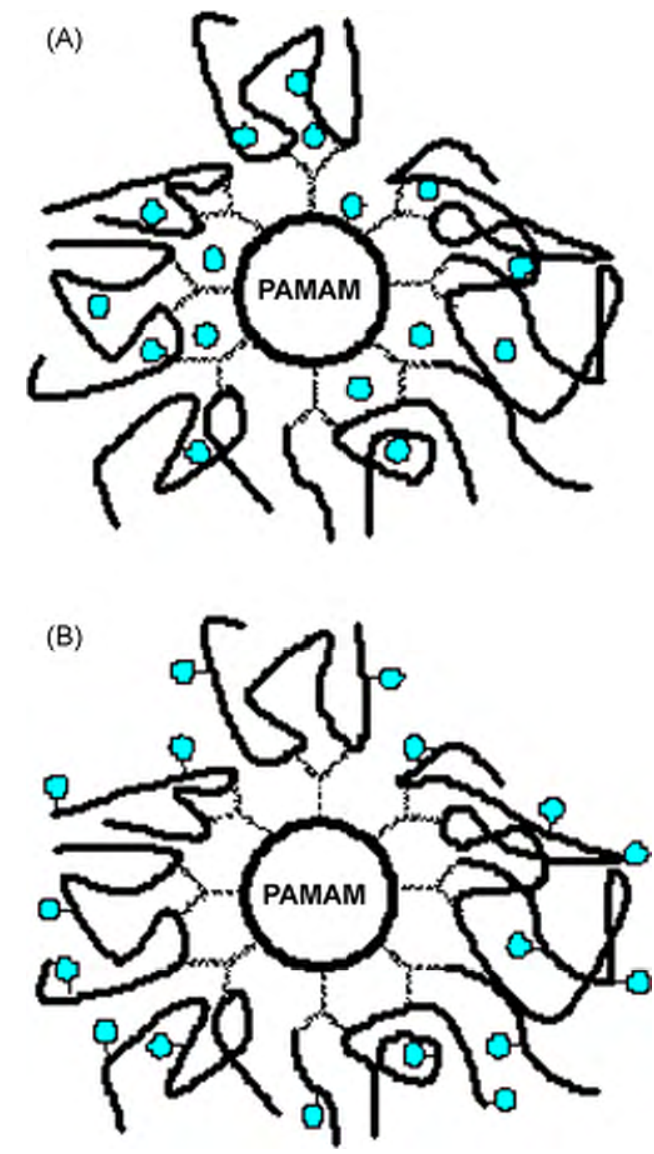

Fig. 4. Dendronized polymer loaded with a drug: incorporation in the bulk (A) and covalent bonding to functional groups (B).

the mono-functional structure, L-lysine dendrimers with 8 or 16 sialic-acid residues show enhance binding properties and efficiently suppress the haemo-agglutination of erythrocytes.

A surface engineering strategy was also on the basis of Jevprasesphant et al. [188] work to improve the properties of dendrimers. It was found that conjugation of cationic PAMAM dendrimers with lauroyl chloride decreased their cytotoxicity and increased their permeation through Caco2 cell monolayers. Another study [176] demonstrated that when the tripeptide Arg-Gly-Asp (RGD) was conjugated to PAMAM dendrimers (G4), these were less potent in causing embryo toxicity as compared to non-conjugated dendrimers.

Dendronized polymers can display a higher loading capacity and allow the bulk incorporation of bioactive molecules of higher molecular weights and of different chemistry, while maintaining high internalization and transfection efficiency as compared to conventional dendrimer (Fig. 4). For example, Kono et al. [189] designed PEG-modified dendrimers having a shell of hydrophobic amino acid residues in the peripheral moiety of the dendrimer to increase their encapsulation ability. L-phenylalanine or $\gamma$-benzyl-L-glutamate residues were introduced to all chain ends of fourth-generation PAMAM dendrimers, and then PEG $\left(M_{\mathrm{W}} 2000\right)$ chains were attached 

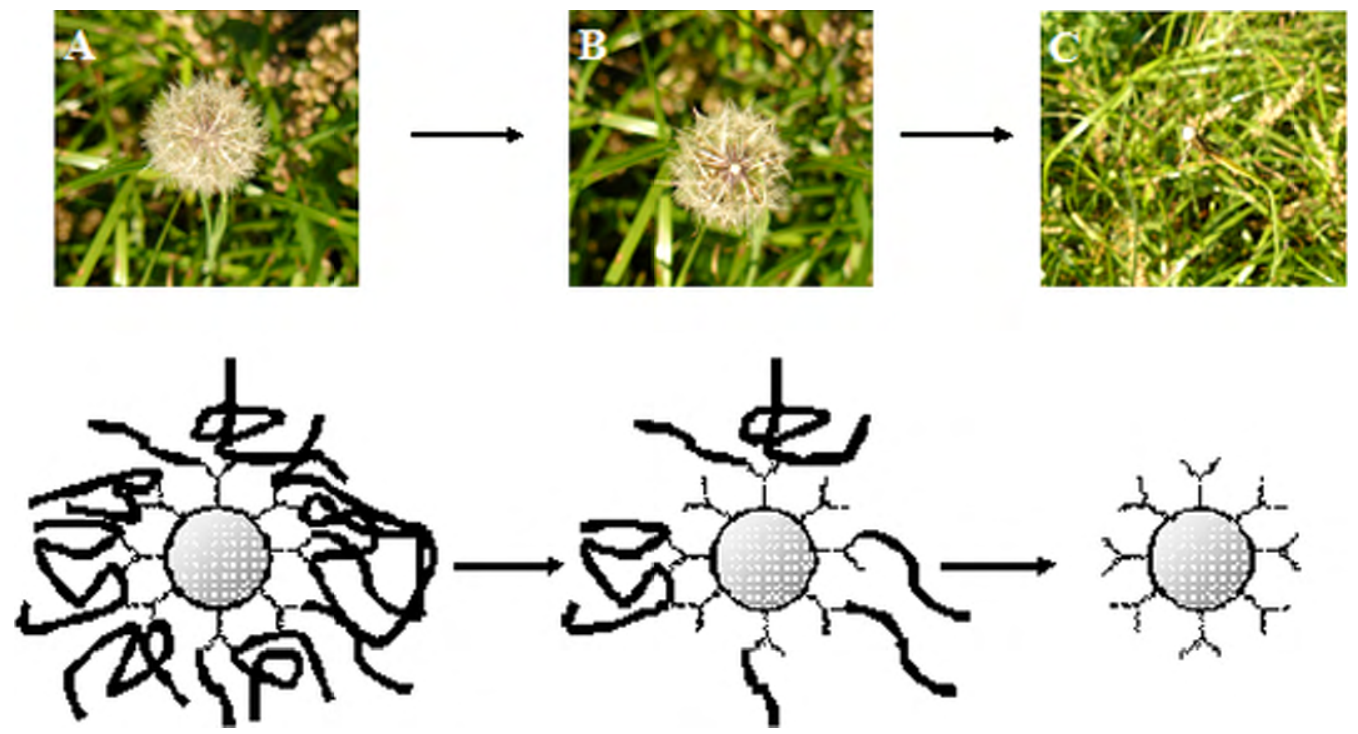

Fig. 5. Photos of dendrons and figurative representation of nature's architecture and controlled-release strategy (top). Schematic representation of the step-wise $(A \rightarrow C)$ degradation of dendronized polymers, from periphery to core (bottom).

to the amino acid residues. Results have shown that the surface engineering of the PAMAM dendrimers improved the binding of Rose Bengal guest molecules than the dendrimer without the external layer.

Dendritic polymers offer an interesting possibility as complexing agents for enhanced transdermal delivery of hydrophobic drugs [105]. Several dendrimers have shown solubility enhancement of drugs such as dexamethasone (Dex), nifedipine, camphotecin, quinolones and indomethacin that are hydrophobic or not very soluble in water [93,105,190,191]. Other studies [192,193] have also demonstrated the ability of PAMAM dendrimers to enhance the solubility of non-steroidal anti-inflammatory drugs (NSAIDs), such as naproxen, ketoprofen, ibuprofen and diflunisal.

The existence of inner cavities with different architectures in the dendrimers can be used to design controlled delivery systems [194], where the drug pharmacokinetics can be modulated as desired $[81,105,195,196]$. The interior of the dendrimers needs to be hydrophobic so that a drug can be loaded. The exterior of the dendrimer, however, usually needs to be hydrophilic to improve the bioavailability in the body [81]. Factors such as the ionization state of the drug have also been reported to affect the release of drug from PAMAM dendrimers [197].

On the other hand, high drug-loading influences the water solubility of the product and the biodistribution of the conjugates [198]. Agashe et al. [199] have studied the biodistribution pattern of the PPI dendrimer-based carbohydrate (mannose and lactose)-coated glycodendrimers (G5) in mice, in order to explore the potential of these systems as drug carriers. These complexes were found to be stable both in vitro and in vivo. All systems were cleared rapidly from circulation. Moreover, clearance of mannosecoated PPI dendrimer and lactose-coated PPI dendrimer was faster than with PPI alone. All complexes accumulated in liver, but only those with terminal carbohydrate moi- eties were retained for a longer period of time, which was related to lectin-carbohydrate interactions. This information is significant since it serves as a useful platform in designing carbohydrate-coated dendrimers for the delivery of bioactive agents to liver.

The attraction of dendronized polymers as DDS arises from the possibility to control and refine drug delivery. Actually, they can allow a temporally controlled delivery of single or multiple compounds, since step-wise degradation can be achieved due to the variety of chemical linkages within their structure (Fig. 5).

Response to a specified stimulus is a fundamental process of living systems. Learning from nature-inspired scientists to develop materials that respond to external stimuli such as temperature, $\mathrm{pH}$, light, electric field, chemicals and ionic strength [200]. Thus, smart or stimuliresponsive polymers respond to specific changes in their environment and as a consequence dramatic changes in their physical properties occurs (e.g., shape, surface characteristics, solubility, formation of an intricate molecular self-assembly or a sol-to-gel transition). The versatility of smart polymeric materials makes them one of the most appealing interfaces of chemistry and biology. Dendrimers' degradation leading to complete depolymerization may be initiated by reactions at either the periphery or the core, the so-called self-immolative dendrimers [201-204]. Hiu et al. [205] reported a dendritic PAMAM core (G3) and poly $(N, N$-dimethylaminoethyl methacrylate) (PDMA) synthesized via an atom transfer radical polymerization (ATRP), the so-called G3-PAMAM-g-PDMA. Chlorambucil (CLB), an anti-cancer drug was used as a model drug. Controlled drug release from polymers with different average graft lengths of PDMA was investigated by UV spectroscopy. Results showed that the rate of the drug release could be controlled by $\mathrm{pH}$; the release of CLB from the dendrimer derivative was faster at $\mathrm{pH} 1.4$ than at $\mathrm{pH}$ 10.0. Moreover, the release of CLB from G3-PAMAM-g-PDMA 
was apparently slower than that from CLB incorporated into the PAMAM dendrimer. In addition, these studies also showed that G3-PAMAM-g-PDMA presented a typical thermo-responsive character.

Pistolis et al. [206] reported that amine-terminated diaminobutane PPI dendrimers (DAB-32 or DAB-64) were $\mathrm{pH}$-sensitive controlled-release systems. As a model system, pyrene was incorporated into PPI dendrimers. Release studies revealed that pyrene incorporation is favored in basic environments and mainly close to the core of PPI dendrimers, while its release is induced in acidic media.

Zheng and Pan [207] synthesized dendrimer-star poly(N-isopropylacrylamide) (PNIPAAM) polymers with narrow molecular weight distribution using a dithiobenzoate-terminated PPI dendrimer (G2 and G3) via a reversible addition-fragmentation transfer (RAFT). The aqueous solution of the dendrimer-star PNIPAAM was found to be thermo-sensitive, with a lower critical solution temperature (LCST) around $32{ }^{\circ} \mathrm{C}$. Thus, the use of methacrylic acid along with NIPAAM, not only induces changes in the LCST, but also provides materials responsive to both temperature and $\mathrm{pH}$.

$\mathrm{pH}$ and temperature-activated polymers are known to be successful drug delivery systems. Photochemicalinternalization (PCI) can facilitate site-specific delivery, e.g., escape of the macromolecules from endocytic vesicles into the cytosol. Lai et al. [208] conjugated doxorubicin (Dox) to PAMAM dendrimers via $\mathrm{pH}$-sensitive and insensitive linkers, acid-labile hydrazone linkages (PAMAMhyd-Dox) and amide (PAMAM-amide-Dox), respectively. They combined doxorubicin-dendrimers with different PCI strategies to evaluate the cytotoxic effects. Results showed that both PCI strategies promoted the PAMAM-amide-Dox cytosolic distribution, but significantly enhanced the cytotoxicity of free Dox on human gingival cancer (Ca9-22) cells at higher concentrations. The authors failed to develop a multi-modality cancer treatment, but their data provided insights on possible research directions, namely the need to exploit spacers other than amide-linkage in drug-polymer complexes.

Papagiannaros et al. [209] have screened the cytotoxic of Dox-PAMAM dendrimer complex attached to liposomes using different human cancer-cell lines (e.g., lung, colon, breast, central nervous system and prostate). In this innovative work Dox was incorporated into PAMAM dendrimers (3:1 molar ratio) (1) with an efficiency of $97 \%$, and the anti-cancer activity investigated. Dox-PAMAM complex was also attached to hexadecylphosphocholine:eggphosphatidylcholine:stearylamine 10:10:0.1 (molar ratio) (2) and eggphosphatidylcholine:stearylamine 10:0.1 (molar ratio) (3) liposomes, with incorporation efficiencies of 91 and 95\%, respectively. The in vitro cytotoxicity tests revealed that Dox-PAMAM dendrimers retained high growth inhibiting activity, which was decreased when the complex attached to liposome 3 . The activity of Dox was enhanced when hexadecylphosphocholine was incorporated to liposomal formulation (2). Formulation 2 was superior among the three formulations against all cell lines tested. The dendrimeric liposomal formulation enhanced the activity of Dox against one type of breast cells. The most sensitive cell lines were those originated from lung cancer, suggesting a selective action of Dox as compared to the rest of the cell lines. These were the encouraging and promising data, showing that dendrimeric liposomal formulations may be a valuable strategy for the superior performance of DDS aimed at treat several types of cancer.

Wiwattanapatapee et al. [210] investigated the use of dendrimers for colon-specific drug delivery applications. In their studies, 5-aminosalicylic acid (5-ASA) was bound to the water-soluble dendrimer using different spacers containing azo-bond (e.g., $p$-aminobenzoic acid, PABA and $p$-aminohippuric acid, $\mathrm{PAH}$ ). $\mathrm{PAH}$ provide the polymer conjugates a higher loading capacity (3 times) for 5-ASA as compared to that of dendrimer conjugates with PABA as the spacer. In vitro studies of rats with cecal content were carried out to investigate drug release from dendrimer conjugates. The release of 5-ASA from both conjugates was significantly slower as compared to that of sulfasalazine (SA), a commercial prodrug. Moreover, the conjugate with $\mathrm{PAH}$ linker showed significantly higher amount of initial drug release than the conjugate with the PABA linker. As a consequence, the amount of drug released from PAMAM-PAH-SA was significantly higher than that of PAMAM-PABA-SA conjugate. This study nicely illustrated the potential use of PAMAM dendrimer for colon-specific drug delivery, and the important role of the spacers for the optimization of drug release.

Ghorai et al. [211] have described the first molecules of anthracene capped chiral dendrimers derived from a 1,3,5trisubstituted aromatic core and carbohydrate units in the interior and periphery. These are claimed to be suitable for anchoring other useful functionalities aimed at applications as DDS and light harvesting materials.

It is known that carbohydrate substructures of cellsurface glycoconjugates constitute important binding sites for pathogen infection. Dendrimeric systems for use in a lectin-binding assays have been developed [212]. Mannose receptors are present in the surface of monocyte/macrophages (Mo/Mac), alveolar macrophages, astrocytes in brain, and hepatocytes in liver. For example, targeting of anti-retroviral drugs to macrophages, which in turn are the target cells for HIV, could be an attractive approach in improving the therapeutic efficacy and reducing the toxicity of anti-retroviral drugs. In this context, Dutta and Jain [121] explored the targeting potential and anti-HIV activity of lamivudine (3TC, anti-retroviral drug) loaded mannosylated fifth-generation poly(propyleneimine) dendrimers (MPPI). The entrapment efficiencies of 3TC loaded MPPI and PPI dendrimers (G5) were found to be $\sim 43$ and $\sim 36 \%$, respectively. The in vitro release profile showed that mannose-modified PPI slows drug release as compared to that of unmodified PPI dendrimers. The results of in vitro internalization studies showed significant increase in lymphoblast human T (MT2) cells uptake of 3TC when MPPI was used, as compared to that for PPI and free drug. This result is evidence that MPPI interacts with the lectin receptors present on the surface of MT2 cells leading to its enhanced cellular uptake. Antiretroviral activity was determined using MT2 cell lines by estimating p24 antigen by ELISA, a widely accepted method of quantifying the viral load in HIV infection. 3TC loaded 
PPI and MPPI formulations were found to possess higher anti-HIV, mainly due to the enhanced cellular uptake of 3TC. These data suggest that the proposed MPPI drug delivery carrier has great potential to increase the efficacy and reduce the toxicity of anti-retroviral therapy.

Tuftsin, a natural macrophage activator tetrapeptide with Thr-Lys-Pro-Arg components, presents a broad spectrum of activities and binds to several cells of immune system. For example, Dutta et al. [120] synthesized tuftsinconjugated-PPI dendrimers (G5) for targeting to circulating Mo/Mac. These systems proved to hold potential for the controlled and targeted delivery of anti-retroviral drugs. Tuftsin-conjugated-PPI stimulated the phagocytic activity of the Mo/Mac, especially in HIV infected cells, contributing to the anti-HIV activity of the drug due to its inherent anti-retroviral activity. These materials were also found to be non-cytotoxic, in vivo [186].

Research on dendrimeric-based artificial virus receptors has attracted great deal of attention. Yamada et al. [213] successfully synthesized a novel class of carbosilane dendrimer periphery-functionalized lacto- $N$-neotetraose, aimed to mimic dengue virus receptor. In another work [212], they synthesized carbosilane dendrimers peripheryfunctionalized with lactotriaose (GlcNAc $\beta 1-3 G a l \beta 1-4 G l c)$ with valencies of three, four, six, and 12 for use in a lectinbinding assay. The hexavalent glycodendrimer showed a 2500-fold larger binding effect than that of free lactotriaose, though the dodecavalent one exhibited only a 1200 -fold larger binding effect. The same group also reported [214] on the potential of carbosilane dendrimers periphery-functionalized with galabiose (three, four, and six galabiose residues) for use as artificial inhibitors against Shiga toxins. Bhadra et al. [215] synthesized PPI dendrimers-coated with galactose and investigated the efficiency on delivering primaquine phosphate (PP, a liver schizonticide) directly to liver cells. The results showed that the coating of PPI systems with galactose increases the drug entrapment efficiency, prolonged circulation and drug release as compared to uncoated PPI delivery systems. Agrawal et al. [216] demonstrated a method to synthesize galactose-coated PLL dendrimers having polyethyleneglycol (PEG-1000) as core. This method consisted on alternating protection and deprotection steps of L-lysine by di-tert-butyl dicarbonate (di-BOC) until the formation of peptide dendrimer (G4) took place. Moreover, they successfully loaded these macromolecules with chloroquine phosphate, which is extensively employed for the suppression and treatment of malaria. The internalization studies of uncoated and coated drug dendrimer formulations in macrophages revealed almost 5 times reduced phagocytosis due to galactose coating. Galactosecoated peptide dendrimers drastically reduced haemolytic activity compared to uncoated PLL formulation. Haematological data suggested that galactose-coating strategy decrease immunogenicity as compared to uncoated formulations.

Carbosilanes bearing saccharide residues on their surface were first introduced by Matsuoka et al. [217]. An innovative work [218], described the synthesis of glycodendrimer via carbosiloxane formation. In this work, a hydrosilylation route was described to attach carbohydrate derivatives to carbosilane backbones without using any hetero atoms.

Prieto et al. [219] investigated the cytotoxicity of sulfadiazine complexed with fourth-generation PAMAM dendrimers. Cell culture studies using fibroblasts (Vero cells) and macrophages (J-774 cells) revealed that the dendrimeric sulfadiazine complexes did not affect membrane integrity at low concentrations $(0.03 \mu \mathrm{M})$. Moreover, cytotoxicity tests using human intestinal adenocarcinoma cell line (Caco-2 cells) showed that dendrimeric sulfadiazine did not reduce viability of Caco-2 cells over the tested concentrations as compared to that for PAMAM(G4). Remarkably, the in vivo study has shown that brain and muscle of Wistar rats are the main targets of intravenous administration of dendrimeric sulfadiazine, which can be advantageous for drug delivery applications directed to central nervous system.

For efficient encapsulation and delivery of 5fluorouracil (anti-cancer drug), Bhadra et al. [220] also exploit the surface modification route of PAMAM dendrimers with PEG. PEGylation of the systems was found to increase the drug-loading capacity of the nanocarrier, reduce the drug release rate and haemolytic toxicity. In another work [221], PEGylated PPI (G5) dendrimers were developed for sustained delivery of famotidine, a $\mathrm{H}_{2}$ receptor antagonist. In vivo investigations demonstrated a marked difference in the percentage of drug distribution from the bound drug through PEGylated dendrimer when compared with the free drug. Similar studies were carried out by Haba et al. [222]. They have prepared biocompatible nanocapsules consisting of a PAMAM dendrimer (G4) having both a PEG chain and a methacryloyl group at every chain end of the dendrimer through an L-lysine residue. These studies support previous findings showing that PEGylation can increase circulation time, provide sustained release of therapeutic molecules and improve haemocompatibility. Recently, Kono et al. [223] provided deeper insights on the designing of dendrimer-based carriers for accurate drug delivery. They have developed PAMAM dendrimers (G4) that have a glutamic acid (Glu) residue at every chain end of the dendrimer. Then, to obtain PEG-modified dendrimers with sites for conjugation, PEG chains were attached to amino groups of Glu residues. Dox was linked to side chains of the Glu residues by an amide bond, [PEG-Glu(Dox)-G4], or hydrazone bond, [PEG-Glu(NHN-Dox)-G4]. The developed systems were stable under physiological conditions, and Dox molecules were released from PEG-modified dendrimers in acidic environments such as those of endosomes/lysosomes. The Dox-bearing dendrimers showed much lower toxicity to HeLa cells as compared to free drug. However, it was evident that the conjugates with hydrazone bonds exhibited higher cytotoxic effects than those with amide bonds. These results suggest the importance of $\mathrm{pH}$-sensitive hydrazone linkage for high cytotoxicity. Furthermore, the PEG-modified dendrimers exhibited a similar level of toxicity to that of Dox-resistant (SBC-3/ADR100) cells and their parent Dox-sensitive SBC-3 cells.

Early studies have been performed with peptide dendrimers and other peptide-binding dendrimers, to evaluate peptide-protein and protein-protein interactions. These 
showed that dendrimer-based research can be a valuable tool for elucidating these processes. For example, Tam [111] proposed peptide dendrimers to act as immunogens, also known as multiple antigen peptides (MAPs).

$\mathrm{CD}$ derivatives bearing peptides may be useful as carriers for transporting drugs to biological targets containing specific peptide receptors. Thus, peptide biorecognizability together with the $C D$ host-guest complexation properties makes such systems suitable templates for the application in site-specific drug delivery. Much effort has been made to complex low generation dendrimers with other polymers. For example, Dodziuk et al. [224] reported attempts to complex a first-generation dendrimer having four branches with $\alpha$-, $\beta$ - or $\gamma$-cyclodextrins, found to be unsuccessful in their subsequent NMR studies. Muhanna et al. [225] reported a different strategy, with the synthesis of tetradecavalent amino acid and peptide dendrimers based on a $\beta-C D$ core. These were found to have great potential for application in MAP concept as a means to increase the peptide-receptor binding, and hence improve the site specificity of the drug delivery system. Imae et al. [226] investigated the binding of PAMAM dendrimer to sodium hyaluronate (NaHA). They successfully synthesized the PAMAM/NaHA complexes. Moreover, static light scattering data showed that when the dendrimers bind to the NaHA chain, the wormlike character of NaHA is scarcely changed at low $\left[\mathrm{NH}_{2}\right] /\left[\mathrm{COO}^{-}\right]$ratios. However, the structure of NaHA changed to a rod-like one at high $\left[\mathrm{NH}_{2}\right] /\left[\mathrm{COO}^{-}\right]$values, where the terminal numbers of dendrimers exceed at least five times the repeating unit numbers of a NaHA chain. They postulated that electrostatic interaction is essential, but not sufficient to connect such large numbers of dendrimers to NaHA because the number of amino terminal groups is 42 times larger than the number of carboxylates. They concluded that hydrogen-bonding interaction, besides the electrostatic interaction, should play an important role in the formation of these complexes. For rational design of intracellular nanocarriers, it is important to better understand the transport mechanisms across biological barriers. In general transport of nanosystems is dependent on one hand, on their nature, including their location, function and permeability, and on the other, on the nature of the nanocarrier molecules (e.g., molecular weight, charge, hydrophobicity, flexibility) and geometry [227]. Fig. 6 shows a simplified representation of the endocytic route of nanoparticle aimed at act as intracellular reservoir of drugs. Ultimately, these are expected to be released inside the cells and both modulate and control the cell machinery.

Recently, Perumal et al. [228] investigated the effect of surface functionality on cellular trafficking of dendrimers. In this report, different dendrimers (G4 OH-terminated, G4 amine-terminated and G3.5) were firstly, labeled with FITC. Results revealed that dendrimers are internalized by human lung carcinoma epithelial cells (A549 cell line). Using inhibitory drugs (e.g., sucrose, chlorpromazine, filipin, nocodazole and cytochalasins) for endocytosis, they found that nanoparticles uptake is mainly by fluid-phase endocytosis, independently of the external functionality, but significant differences in uptake mechanisms were seen. For example, anionic dendrimers appear to be mainly

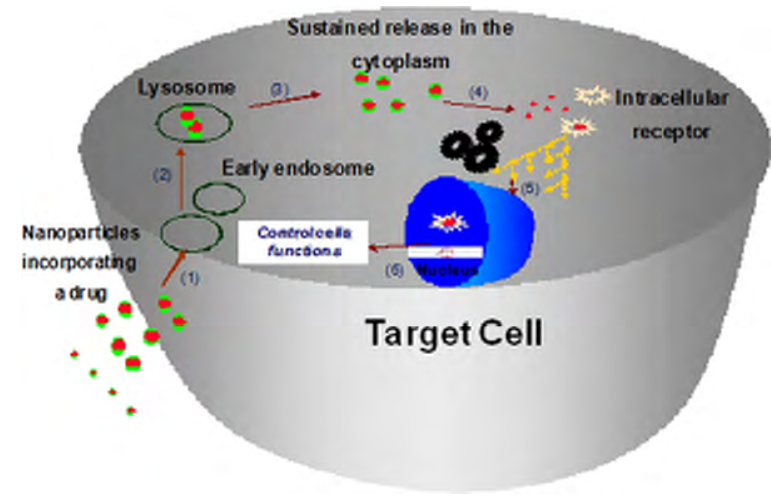

Fig. 6. Simplified representations of a nanoparticles intracellular reservoir for the sustained release of drugs aimed at modulate the cell machinery. (1) Internalization contact and crossing of the cell membrane; (2) uptake of the vector complex into intracellular endosome; (3) nanoparticles release from the endosome into cytoplasm; (4) sustained drug release and interaction with the intracellular receptor release from the endosome into the cytoplasm; (5) activation of cells machinery or translocation of the complex receptor/drug into the nucleus; (6) gene expression: mRNA transcription and protein translation from mRNA.

internalized by caveolae mediated endocytosis in A549 lung epithelial cells, while there was evidence of cationic and neutral dendrimers internalization by a non-clathrin, non-caveolae mediated mechanism that may be by electrostatic interactions or other non-specific fluid-phase endocytosis. Confocal microscopy studies revealed that cationic dendrimers were mostly localized in the endosomes in the cell periphery, with both anionic and neutral dendrimers found to localize in the lysosomes. These data showed that the surface charge of the dendrimers strongly influences their uptake by cells and intracellular localization, thus opening up new possibilities of targeting therapeutic agents to subcellular organelles. Pisal et al. [229] investigated the permeability of arginineand ornithine-conjugated PAMAM dendrimers (G4) across Caco- 2 cell monolayers. Conjugates were obtained by linking the polyamines to the amine groups of the PAMAM dendrimers (G4) using an Fmoc synthetic route, and then the conjugates were labeled with fluorescein isothiocyanate (FITC). The in vitro cell culture studies revealed that surface-modification of dendrimers increase permeability. Although the mechanisms by which the polyamines improve the permeation of the dendrimers remain unclear, the authors speculated that disruption of intercellular tight junctions could provide a possible mechanism. Similarly, Seib et al. [230] reported on the endocytic properties and intracellular trafficking of both linear and branched PEIs, and cationic PAMAM dendrimers (G2-4) in B16F10 murine melanoma cells. All polymers were first conjugated to Oregon Green (OG) and carefully characterized for $\mathrm{pH}$ - and concentration-dependence fluorescence. Flow cytometry studies revealed that uptake rate for PAMAM (G4) was the highest, followed by branched PEI, linear PEI, PAMAM (G3) and at last PAMAM (G2). Cells were cultured in the presence of the dendrimers and chlorpromazine or wortmannin to assess the mechanisms of uptake. The precise mechanisms of PAMAM internalization were once not totally clarified, 
but the authors suggest that PAMAM (G4) internalization can be cholesterol-dependent.

When compared to traditional macromolecular architectures (e.g., linear, cross-linked, branched), the unique features of the dendrimers and dendrimeric systems can improve the cellular uptake, bioavailability of therapeutic molecules inside the cells for long time periods, and consequently decrease the dosage and frequent re-dosage needs. There is a need to intensify the comprehensive research on the mechanisms of cellular uptake to develop safer and even more efficient dendrimeric nanocarriers.

\subsection{Tissue engineering (TE) applications of dendrimers and dendronized polymers}

In the recent years, great advances have appeared in the emerging field of TE and regenerative medicine, affording the opportunity for this review of recent achievements and scientific considerations on the subject.

In the early 1990s, Langer and Vacanti [231] coined TE to indicate "an interdisciplinary field of research that applies the principles of engineering and the life sciences towards the development of biological substitutes that restore, maintain, or improve tissue function". This concept is based on understanding of how tissue formation and regeneration occur, and instead of traditional implantation of new spare parts it envisions the use of new functional tissues. To accomplish this goal, three main therapeutic strategies have been proposed [232]: (i) implantation at injury site of freshly isolated cells (e.g., own patient cells) or cultured cells (differentiated cells alone or in combination with stem cells, for example); (ii) in situ tissue regeneration, e.g., implantation of a scaffold at the diseased/damaged tissue aimed at promote healing/repair by the patient's own cells; and (iii) implantation of tissues obtained from combining cells and scaffolds that are cultured in vitro with or without the presence of bioactive molecules. Thus, the basic TE triad consists of cells, scaffolds and bioactive agents, which can be used separately or in combination. Regenerative medicine uses the cell and tissue engineering principles for the regeneration of damaged/diseased body tissues.

The use of dendrimers' architectures in cells and TE applications is still in its infancy. A few examples have been reported, and these are mainly related with applications in cell-adhesion studies as nanopatterning [233]. Interestingly, ligand-modified dendrimers have been proposed for use as substratum for cell culture and high performance bioartificial organs [234].

On the other hand, it has been reported [88] that when a dendrimer reaches a certain generation (a variable factor according to the dendritic structure, but in general equal to or greater than G4), important conformational change occurs and the structure assumes a densely packed globular shape. Several authors $[80,88,235]$ have discussed the potential of tuning dendrimers to develop macromolecules that can mimic globular proteins. In fact, partial core shell-filled tecto(dendrimers) can be obtained by covalently assembling PAMAM dendrimers (nucleophilic or electrophilic) around other electrophilic or nucleophilic core dendrimers [236]. This feature allows many new tech- nological applications. One possibility is to take advantage of dendrimer architecture towards resembling the role of different proteins in the cells culture media. For example, dendrimers may be a valuable tool for the development of synthetic serum-free culture media and adequate substratum for superior cell culturing. Fluorescence spectroscopy, differential scanning calorimetry and fluorescent-probes studies [237,238] showed that dendrimers interact with proteins giving rise to stable complexes by establishing both electrostatic and non-electrostatic interactions.

Kim et al. [239] also investigated the response of human epithelial cells to dendrimer-immobilized substrates, with or without D-glucose displayed as a terminal ligand. When the topographic surface possessed a roughness of $4 \mathrm{~nm}$, epithelial cells cultured on naked dendrimer surface without D-glucose were somewhat stretched in their morphology compared with those on a non-modified plain surface. However, for the roughness values higher than $4 \mathrm{~nm}$ cell stretching was inhibited, thus resulting in the predominance of round-shaped cells. The change in cell morphology was quite evident on the surfaces with D-glucose-displayed dendrimers. Fluorescence microscopic observation showed that when the roughness value increased up to $4.5 \mathrm{~nm}$ on these surfaces, an enhancement of cell stretching occurs. These results suggested that surface roughness and D-glucose display induce changes in cellular morphology caused by the cytoskeleton formation accompanied by marked cell elongation. Therefore, this study demonstrated that dendrimer surfaces can offer a promising design for optimizing cells culture conditions.

Benhabbour et al. [240], demonstrated that cells showed a greater affinity for the dendronized surfaces as compared to Au surfaces (control). Moreover, in vitro cell culture studies with mouse 3T3 fibroblasts showed that cell attachment was diminished for the PEG-grafted Au surfaces as compared to the control Au and G1-G4 dendronized surfaces. These results showed that dendronized surfaces presenting a large number of hydroxyl groups can be a reliable alternative to the use of peptides to promote cell-adhesion and proliferation.

\subsubsection{Bone TE}

Bone is a very dense and specialized form of connective tissue, highly specialized in the several regions that constitutes it and acts as a support for the body. Bone lesions above a critical-sized segmental defect still remain a huge challenge to reconstructive surgery and regenerative medicine. This is mainly due to the fact that bone has a limited ability to heal $[241,242]$. In many clinical situations there is the need for a surgical intervention and the use of autografts [243,244], allografts or xenografts [244,245] transplantation. Still, the preferred clinical strategy is an autologous transplantation, since it avoids the problem of immune rejection [246] and consequent administration of drugs for immunosupression of the host [247]. Currently available treatment possibilities are far from affording truly ideal solutions. Recently, TE principles have been applied to this problem, e.g., by seeding bone marrow stem cells onto scaffolds (constructs) [248] or prostheses [249] to recreate a regenerative environment at the defect area and achieve a superior bone healing. Despite important advances, the 


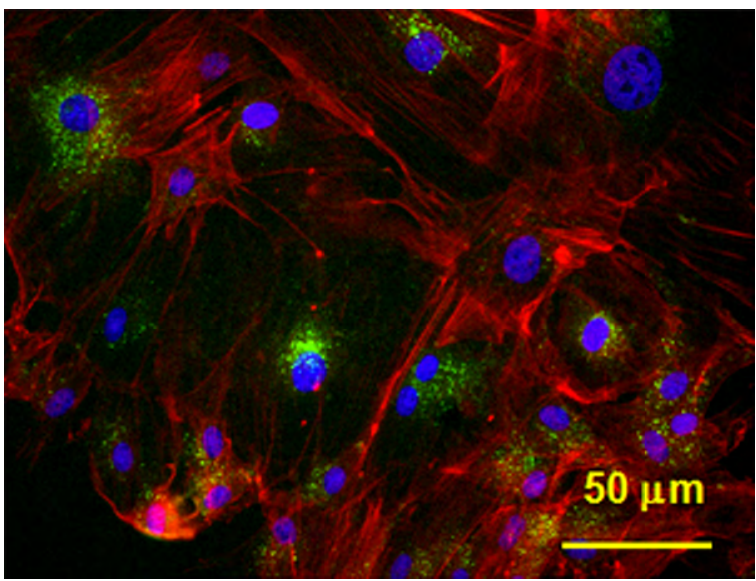

Fig. 7. Fluorescence microscopy image of the RBMSCs cultured in the presence of FITC-labeled CMCht/PAMAM dendrimer nanoparticles (green) for seven days. Nuclear DNA and cytoskeleton were labeled with Hoechst 33258 (blue) and Texas-Red phalloidin (red), respectively. (For interpretation of the references to color in this figure legend, the reader is referred to the web version of the article.).

performance of constructs remains limited, in part due to the need of optimized cell culture techniques [250]. To circumvent these limitations substantical efforts are focused on developing novel nanocarriers aimed at modulate cells behavior. Previously, our group [183] investigated Dexloaded CMCht/PAMAM dendrimer nanoparticles for their potential role in the regulation of osteogenesis, in vitro. That study focused on the uptake efficiency and mechanism of FITC-labeled CMCht/PAMAM dendrimer nanoparticles using rat bone marrow stromal cells (RBMSCs). Fluorescence microscopy studies revealed that the developed nanocarriers could be efficiently internalized by RBMSCs, after a few hours (Fig. 7).

Flow cytometry studies revealed that RBMSCs cultured in the presence of colchicine, an endocytotic inhibitor, reduce the internalization of the nanoparticles. These data showed that uptake by cells was primarily via an active endocytosis mechanism, but not exclusively. Moreover, the biochemical data demonstrated that the Dex-loaded CMCht/PAMAM dendrimer nanoparticles were not cytotoxic and promote osteogenesis (2-D system). Recent studies $[251,252]$ have shown that combination of hydroxyapatite (HAp) scaffolds, bone marrow stromal cells and Dex-loaded CMCht/PAMAM dendrimer enhanced osteogenesis in vitro (3-D systems), and de novo bone formation as compared to controls, in vivo (Fig. 8). Remarkably, animal studies showed that the novel Dex-loaded CMCht/PAMAM dendrimer nanoparticles may be beneficial as intracellular nanocarriers, supplying Dex in a regimented manner, while avoiding the need of culturing the cells in vitro for long periods of time. Moreover, this strategy facilitates modulation and direct stem cells differentiation towards the osteogenic phenotype, to enhance in vivo proteoglycan ECM synthesis and de novo bone formation.

Dendritic monomers have also been studied as components in dentistry applications, to allow polymerization to extend further, as incomplete polymerized matrixes can cause irritation, allergy or toxicological effects [253].

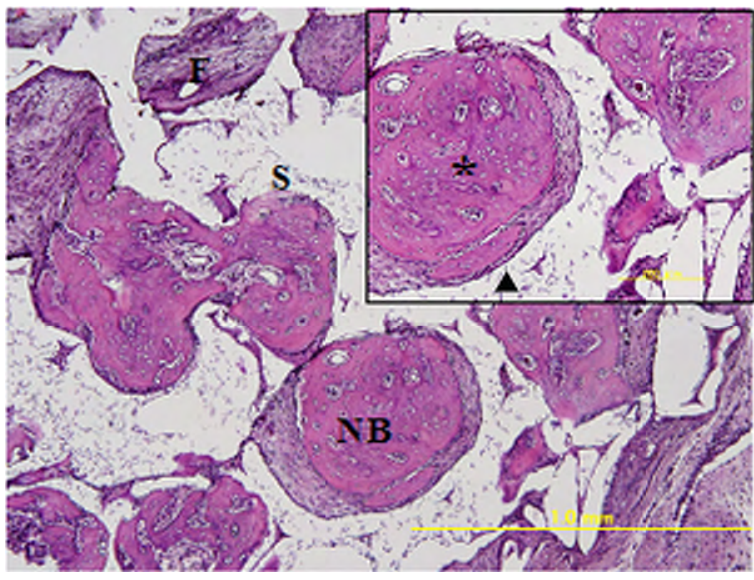

Fig. 8. Light microscopy photographs of the HAp-RBMSCs implant section (decalcified), stained with haematoxylin and eosin after 4 weeks of subcutaneous implantation: HAp scaffold seeded with $1 \times 10^{6}$ RBMSCs that were expanded in vitro ( 7 days), in MEM medium supplemented with $0.01 \mathrm{mg} \mathrm{mL}^{-1}$ Dex-loaded CMCht/PAMAM dendrimer nanoparticles, prior implantation. It is possible to observe representative areas of the HAp scaffold (S), de novo bone formation (NB), fibrous tissue (F). Black arrows reveal the cells lining, which is suggestive of active osteoblasts. Osteocytes can also be visualized (*).

In fact, photopolymerized dendritic copolymers and particulate filler composites have been combined for use as dental restorative materials [254]. In that study, dendritic monomers were found to enhance the copolymerization of methyl methacrylate and to lower the viscosity, which can be advantageous to improve the biocompatibility of the fillers.

\subsubsection{Cartilage TE}

Two main types of cartilage are found in the human body, namely the "unstressed" and "stressed" cartilage, in ear and joints, respectively. The general features of cartilage tissue include: (i) a small number of chondrocytes (less than $10 \%$ of the weight of articular cartilage) with low proliferation rate and having both catabolic and anabolic functions; (ii) a high content of water (75\% of the wet weight of articular cartilage); (iii) an abundant ECM composed by proteoglycan and different types of collagens (mainly type II), corresponding to 15-30 and $50-73 \%$ of the solid ECM weight, respectively; (iv) the absence of nerve and vascular systems [255,256]. Although a classical wound healing response is initiated, articular cartilage lesions are repaired without complete restoration of the component and architecture of the native tissue. This occurs since in the avascular tissue regenerative cells cannot migrate to the defect void unless the lesion goes beyond the subchondral bone plate [257,258]. Therefore, a regenerative response will be only possible when it is provided an artificial access by the marrow [259]. This consideration underlies several clinical strategies that are currently employed in the treatment of small cartilage lesions namely, the subchondral abrasion, Pridie's perforations, micro-fracture, and transplantation of osteochondral plugs [258,260-262]. Although, in most cases after clinical intervention the repaired tissue tends to degenerate, with the formation of undesired fibrocartilage [257,263,264]. 
Many attempts have been made to develop biomaterials for cartilage repair/regeneration. A few have exploited the advantages of dendrimers for this type of applications. Sontjens et al. [265] synthesized a photo-crosslinkable hydrogel scaffold for cartilage repair based on a triblock copolymer consisting of PEG core and methacrylatedpoly(glycerol-succinic acid) (PLGSA) terminal blocks. In vitro chondrocyte encapsulation studies demonstrated that the developed hydrogels supported the synthesis of proteoglycans and type II collagen, which denotes cartilaginous extracellular matrix formation. Moreover, encapsulated chondrocytes showed no signs of dedifferentiation. Despite the promising results in vitro, the authors discussed the need to improve mechanical properties and tailor the degradation rate of the developed hydrogels to obtain superior performance of the hydrogels, in vivo.

\subsubsection{Ocular wounds}

Another example of dendrimer applications in TE is related to attempts to improve the biological response of different biomaterials. In one study [43], laminin-based peptide YIGSR was introduced into a dendrimer-collagen hydrogel by linking the peptide to the residual dendrimer amine groups. The incorporated YIGSR peptide promoted the adhesion and proliferation of the corneal epithelial cells cultures onto the collagen hydrogel, in vitro. Moreover, neurite extension and nerve cell density were enhanced on these materials relative to unmodified gels or controls. This work is an unprecedented example of the ability to tune the biological function through the dendrimer crosslinker, and a new strategy towards obtaining polymer-based tissue engineering scaffolds with improved biological performance.

Inspired by the functional significance of collagen in nature and its remarkable physiological roles, Khew et al. [266] have developed the so-called enzymatically crosslinked collagen-mimetic dendrimers. These were obtained in a two-step procedure: (i) collagen-mimetic peptides supplemented with a cell-binding sequence (GFOGER) and enzyme-specific cross-linking domains (EDGFFKI and APQQEA) were conjugated onto a PAMAM dendrimer (G2), resulting in a crosslinkable collagen-mimetic dendrimer, and (ii) enzyme-mediated cross-linking the different collagen-mimetic dendrimers by tissue transglutaminase. Collagen-mimetic dendrimers were first assessed for their cytotoxicity, and then adhesion studies were carried out using L929 mouse fibroblasts and a hepatoma cell line (Hep3B cells), respectively. Results were indicative of the non-cytotoxic nature of the polymers. The adhesion studies have proven that enzymatic protein cross-linking, which is a common physiological event in the extracellular environment, can significantly improve cell-adhesion on the novel collagen-like biomaterial. Moreover, it was observed that combining collagen-like structural domain and biologically relevant epitopes (e.g., cell-binding sequence and enzyme-substrates) into a molecular design of a biomimetic collagen could be a promising approach for mimicking more closely its biological function.

The repair of wounds after traumatic or surgical injury is of significant clinical and research importance. For example, corneal wounds arise from surgical procedures (e.g., transplants, incisions for cataract removal and intraocular lens implantation, laser-assisted in situ keratomileusis), infections (ulcers), and traumatic injury (lacerations, perforations). Currently, these wounds are repaired using nylon sutures, but this technique is not ideal because the suture material does not actively participate in healing, and the procedure is inherently invasive. Therefore, alternative strategies using adhesive polymers have been tested. For example, Duan and Sheardown [267] cross-linked collagen with multi-functional dendrimers. PPI octaamine dendrimers (G2) were used to generate highly cross-linked collagen hydrogels with mechanical properties that would make it appropriate for use as a corneal TE scaffold.

For the superior performance of ocular wounds, hydrogel adhesives should meet some specific criteria, namely: (i) adhere to the moist corneal surface and seal the wound to withstand high intraocular pressures; (ii) possess adequate rheological properties to permit a controlled and rapid placement; (iii) ability to seal the corneal wound in a controlled manner and restore the intraocular pressure; (iv) maintain the structural integrity of the eye and possess a refractive properties resembling as much as possible to native cornea; ( $\mathrm{v}$ ) be biocompatible and provide a microbial barrier; and (vi) be biodegraded or bioabsorbed on a time scale consistent with tissue regeneration.

Grinstaff [268] has developed a set of dendrimeric adhesives composed of dendrimers of different generations (G1, G2 G3) combined with PEG, glycerol, and succinic acid for finding application in the repair of corneal wounds. The polymer was modified to contain terminal methacrylate (MA) groups, [G1]-PGLSA-MA) 2 -PEG. Two strategies to develop the ocular adhesives were explored: (i) the use of a photo-cross-linking reaction to form the dendrimerPGLSA-MA) 2 -PEG, and (ii) the use of a peptide ligation reaction to couple the individual dendrimers together to form the lysine-based dendron with terminal cysteines adhesive hydrogel G2-(Lys) ${ }_{3}-\mathrm{Cys}_{4}$ ) and PEG-dialdehyde (PEG-DA). Both strategies afford hydrogels that are adhesive, transparent, elastic, hydrophilic, and soft. The in vivo studies in chicken eyes have shown that the photocrosslinkable ([G1]-PGLSA-MA) 2 -PEG adhesive completely sealed the linear lacerations on post-operative day. The histological studies demonstrated that wounds sealed with these adhesive gels appeared to be more complete as compared to sutured wounds, after 28 days. The dendron ([G2]-(Lys) $\left.)_{3}-\mathrm{Cys}_{4}\right)$ and PEG-DA proved to be effective in the repair of corneal lacerations and required less surgical time than conventional suturing, ex vivo. The advantage of photo-cross-linked gels lies on the ability of the polymer to crosslink and adhere to the tissue where the clinician directs the light. However, a limitation is the potential risk of ocular damage when using light. Thus, a cross-linking strategy based on peptide bonding is attractive since it can avoid the need for light and the reaction is performed at neutral $\mathrm{pH}$; thus the polymer can be cross-linked upon placement on the tissue.

\subsubsection{Diagnosis and inflammation}

In autograft transplantation, biopsies are performed harvesting the smallest amount of tissue possible from patients, to prepare starter cells. Frequently, tissue is lised 
and cells are expanded. During culturing changes in intracellular states can cause variation in individuality in cell population and behavior. Moreover, due to terminal differentiation cellular senescence can occur. Therefore, there is the need to investigate the cellular status, prior implantation into the patient. In this context, Hata et al. [269] proposed a novel image analysis based on the observation of the partial anchoring of the cells to a glucose-dendrimerimmobilized culture surface as a mean to evaluate the formation of the cellular cytoskeleton in a non-invasive manner. In this study, formation of the cellular cytoskeleton was correlated with the growth cellular potential. This innovative method allowed observation of the cells morphology, and evaluate the regenerative potential of the cells for use in TE strategies.

In the last few years, there has been great interest [270,271] in the mediators responsible for the selective recruitment and activation of immune cells at inflammatory sites. Among these mediators, chemokines have received particular attention in in vivo studies involving the investigation of cytokine-associated responses to biomaterials. Chemokines are a large family of small (7000-15,000 Da, from 67 to 127 amino acids in length), structurally related heparin-binding proteins, which are classified into four subfamilies according to the configuration of cysteine residues near the $\mathrm{N}$-terminus, depending on whether the first two cysteines are separated (CXC, CX3C) or not (CC, C) by an intervening amino acid [272].

Chemokine messages are decoded by specific receptors [273-275] that initiate signal transduction events, leading to a multitude of cellular responses, including chemotaxis and activation of inflammatory and bone cells. Thus, the development of synthetic chemoattractants by linking small peptide sequences that are known to interact with chemokine receptors to dendrimers and, when appropriate, chemokine inhibitors [276] can be envisioned. In regenerative medicine, the development of dendrimerbased chemoattractants can find interesting applications towards recruiting stem cells [277]. This unexploited area can open up new therapeutic avenues, not only for treating autoimmune diseases, but also, to be used in innovative TE strategies, since it can lead to the superior repair/regeneration of damaged/diseased tissues by endogenous cells.

\subsection{Central nervous system (CNS) applications of dendrimers and dendronized polymers}

In spite of considerable study, the brain and the central nervous system (CNS) still encase many mysteries, and therefore their pathologies still represent a major challenge for biomedical science. Neurodegenerative disorders such as Parkinson's or Alzheimer's disease, stroke, brain tumors or multiple sclerosis (MS) are among leading debilitating diseases within our society to which feasible and long lasting therapeutic approaches are yet to be found.

The brain is protected from the rest of the body by structures known as barriers that most often represent a major hurdle for the delivery of diagnostic and therapeutic agents [278]. In fact most of the systemically administered drugs do not enter the brain in adequate amounts, and the attempt to resolve this problem by increased dosage usually leads to undesirable side effects. The most well-known barrier is the blood brain barrier (BBB), which consists of "walls" of capillaries that separate the brain from the circulating blood [278]. Its low permeability is mostly attributed to brain micro-vessel endothelial (BMVEC) cells which form tight junctions and have a low pinocytic potential [278-281]. Moreover, the BBB is also formed by astrocytic processes, leptomeningeal cells and a parenchymal membrane that together isolate the brain from unwanted molecules [278]. However, not all molecules are "unwanted" by the BBB. For instance, the latter provides for selective transport of small molecules, lipophilic and low molecular weight compounds, polypeptides and even cells to the CNS. In particular, nutrients and endogenous compounds such as amino acids, glucose, essential fatty acids, vitamins, minerals, and electrolytes are effectively carried by the BBB. Most of these processes are based on receptor-mediated endocytosis [279]. For example, receptors such as insulin, transferrin, endothelial growth factors, amino acids, glucose (GLUT 1) transporter are known to be expressed by the BBB [279]. In this sense the BBB can be seen as regulatory membrane, which selectively allows the passage of essential molecules to the homeostasis of the CNS, while inhibiting what is believed to be "harmful" ones. Thus, when designing a strategy to deliver a therapeutic agent into the CNS one must understand the properties of the BBB in order to allow an efficient delivery nanocarrier to the target site(s). Initially films, tablets, microspheres and intracranial polymeric materials were tested for these applications. However, as recently reviewed by Kabanov and Gendelman [278], such strategies had limited success namely due to their invasiveness, inflammatory responses to implants and limited distribution of therapeutic molecules around the implantation site. It was in this context that nanomedicine based approaches were put forward as a possible solution. Within these one can found liposome's [282,283], polymeric nanoparticles [284,285], and nanogels [286]. Dendrimers are particularly interesting for applications mentioned [287]. Surprisingly, their application to the CNS is also still quite scarce. Nevertheless, some nice examples can be drawn from the literature of the possible applications of these systems for drug delivery in the CNS. For instance Suppatone et al. [288,289] suggested the use of dendrimers for the removal of prion infection. In a couple of studies it was reported that branched polyamines, including PAMAM, PPI and PEI dendrimers, were able to purge PrPSc, the protease-resistant isoform of the prion protein, from scrapie-infected neuroblastoma ( $\mathrm{ScN} 2 \mathrm{a}$ ) cells in culture. The removal of PrPSc by these compounds depended mainly on both the concentration of branched polymer and the duration of exposure. Structure-activity analysis revealed that a high surface density of primary amino groups was required for polyamines to eliminate PrPSc effectively from cells. In a subsequent study it was also demonstrated that exposure of ScN2a cells to $3 \mathrm{mg} \mathrm{mL}^{-1}$ of PPI (G4) for four weeks not only reduced PrPSc to a level undetectable by Western blot, but also eradicated prion infectivity as determined by bioassays in mice. Moreover exposure of purified RML prions to branched polyamines 
in vitro disaggregated the prion rods, reduced the $\beta$-sheet content of PrP 27-30, and rendered PrP 27-30 susceptible to proteolysis.

Cationic phosphorous dendrimers have been proposed for the same applications, also through inhibition of fibril assembly [290]. Spectrofluorometric assays with thioflavin T (ThT) and Fourier transformed infra-red (FTIR) spectroscopy show that these classes of phosphorous dendrimers were able to clearly interfere with the PrP 185-208 aggregation process, both by slowing the formation of aggregates (by causing a decrease of the nucleation rate) and by lowering the final amount of amyloid fibrils, a common hallmark of conformational diseases. In fact, time-course experiments demonstrated that phosphorus dendrimers were able to remove quickly existing PrPSc molecules and the clearance occurred within $4 \mathrm{~h}$ of treatment [123]. The mechanism behind these actions is mostly unknown. However, similar to what happens with PAMAM dendrimers, the breakage of oligomers or whole fibrils caused by dendrimers probably has a strong role on the observed phenomena. A similar report was put forward by Klajnert et al. [122] in a study in which PAMAM dendrimers $(\mathrm{G} 3)$ were used to control the nucleation rate of amyloid plaques. The outcome of this study revealed that dendrimers at low concentrations can modulate the aggregation process by affecting the nucleation rate. However, at higher concentrations it seemed that dendrimers promoted the elongation of nucleation chains. Therefore, interest in the reported effect of dendrimers has to be considered within the ongoing search for compounds that can affect amyloid formation and in relation to the structural intermediates in this process responsible for cytotoxic effects. In this sense low dendrimer concentrations could contribute to a decrease of the lifetime of low molecular weight intermediates and contribute to decrease the potential cytotoxic effects of the peptides. For instance Patel et al. [291] described the use of modified PAMAM dendrimers for Alzheimer's disease. In this particular, case sialic-acid conjugated PAMAM dendrimers using a physiologically relevant attachment of the sialic-acid to the dendrimeric termini were prepared. Computer-aided EPR analyses have proved to be a valuable tool to study the interactions between dendrimers and peptides involved in Alzheimer's and prion diseases [292].

Another route to use dendrimers for CNS related applications, namely for transfection purposes, is by coating the latter with specific peptides. An example of such an approach was presented by Kim and co-workers [293,294], in which arginine-grafted PAMAM dendrimers were used. In this case these PAMAM-Arg dendrimers were complexed with expression of both a reporter gene (luciferase expression plasmid pCN-Luci) and a high mobility group box 1 (HMGB1) shRNA transgene-expressing plasmid for gene knock down. Results revealed that these PAMAMArg/DNA complexes showed particularly high transfection efficiencies and low cytotoxicity in primary cortical cells, as compared to other gene carriers, such as native PAMAM.

Other classes of dendrimers have also been proposed for CNS regenerative medicine, such as those based on polyesters. Dhanikula et al. [194,287] suggested the use of polyether-copolyester (PEPE) dendrimers conjugated with
D-glucosamine, and loaded with methotrexate (MTX) in order to allow a better delivery across the BBB. The results revealed that the efficacy of MTX-loaded dendrimers was established against U87 MG and U 343 MGa cells (two glioma cell lines). In vitro studies revealed that glucosylated dendrimers were internalized by endocytosis in significantly higher amounts than non-glucosylated dendrimers by both the cell lines. Moreover, the amount of MTX-transported across an in vitro model of the BBB was three to five times more after loading in the dendrimers, which indicates that glucosylation further increased the cumulative permeation of dendrimers across BBB, and hence increased the amount of MTX available across it. This work evaluated a different set of dendrimers, as well as different strategy, for potential use delivery across the BBB. However, it should be considered with caution, as only in vitro models were used, and the in vivo proof of concept is yet to be demonstrated. A similar strategy (e.g., cell targeted particles) was followed by $\mathrm{Wu}$ et al. [295], who developed a vehicle for boron neutron capture therapy (BNTC), instead of MTX. A heavily boronated PAMAM dendrimer was chemically linked to C225 by means of the heterobifunctional reagents $\mathrm{N}$-succinimidyl 3-(2-pyridyldithio)-propionate and $\mathrm{N}$-(k-maleimido undecanoic acid)-hydrazide. Initial in vitro studies revealed that the F98EGFR glioma cells mentioned above specifically internalize the particles when compared to receptornegative F98 wild-type cells. Further in vivo studies were conducted by stereotactically implanting F98EGFR cells into the brains of Fischer rats. The targeted boronated dendrimers were administered 14 days after either convection enhanced delivery (CED) or direct intratumoral (i.t.) injection. Results revealed that not only were the targeted dendrimers receptor specific in vivo, but also that animals exposed to the tested therapy displayed higher survival rated when compared to controls. In this sense it appears that this strategy for using dendrimers as targeted particles for therapeutic usage is more favorable than the former. Another in vitro study [296] described a set of polyester based dendrimers denoted as PLGSA. Reports regarding CNS applications are scarce, but it was demonstrated that these dendrimers could encapsulate camptothecins and could be internalize by glioblastoma cells (SF-268 cell line). Another study [297] suggested a possible source of delivery vehicles based on dendrimers denoted as CMCht/PAMAM dendrimer nanoparticles. Experiments with post-natal hippocampal neurons and cortical glial cells revealed that both cell populations were able to take up the CMCht/PAMAM dendrimer nanoparticles. The internalization rates changed according to the cell populations, reaching a maximum peak after $48 \mathrm{~h}$ of incubation. Overall astrocytes and microglial cells disclosed higher internalization rates (around 100\% of the total cell sub-population) followed by neurons and oligodendrocytes (up to 80-90\% of the observed cells). Further experiments for periods of up to seven days revealed that the periodical addition of CMCht/PAMAM dendrimer nanoparticles was required to maintain the levels of internalization. Finally, it was also observed that cell viability and proliferation were not significantly affected by the presence of the CMCht/PAMAM nanoparticles. These results were quite promising, but sim- 
ilar to what it was described for other studies described here, further in vivo proof of concept needs to be done.

\subsection{Gene delivery applications of dendrimers and dendronized polymers}

The ability to transfer genetic material efficiently, into the nucleus and cytoplasm of eukaryotic cells may allow treatment of a variety of genetic disorders. There are two types of vectors to gene delivery: (i) viral and (ii) non-viral. Viral-mediated DNA vehicles (infection) have played a major role in gene therapeutics. Unfortunately, initial enthusiasm associated to the high infection yields, has been tempered by growing concerns regarding safety issues such as toxicity, immunogenicity and oncogenicity $[298,299]$. On the other hand, synthetic DNA delivery systems "transfection" provide potential alternatives for gene therapy and DNA vaccination. Major drawback of current transfection technology is the low efficiency compared to infection techniques, although new materials and formulations [300-302] are under study.

Genetic material is usually imported into the cell by endocytosis where, via the endosomes, it can be transported to lysosomes to other intracellular membrane compartments or to the cytosol. Thus, they first reach mildly acidic endosomes ( $\mathrm{pH} 5.0-6.5$ ) and then end up in lysosomes, where they face much lower $\mathrm{pH}$ conditions and possible enzymatic degradation. Therefore, the importance of transferring genetic material into the cytosol is an extremely important process in the development of effective gene therapies. Moreover, transport of the gene into the nucleus must occur without imparting damage/inactivation from the vehicle itself. This renewed the interest in $\mathrm{pH}$-responsive dendrimeric nanocarriers as a mean to enable these macromolecules to reach their subcellular targets.

Dendrimers play a significant role in the development of non-viral vectors for gene delivery due to the high charge density and tunable surface functional groups, thus allowing optimal condensation and formation of nanostructures with DNA, the so-called "dendriplexes".

Amine-terminated PAMAM dendrimers (polycationic) can interact with the negatively charged phosphate groups of nucleic acids. This ensures consistent formation of transfection complexes. In fact, the transfection reagent called SuperFect ${ }^{\circledR}$ consisting of activated dendrimers is commercially available. Activated dendrimers can carry higher amounts of genetic material compared to that of viruses. SuperFect-DNA complexes are characterized by high stability, and provide more efficient transport of DNA into the nucleus than liposomes. It has been proposed that the high transfection efficiency of dendrimers may not only be due to their well-defined shape, but may also by the low $\mathrm{pK}$ of the amines (3.9 and 6.9). The low $\mathrm{pK}$ permit the dendrimer to buffer the $\mathrm{pH}$ change in the endosomal-lysosomal compartment. This can be beneficial since it can promote polymeric swelling, thus facilitating the disruption of the organelle membrane, the complex release or DNA itself. Therefore, they have an intrinsic endosomolytic escape capacity, or can mediate their escape by degradable spacers. Another advantage is that these vec- tors can also prevent fast degradation of DNA by endoand exo-nucleases. PAMAM and other cationic dendrimers such as PPI, thus fulfill these requirements. Initial work by Haensler and Szoka [303] have shown that the threedimensional spherical structure of the PAMAM dendrimers (G5) could be broken by heating and, surprisingly the fractured dendrimers led to significant enhanced transfection efficiency over naked plasmid DNA. Recently, Kim et al. [304] have proposed the use of poly(amino ester) obtained by bulk condensation of two monomers-containing multiple reacting groups towards obtaining a non-viral and cationic polymer-based gene delivery system. The particular feature of this system consisted on the low cytotoxicity and slow degradation which possibly long-term therapeutic applications.

Many factors affect the efficiency of non-viral gene delivery systems. For successful gene therapy the genetic material should be permanently integrated and expressed by cells. In this context, Galetti et al. [305] demonstrated that antisense oligonucleotides (ONs, gene-specific sequences of nucleic acids with 15-25 bases) directed to LMP1 mRNA, effectively suppressed LMP1 gene expression, which plays a key role for growth transformation and immortalization of B lymphocytes. The efficiency of three cationic carriers on the delivery of anti-LMP1-ON to their site of action in Epstein Barr virus (EBV)-infected B lymphocytes was investigated. Results showed that liposomes, dendrimers or transferrin-PLL-conjugated ON were internalized by the cells at an extent several fold higher than that of the naked oligomers. Using Superfect ${ }^{\circledR}$, a dendrimeric polycation with terminal amine groups, a higher intracellular concentration of ON was obtained as observed by both cytofluorimetric and confocal microscopy analyses. However, there was some evidence of toxicity induced by the positively charged dendrimers on the lymphocytes' membranes, and the lack of intracellular mRNA-ON duplex formation and of LMP1 mRNA degradation indicated a failure of this carrier.

Water-soluble phosphorus-containing dendrimers [306,307], e.g., those possessing hydrophilic end groups decorated with either positive or negative charges, also show interesting biological properties. Loup et al. [308] demonstrated that cationic phosphorus-containing dendrimers may be used as in vitro DNA transfecting agents, and that the generation has an important influence on both efficiency of transfection and cytotoxic behavior.

Different strategies have been proposed to improve transfection efficiency and biocompatibility. Arima et al. [309] prepared a novel conjugate consisting of a dendrimer (G3) with $\alpha$-cyclodextrin bearing mannose (Man- $\alpha-C D E$ conjugates) with various degrees of substitution of the mannose moiety. The Man- $\alpha-C D E$ conjugate (G3, DSM10) provided the highest gene transfer activity in different cell types and provided new insights on the cellular association of polyplex with Man- $\alpha-C D E$ conjugate (G3, DSM10). Results also suggested that the conjugate has less cytotoxicity, able to escape from endosomes and to be translocated into the nucleus. Similarly, Joester et al. [310] proposed the use a series of amphiphilic dendrimers based on a rigid tolane (diphenylethyne) core and possessing different numbers of $\mathrm{C}_{12}$ chains in the lipophilic dendron 
for efficient gene delivery. In their studies, it was evident the enhancement of the transfection efficiency by amphiphilic dendrimers 2 (three $\mathrm{C}_{12}$ chains and nominal charge $3+$ ) and 3 (three $C_{12}$ chains and nominal charge $9+$ ) as compared to reference compounds PEI, N-(1-(2,3-dioleoyloxy) propyl)-N,N,N-trimethyl ammonium methylsulfate (DOTAP), and SuperFect ${ }^{\circledR}$. The reason for this behavior was consistent with the proton sponge endosomal escape hypothesis.

Luo et al. [311] revealed the low cytotoxicity of PEG-modified PAMAM and their efficiency on the DNA delivery. These systems were obtained using low generation dendrimers with PEG chains, which mimics the fractured high-generation dendrimers. In fact, the proposed molecules showed a 20 -fold increase in transfection efficiency as compared to that of partially degraded dendrimer controls.

Zhang et al. [312] have investigated the effect of the core structure and generation of PAMAM dendrimers on the formation and transfection efficiency of the dendriplexes. This work evaluated in vitro, the transfection efficiency of a series of dendrimers with a trimesyl core (DT, three-arm) using COS-7 cells, HeLa cells and primary hepatocytes. Dendrimers derived from pentaerythritol (DP, four-arm) and inositol (DI, six-arm) were used for comparison. Results revealed that the minimal generation of 6 for DT for complex with DNA, and 5 fpr DP and DI. Thus, the difference in core structure resulted in different dendrimer flexibilities, and consequently influenced the interaction between the dendrimers and the DNA. As expected, the optimal generation numbers at which dendrimers showed higher transgene expression was 5 for DPs and DIs and 6 for DTs. Importantly, DT dendriplexes show higher transfection efficiency, attributed to its buffer capacity inside the endosome.

Boussif et al. work [313] uses PEI to test its potential for gene delivery. PEI is a protonable amino nitrogen atom, which makes the polymeric network an effective "proton sponge" at virtually any $\mathrm{pH}$, and can protect DNA from nuclease activity. The PEI/luciferase reporter gene complex was transferred into a variety of cell lines and primary cells gave results comparable to that of lipopolyamines (the gold standard).

Dung et al. [314] prepared dendriplexes of cholesteryl dendrimers with antisense oligonucleotides (5:1). These were biologically active, and mediated delivery of antisense oligonucleotide into HeLa cells in a moderate level. The enhanced delivery of the antisense oligomer into nucleus of the cells resulted in the expression of the reporter gene product, a luciferase. Thus, that work demonstrated that the increase of hydrophobicity by the conjugation of cholesterol to dendrimer enhanced the delivery efficiency of antisense oligonucleotide into cells.

Recently, Russ et al. [315] synthesized grafted-PPI dendrimers of PPI dendrimers (G2 and G3) by surface engineering with either oligoethylenimine (OEI) via esterdegradable or PPI dendrimer (G2). They investigated their potential as vectors for gene delivery both in vitro and in vivo. In vitro transfection studies with the polyplexes (surface-modified PPI dendrimers and plasmid DNA PCMVLuc-firefly luciferase reporter gene) were carried out using both Neuro2A neuroblastoma cells $\left(\mathrm{ATCC}^{\circledR}, \mathrm{CCl}-131\right)$ and B16F10 murine melanoma cells. Results showed that none of the compounds was cytotoxic, and grafting of either G2 or G3 core units with OEI led to enhanced transfection efficiency, irrespective of the core generation. Increase of the generation of dendrimers did not enhance transfection efficiency, in vitro. Prior in vivo studies, screened possible haemolytic activity of the compounds. Contrarily to previously reported PEI-induced erythrocyte aggregation, this work showed that none of the developed vectors induced erythrocyte aggregation. In vivo, a clear influence of the dendrimers in the tumor gene expression levels was observed, e.g., higher dendrimer core generation increased gene expression, demonstrating that surface-modification and incorporation of ethyleneimine core are key factors contributing to improve biocompatibility and transfection efficiency. Tziveleka et al. [316,317] proposed different synthetic vectors for the prospective application as gene transfection agents. Fourth-generation PPI dendrimers partially or fully surface-modified with guanidinium groups were able to complex with plasmid DNA (pEGFP-C2 and pGL3 luciferase reporter vectors). In vitro studies using human embryonic kidney (HEK 293) and the monkey kidney fibroblast (COS-7) cells showed that complete replacement of primary amino groups with the hydroxylated moieties resulted in complete loss of transfection efficiency. Contrarily, functionalization of the dendrimers with guanidinium groups enhanced transfection efficiency. This enhancement was dependent on the number of guanidinium groups at dendrimer periphery and cell type. In fact, the fully guanidinylated-modified dendrimer showed the best transfection efficiency. That is attributed to an accumulation of the guanidinium group at the dendrimeric surface, improving their penetrating ability. However, cytotoxicity studies demonstrated that increase in the degree of guanidinylation increases the dendrimers cytotoxicity. Thus, in light of these data, functionalization strategies can be a valuable strategy for superior transfection efficiency, but special attention should be addressed to cytotoxicity, which can limit gene transfer potency.

Choi et al. [318] adopted a different strategy to improve transfection efficiency of PAMAM dendrimers, demonstrating the positive effect of polyplexes on the transfection efficiency by bonding Dex to PAMAM dendrimers. In vitro studies using human embryonic kidney (293) and mouse neuroblastoma (Neuro2A) cells, showed that PAMAM-Dex/plasmid DNA (pCMV-Luc) complex had a higher transfection efficiency as compared to PEI and PAMAM, in the presence of serum proteins. Using 1,2bis-(o-aminophenoxy) ethane-N,N, $\mathrm{N}^{\prime}, \mathrm{N}^{\prime}$,-tetraacetic acidacetoxymethyl ester (BAPTA-AM), a glucocorticoid receptor inhibitor, they proved that Dex-induced translocation of the glucocorticoid receptor facilitate transport of complexes into nucleus, thus enhancing transfection efficiency.

Great efforts have been made as an attempt to clarify the mechanism(s) of transfection. Manunta et al. [319] reported on the route by which dendriplexes are internalized and mediate gene transfer. This work demonstrated that internalization is dependent on the cell type, and is a successful example of dendrimer application as a non-viral 
vector for gene delivery. The report showed that transfection of the dendriplexes may occur via different pathways, but in cells expressing caveolae, results suggest that gene delivery might be occurring by a caveolin-dependent pathway. Ruponen et al. [320] carried out a comparative study to investigate the performance of both cationic lipids (e.g., DOTAP and 1,2-dioleyl-3-phosphatidylethanolamine (DOPE)) and polymers (e.g., PEI, PAMAM dendrimers and PLL) for gene delivery. The study investigated the effect of interactions of extracellular polyanionic glycosaminoglycans (GAGs), such as hyaluronic acid (HA), chondroitin sulfate, and heparan sulfate with positively charged plasmid DNA complexes on the transfection efficiency. The results showed that polycations condensed DNA more effectively than monovalent lipids. Furthermore, polyplexes (PEI, PLL) were internalized by the cells more efficiently than lipoplexes. It was also found that sulfated GAGs (heparan sulfate, chondroitin sulfates B and C) completely blocked transfection, except in the case of liposomes with DOPE. Moreover, it was found that sulfated GAGs induced DNA release from PEI complexes, but that DNA release from the complexes was not required for the inhibition of transfection. Transfection by PEI, PAMAM dendrimers was inhibited by HA. This comprehensive study suggested that cell-surface GAGs, namely heparan sulfate can inhibit transfection mediated by both cationic lipids and polymers indicating that mechanistic information can help to develop more efficient vectors for gene delivery.

The protection of DNA from in vivo degradation by the vectors is another key feature for success in gene delivery. Diaz-Mochon et al. [321] showed that a hybrid combination of PAMAM and peptide dendrimers, the so-called peptoid dendrimers, were able to transfect cells with higher efficiency than the PAMAM counterpart, and were nontoxic. In part, this work supported previous findings which demonstrated that combination of primary and secondary amines generates a "proton sponge" effect, which can facilitate the DNA transfection process, by promoting the release of the plasmid from the cytoplasmic lysosome. Thus, efficiency of dendrimer/DNA complexes may be favored by prolonging the release of plasmid.

An early stage work reported by Herrmann et al. [322] described the synthesis of polyphenylene dendrimers functionalized with lysine residues or substituted with short peptide sequences composed of five lysine or glutamic acid repeats and a $\mathrm{C}$ - or $\mathrm{N}$-terminal cysteine residue. This group postulated that these amino acid and peptide functionalized dendrimers may be of interest as model compounds to study DNA complexation.

There are few papers which employ dendritic PLL as a gene delivery carrier, either alone or in combination with linear polymers or PEG. However, Männistö et al. [323] showed that the shape and charge of these nonviral vectors greatly influence their complexation with DNA and ultimately their transfection efficiency. Their study showed the ability of PLL dendrimers for complexing with DNA. Linear polymers were more efficient than dendritic ones. At low $M_{\mathrm{w}}$ of PLL, DNA-binding and condensation were less efficient, particularly with dendrimers. PEGylation did not decrease DNA condensation of PLLs at less than $60 \%$ (fraction of $M_{\mathrm{W}}$ ) of PEG. Moreover, introduction of PEG stabilized the complexes sterically. Internalization of PLL/DNA complexes was high and PEGylation increased the transfection efficacy. However, the overall transfection level of PLL was low, possibly due to inadequate escape of the complexes from endosomes or poor release of DNA from the complexes. Higashi et al. [324] studied the interaction of water-soluble PLL-shelled dendrimers possessing various PLL segment $(n=5-40)$ with DNA by circular dichroism spectroscopy, dynamic light scattering, and melting behavior of double-stranded DNA. Double helical DNAs were found to complex with dendritic PLLs (G3) $[5,10,20]$ primarily via electrostatic interactions. Moreover, a longer PLL-containing (G3) was found to interact with DNA more effectively than a shorter one. Okuda et al. [325] have also investigated the effect of substituting terminal cationic groups in PLL on the gene delivery into cells, in particular, the effect of guanidinium groups on the transfection. Monodispersed PLL (G6) dendrimers in which external amino acids were replaced by arginines and histidines were synthesized. A particular attention was given to clarify whether histidine shows the activity as an endosomal disruption agent. DNA-binding and transfection studies revealed that arginine-terminated PLL dendrimers could bind to the DNA more efficiently, and presented higher transfection efficiency as compared to those for histidine-terminated PLL. In fact, histidineterminated PLL did not mediate transfection. Despite, the terminal histidines of PLL dendrimers, especially the imidazole groups, had a key role in the $\mathrm{pH}$-dependent complex formation and transfection (neutral and acidic pHs). The unique character of histidine-PLL dendrimers is most promising.

As aforementioned, cationic PAMAM dendrimers have proved to efficiently mediate transfection of DNA into a variety of mammalian cells, in vitro. However, as highlighted, the major drawback of high-generation cationic dendrimers is their associated cytotoxicity. Anionic dendrimers, on the other hand, have shown no cytotoxic effect on cells over a broad range of concentrations. Hussain et al. [326] have reported the successful use of ONs conjugated with pentaerythritol-based anionic dendrimers in inhibiting cancer-cell growth. In vitro studies using cancer cells showed that ONs-dendrimer conjugates enhance the cellular uptake, up to four times as compared to that for naked ONs. These data clearly demonstrated that anionic ONs-dendrimer conjugates may represent attractive alternatives to cationic non-viral vectors for the delivery of gene silencing ONs. However, it is not known whether the system may facilitate the delivery of duplex siRNA for gene silencing by RNA interference. Therefore, further studies are necessary to evaluate the full potential of the delivery system. Similarly, Vincent et al. [327] investigated the efficacy in cancer therapy of non-viral gene transfer using the anti-angiogenic angiostatin (Kringle 1-3) and tissue inhibitors of metalloproteinases (TIMP) genes. This study revealed that it was possible to inhibit tumor growth and angiogenesis by using PAMAM dendrimers-like superfectant associated with 36-mer anionic oligomers (ON36) for delivering angiostatin and (TIMP)-2 genes. This strategy was validated in vivo, since i.t. angiostatin or TIMP-2 gene delivery using these dendrimers inhibited tumor growth by 
$71 \%$ and $84 \%$, respectively, while combined gene transfer resulted in $96 \%$ inhibition of tumor growth.

Electrophoretic studies carried out by Kuo and Lin [328] have demonstrated that fifth-generation PAMAM and PPI dendrimers altered or blocked the mobility of RNA isolated from human macrophage-like cells (U937 cell line) and mouse fibroblast $\mathrm{NIH} / 3 \mathrm{~T} 3$ cells previously exposed to DNA/dendrimer complexes. At higher dendrimer:DNA ratio, dendrimers interacted with RNA after isolation, but gene expression of these complexes was not affected. Electrostatic forces were found to be responsible for the dendrimer-induced alteration in RNA mobility. Because RNA isolation is routinely used for biological applications, such dendrimer-induced alteration in RNA mobility should be accounted for when further processing RNA for related applications, and the use of high ionic strength solvents ( $2 \mathrm{M} \mathrm{NaCl}$ solution) to disrupt the electrostatic forces binding dendrimers to RNA is advised.

A final key aspect in the gene delivery is related to the need to control gene transfection. This can be accomplished by developing controllable and non-toxic gene delivery systems that are stimuli-responsive. For example, Nishiyama et al. [329] proposed an innovative strategy based on PCI gene delivery. In their work, they have developed a ternary complexes (size between 100 and composed of a core of and cationic peptides (C(YGRKKRRQRRRG) $)_{2}$ ) that were enveloped in the second generation aryl ether dendrimers (32 carboxyl groups at the periphery) with a phtalocyanine core (photosensitizer). In vitro transfection studies using human cervical epithelioid carcinoma (HeLa) cells demonstrated that this ternary system enhanced ( $>100$-fold) transgene expression as compared to conventional reagents, such as PEI and Lipofectamine, in vitro. Moreover, it was shown that PCI-mediated gene delivery reduced phototoxicity of the ternary complexes. For the in vivo studies a reported gene was used. Fluorescence microscopy studies of rat conjunctival tissue revealed that the ternary complex positively induced gene delivery by PCI. That work demonstrated that polyplexpolycations significantly affect both transfection efficiency and toxicity. Therefore further optimization of this type of systems should involve research on the use of other polycations. Thus, PCI provides us with an opportunity to develop efficient light-inducible gene delivery systems. Shieh et al. [330] also investigated photo-triggered gene transfection by core-modified PAMAM dendrimers (G4). In their work, a 5,10,15-tri(4-acetamidophenyl)-20mono(4-carboxylphenyl) porphyrin (hydrophobic core) was introduced into the PAMAM dendrimers by activation with DCC and N-hydroxysuccinimide. In vitro characterization studies revealed that porphyrin core-PAMAM dendrimer conjugates were able to complex with green fluorescent protein (EGFP) plasmid DNA, and that the internalization by HeLa cells was concentration-dependent. Moreover, results from phototoxicity showed that without irradiation more than $94 \%$ of the cells survived when incubated with conjugates at a concentration of $20 \mu \mathrm{M}$. However, the complexes induced toxicity at $50 \mu \mathrm{M}$. For photodynamic therapy, results show that conjugation of porphyrin core to dendrimers did not increase the cytotoxicity of the PAMAM dendrimer below $20 \mu \mathrm{M}$, but significantly induced cell death after suitable irradiation. Nevertheless, the expression of EGFP was enhanced in HeLa cells using the PCI treatment. Thus, that study demonstrated that PAMAM dendrimers conjugated with porphyrin core can be an efficient and safe vector for PCImediated gene delivery.

Dendrimers are one of the most useful non-viral gene delivery systems. Their ability to transfect cells without inducing toxicity and be tuned for stimuli-induced gene delivery confers a great advantage over other gene delivery vectors for use in vivo.

\subsection{Theranostics applications of dendrimers and dendronized polymers}

Although opportunities to develop nanotechnologybased drug delivery systems extend into all therapeutic classes of pharmaceuticals, the development of effective diagnostic and therapeutic, e.g., one-package systems that can target different tissues, while releasing one or multiple therapeutic agents under an external stimuli have attracted a great deal of attention. For example, in cancer therapy, anti-cancer agents can damage both malignant and normal cells. Additional problems include instability of the drugs/growth factors in the biological milieu and short half-time, systemic migration, and premature drug loss through either rapid clearance by Mo/Mac, and/or metabolism. The design of most sophisticated systems should also consider the need for temporal release of the $\operatorname{drug}(\mathrm{s})$. Thus, dendrimers can be tuned for: (i) be stimuli-responsive nanocarriers, (ii) include moleculartags, (iii) possess high payload efficiency, (iv) decrease dosage requirements as well as re-dosage frequency and (v) target delivery and minimize drug migration, thus suppressing secondary effects during drug treatment. For example, Kuo et al. [331] investigated in vivo, the interactions of second and third generation PPI dendrimers with human macrophages U-937, since these molecules are primarily removed from circulation by the mononuclear phagocyte system. The effect of the type of dendrimer and concentration on the content of intracellular responsesreactive oxygen species (ROS), mitochondria membrane potential, cell size and complexity, and cell cycle profiles were investigated. Although the concentrations of PPI dendrimers used $\left(40-300 \mu \mathrm{g} \mathrm{mL}^{-1}\right)$ were not cytotoxic, various intracellular responses in dendrimer-treated macrophages occurred in a time-dependent manner. Moreover, the intracellular responses were found to be dependent on the dendrimer generation. This work nicely illustrates that a better understanding of the molecular action of these nanosystems in the cellular system may be an advantage for best design of safer and more effective delivery systems.

As previously stated herein, dendrimers fulfill these requirements as they can be stimuli-responsive and controlled-release systems for nucleic acids, bioactive molecules and peptide/protein delivery. Due to the possibility of tailoring the end groups, dendrimers are able to interact with the target, such as cell walls and/or proteins [156]. The external functional groups may allow the simul- 


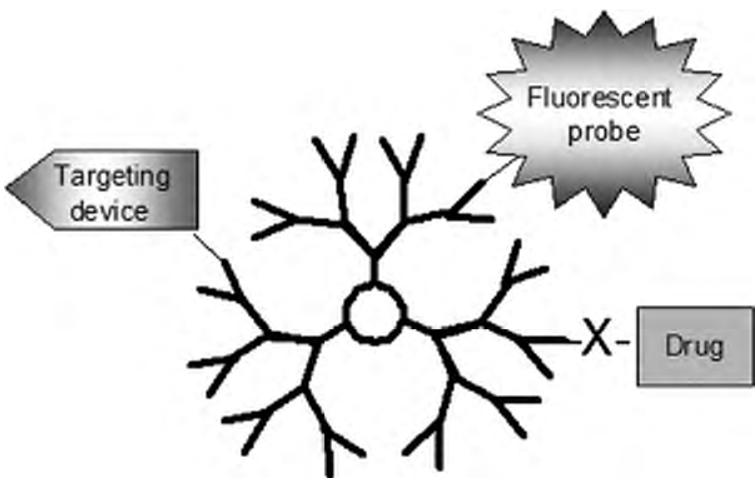

Fig. 9. Schematic representation of dendrimers with external binding to the drug and fluorescent-probes for application in theranostics (one-package system). It is possible to follow the biodistribution, internalization and intracellular trafficking within cells. The use of targeting devices such as antibodies to augment specificity is also possible. The drug can be linked to dendrimers using different spacers or bonds (X), which can be cleaved under a certain external stimuli, thus stimuli- or bio-responsive release is an additional possibility.

taneous, covalent bonding to therapeutic drugs, targeting devices and fluorescent-probes (Fig. 9).

Recently, a combination of polymer chemistry and imaging science approaches has led to the generation of polymer-based bioimaging probes for the diagnosis and treatment of different diseases. The ultimate goal of in vivo imaging is to achieve highly sensitive and reliable imaging techniques viable for diagnosis in personalized medicine for delivering drugs, following their distribution, and monitoring therapy. This concept (theranostics) is based on the "find, fight and follow" approach. New probes with enhanced capabilities and performance should be developed specific to nano-imaging techniques. Key research priorities for targeted delivery and in vivo imaging should address: (i) design of nanostructures with stealth properties that prevent them from being opsonised or cleared before reaching the target cells, (ii) ability to penetrate into cells and crossover biological barriers like the BBB, uptake and recycling of nanostructures, (iii) nanocarriers or strategies that selectively targets diseased cells, tissues and organs, (iv) trans-endocytosis of nanostructures, (v) safety evaluation (in vitro/in vivo cytotoxicity, haemocompatibility and immunogenicity), in vivo carrier biodistribution, and (vi) compatibility with external activation by magnetic field, ultrasound, X-ray, or optics to trigger the therapeutic activity. For example, the Kobayashi et al. [332] have shown that a dendrimer-based magnetic resonance contrast agent may be useful for in vivo detection of renal tubular damage. By its turn, Rietveld et al. [333] developed dendrimers with tetrabenzoporphyrin cores for in vivo oxygen imaging.

While it is promising to incorporate both therapeutic agents and molecular-tags on the dendrimers, and improve their potency [74], the possibility of combining diagnosis and therapy in multi-functional dendrimer-based nanosystems can allow the early detection, targeting and treatment of several diseases.

Thomas et al. [334] have linked PAMAM dendrimers (G5) with FITC for tracking, and two different antibodies, 60bca and J591, that bind to CD14 and prostrate spe- cific membrane antigen (PSMA), respectively. This work showed the receptor specificity as the conjugates bound to specific antigen expressing cells. Shukla et al. [335] synthesized PAMAM dendrimers (G5) conjugated to anti-HER2 monoclonal antibody by tagging the formulation with alexaFluor (AF). Flow cytometry studies revealed the uptake of conjugate by HER2 expressing cells, while no such affinity was found for MCA-207 control cells that did not express HER2, in vitro. Another good example of such versatile dendrimeric systems was put forward by Baek and Roy [336]. A well-defined multivalent T-antigen (Thomsen-Friedenrich antigen)-glycoPAMAM dendrimer was synthesized, aimed at applications in the detection and immunotherapy of carcinomas such as breast cancer. In another study [337], they synthesized a heterobifunctionalized dendritic L-lysine core bearing biotin and T-antigen by coupling the thiolated $\mathrm{T}$-antigen derivative to $\mathrm{N}$-chloroacetylated glycylglycyl Llysine dendritic cores.

According to the literature, the success of entrapping small molecules inside the dendrimer depends on the mutual properties between the host and the guest molecules. For example, Domanski et al. [84] reported attempts to entrap small fluorescent-probes commonly used to evaluate membrane fluidity inside the dendrimer. This work showed that 12-(9-anthroyloxy) stearic acid (12-AS), a non-polar fatty acid derivative, was successfully incorporated into the PAMAM dendrimers cavities, while on the contrary, 1-(trimethylammoniumphenyl)-6phenyl-1,3,5 hexatriene $p$-toluenesulfonate (TMA-DPH), a amphiphilic salt possessing a positive charge, was not.

Kolhe et al. [338] demonstrated that ibuprofen predominantly forms a complex with PAMAM (G3 and G4) dendrimers because of the ionic interaction between the $-\mathrm{NH}_{2}$ end groups and the carboxyl group of ibuprofen. In this work, they demonstrated that the in vitro release of ibuprofen from drug-dendrimer complex is appreciably slower compared to pure ibuprofen. Moreover, the FITC-labeled dendrimer-complexed drug enters human lung epithelial carcinoma A549 cells much faster than pure drug, suggesting that dendrimers may be able to carry the complexed drug inside cells efficiently. That group [57] synthesized a fourth-generation PAMAM (PAMAM-OH) dendrimer covalently linked to ibuprofen using dicyclohexylcarbodiimide (DCC) as a coupling agent. A high payload nanocarrier was obtained; 58 molecules of ibuprofen were covalently conjugated to one molecule of PAMAM-OH (G4) dendrimer. FITC-labeled dendrimer-drug conjugate nanoparticles internalization was evaluated in vitro once using A549 cells. The pharmacological activity of the dendrimer-ibuprofen conjugate was compared to pure ibuprofen at various time points by measuring the suppression of prostaglandin E2. Results demonstrated the high internalization efficiency of the FITC-labeled dendrimer-drug conjugate and superior therapeutic activity due to faster prostaglandin E2 suppression. Thus, the results suggest that the dendrimer-ibuprofen conjugate improve the drug efficacy by enhanced cellular delivery, and may produce a rapid pharmacological response. For example, several ligands are known to be associated with tumor. Ligand based dendritic polymers have been attracting great deal of attention for find appli- 
cations in cancer-cell-specific targeting [108] and tumor therapy [339].

Transferrin is a $\beta$-globulin ( $\beta_{1}$-glycoprotein) and facilitates the transport of ferric ion $\left(\mathrm{Fe}^{3+}\right)$ through transferrin receptors on the plasma membrane. In fact, the use of transferrin as a ligand has been explored as a suitable delivery system for site-specific delivery to tumors [340]. PLL covalently linked with transferrin for delivery of ONs when exposed to human leukemic (HL-60) cells have been stated to promote apoptosis to a greater extent as compared to free ONs. Another paper [341] demonstrated that PEGylated poly(cyanoacrylate) nanoparticles conjugated to transferrin were effective on the delivery of paclitaxel (PTX), an anti-tumor drug. PEGylation prevented aggregation of nanoparticles and transferrin effectively determined tumor site. An innovative study by Choi et al. [108] consisted of the development of dendrimers conjugated to different biofunctional moieties [FITC for imaging, and folic acid (FA) for targeting], linked together using complementary DNA oligonucleotides to produce clustered molecules for targeting tumor cells through folate receptors. This step forward allowed obtain both efficient DNA-linked dendrimer clusters for intracellular imaging and therapeutics, and circumvent the tedious synthesis of multiply-functionalized dendrimers.

Instead of linking oligonucleotides to the dendrimers, Majoros et al. [342] synthesized a multi-functional PAMAM dendrimer (G5) conjugated with FITC, FA, and PTX. In vitro studies have shown that drug-free dendrimer conjugates were not cytotoxic even at high concentrations. On contrary, drug-loaded dendrimer conjugates were toxic to both folate receptor-positive and folate receptor-negative cells as a result of non-specific binding at concentrations around $200 \mathrm{nM}$.

Another good example of PAMAM dendrimer-based multi-functional devices (target the desire cells, releasing the desired drug and monitoring their internalizationfluorescent probe) has been reported by Islam et al. [343]. This group partially acetylated PAMAM dendrimers (G5) that were then conjugated with FITC, FA and MTX. These were devised to target tumor cells through the folate receptor, while releasing an anti-tumor drug intracellularly. They showed that HPLC analysis is a valuable technique to determine the purity and stability of dendrimer-based complexes.

Yang et al. [344] synthesized FITC- and biotin-linked PAMAM dendrimer (G5) conjugates and investigated their ability for targeting cancer cells. The bifunctional conjugate (FITC-biotin-dendrimer) exhibited much higher internalization by HeLa cells than the conjugate without biotin. The uptake was found to be energy- and dose-dependent, and could be effectively blocked by dendrimer-conjugated biotin. The results indicate that the biocompatible biotindendrimer conjugate can be a promising nano-platform for therapy and diagnosis of tumors.

Epidermal growth factor (EGF) is an important factor that controls the disposition of neoplastic cells and potentiates transcription and proliferation of cells. Human growth receptor (HER-2) is a member of EGF family and their number is augmented in several tumors [345], and hence, it provides a potential target for immunotherapeutic agent.
Nanoparticles having a size in the range $1-10 \mathrm{~nm}$ have the capacity to diffuse into tumor cells. This helps to overcome limitations relating to chemotherapy using free drug such as poor in vivo/in vitro correlation and overcome other possible resistances offered by tumors. In fact, Tomalia [346] has also proposed the use of $\sim 5 \mathrm{~nm}$ sodium salt-PAMAM dendrimers (G4.5) nanoparticles possessing a 1,4-diaminobutanecore, as multi-purpose nanodevices for oncology drug delivery and diagnostic MRI contrast agents.

Relevant scientific data were recently reported by Saad et al. [347]. In this interesting work they investigated the role of different nanocarriers (linear polymer, PAMAM dendrimer and liposomes) containing the same bioactive agents, in tumor-specific treatment and imaging. In their comprehensive work it was demonstrated for the first time, that the targeting of nanocarriers to tumor-specific receptors minimizes the influence of the architecture, composition, size and $M_{\mathrm{w}}$ of the nanocarriers on the efficacy of imaging and cancer treatment. This step forward, illustrates that potential of the nanocarriers can only be fully exploited with a much better understanding of how such structures interact with the body and its components, in vitro and in vivo.

\section{Concluding remarks and future outlook}

Nanotechnology and medicine research are merging with other fields, leading to completely new science and superior technological platforms, such as those recently reported for regenerative medicine and neurosciences. The main aim of this review article was to summarize the unique properties, ability to design and improve the biological performance of dendrimers. This novel class of polymers and their derivatives exhibit unique physicochemical and biological properties, which have great potential for use in a variety of applications, including tissue engineering and regenerative medicine, as discussed herein.

Their compatibility with nanoscale building blocks such as genetic material, bioactive molecules and fluorescentprobes, which make them even more versatile than other nanomaterials, indeed probably with unique feature for use in theranostics was also emphasized. The development of dendrimers occurs at a time when common medical practice is based on symptom control, and research is focused on the best drugs to relieve the impact and progression of a given disease. Dendrimers may be used as tools to diagnose pathologies in an early stage thus helping manage disease in a sustainable manner. There is however, the need to conduct comprehensive research in vivo, to better understand and assess their true value as multi-functional packages. In particular, we still do not know whether these synthetic polymers, once they entered the body can cause damage to other tissues. Thus, much effort is required to evaluate the risk of bioaccumulation and redistribution. Research on their adsorption and interaction with biological surfaces, the associated uptake mechanisms, long-term effects, and bio-elimination needs also to be determined. Hence, new and unexplored characteristics of nanoscale are opened, and unsettled issues of biocompatibility, which will remain 
a key challenge without a definitive near term answer. Progress in the field of dendrimers and derivatives will certainly depend on other not less important aspects. In order to be effective, dendrimer-based products should be based on scientific evidence for their usefulness and must be easier to translate from laboratory to the clinic, in other words be quality-controlable, cost-effective and sustainable. Last, but not the least, their application should be validated from the regulator's viewpoint, worldwide.

As a final remark, the process of converting basic discoveries into marketable products can be long and hard, but since the discovery of dendrimers we can envision things never possible before and expect many innovations in the puzzling field of regenerative medicine.

\section{Acknowledgements}

The authors wish to acknowledge the funding provided by the Portuguese Foundation for Science and Technology (FCT) through the POCTI and FEDER programs, and FCT project (SMARTCARBO). This work was carried out under the scope of the European NoE EXPERTISSUES (NMP3-CT2004-500283) and European Union HIPPOCRATES STREP Project (NMP3-CT-2003-505758). Canon Foundation in Europe is also gratefully acknowledged.

\section{References}

[1] Buhleier E, Wehner W, Vögtle F. Cascade- and nonskid-chain-like syntheses of molecular cavity topologies. Synthesis 1978:155-8.

[2] Tomalia DA, Baker H, Dewald JR, Hall M, Kallos G, Martin S, et al. A new class of polymers: starburst-dendritic macromolecules. Polym J 1985;17:117-32.

[3] Feynman R. There's plenty of room at the bottom, in: Society A.P. (ed.). Lecture on 29.12.1959 at the "Annual meeting of the American Physical Society”. Pasadena, CA: California Institute of Technology 1959.

[4] Pridgen EC, Langer R, Parokhzad OC. Biodegradable, polymeric nanoparticle delivery systems for cancer therapy. Nanomedicine 2007;2:669-80.

[5] Muller DJ, Janovjak H, Lehto T, Kuerschner L, Anderson K. Observing structure, function and assembly of single proteins by AFM. Prog Biophys Mol Biol 2002;79:1-43.

[6] Roco MC. Nanotechnology: convergence with modern biology and medicine. Curr Opin Biotechnol 2003;14:337-46.

[7] Bikram M, Gobin AM, Whitmire RE, West JL. Temperature-sensitive hydrogels with $\mathrm{SiO}_{2}-\mathrm{Au}$ nanoshells for controlled drug delivery. J Control Release 2007;123:219-27.

[8] Pinna M, Guo X, Zvelindovsky AV. Block copolymer nanoshells. Polymer 2008;49:2797-800.

[9] Spuch-Calvar M, Pérez-Juste J, Liz-Marzán LM. Hematite spindles with optical functionalities: growth of gold nanoshells and assembly of gold nanorods. J Colloid Interface Sci 2007;310:297-301.

[10] Huang X, El-Sayed IH, Qian W, El-Sayed MA. Cancer cell imaging and photothermal therapy in the near-infrared region by using gold nanorods. J Am Chem Soc 2006;128:2115-20.

[11] Fahmy TM, Schneck JP, Saltzman WM. A nanoscopic multivalent antigen-presenting carrier for sensitive detection and drug delivery to T Cells. Nanomedicine 2007;3:75-85.

[12] Wu C, Brechbiel MW, Kozak RW, Gansow OA. Metal-chelatedendrimer-antibody constructs for use in radioimmunotherapy and imaging. Bioorg Med Chem Lett 1994;4:449-54.

[13] Kennel SJ, Woodward JD, Rondinone AJ, Wall J, Huang Y, Mirzadeh S. The fate of MAb-targeted $\mathrm{Cd}^{125 m} \mathrm{Te} / \mathrm{ZnS}$ nanoparticles in vivo. Nucl Med Biol 2008;35:501-14.

[14] Medintz IL, Clapp AR, Mattoussi H, Goldman ER, Fisher B, Mauro JM. Self-assembled nanoscale biosensors based on quantum dot FRET donors. Nat Mater 2003;2:630-8.

[15] Xing Y, Smith AM, Agrawal A, Ruan G, Nie SM. Molecular profiling of single cancer cells and clinical tissue specimens with semiconductor quantum dots. Int J Nanomed 2006;1:473-81.
[16] Song S, Liu D, Peng J, Sun Y, Li Z, Gu J-R, et al. Peptide ligandmediated liposome distribution and targeting to EGFR expressing tumor in vivo. Int J Pharm 2008;363:155-61.

[17] Katanasaka Y, Ida T, Asai T, Shimizu K, Koizumi F, Maeda N, et al. Antiangiogenic cancer therapy using tumor vasculaturetargeted liposomes encapsulating 3-(3,5-dimethyl-1H-pyrrol2-ylmethylene)-1,3-dihydro-indol-2-one, SU5416. Cancer Lett 2008;270:260-8.

[18] Tsuruta W, Tsurushima H, Yamamoto T, Suzuki K, Yamazaki N, Matsumura A. Application of liposomes incorporating doxorubicin with sialyl Lewis $\mathrm{X}$ to prevent stenosis after rat carotid artery injury. Biomaterials 2009;30:118-25.

[19] Bista RK, Bruch RF. Near-infrared spectroscopy of newly developed PEGylated lipids. Spectrochim Acta A 2008;71:410-6.

[20] Vanniasinghe AS, Bender V, Manolios N. The potential of liposomal drug delivery for the treatment of inflammatory arthritis. Semin Arthritis Rheu 2009;39:182-96.

[21] Simon F, Peterlik H, Pfeiffer R, Bernardi J, Kuzmany H. Fullerene release from the inside of carbon nanotubes: a possible route toward drug delivery. Chem Phys Lett 2007;445:288-92.

[22] Gallo M, Favila A, Glossman-Mitnik D. DFT studies of functionalized carbon nanotubes and fullerenes as nanovectors for drug delivery of antitubercular compounds. Chem Phys Lett 2007;447:1059.

[23] Foley S, Crowley C, Smaihi M, Bonfils C, Erlanger BF, Seta P, et al. Cellular localisation of a water-soluble fullerene derivative. Biochem Biophys Res Commun 2002;294:116-9.

[24] Tanaka K, Kitamura N, Morita M, Inubushi T, Chujo Y. Assembly system of direct modified superparamagnetic iron oxide nanoparticles for target-specific MRI contrast agents. Bioorg Med Chem Lett 2008; $18: 5463-5$.

[25] Maenosono S, Suzuki T, Saita S. Superparamagnetic FePt nanoparticles as excellent MRI contrast agents. J Magn Magn Mater 2008;320:L79-83.

[26] Patel D, Moon JY, Chang Y, Kim TJ, Lee GH. Poly(d,l-lactide-coglycolide) coated superparamagnetic iron oxide nanoparticles: synthesis, characterization and in vivo study as MRI contrast agent. Colloids Surface A 2008;313-314:91-4.

[27] Galperin A, Margel D, Baniel J, Dank G, Biton H, Margel S. Radiopaque iodinated polymeric nanoparticles for X-ray imaging applications. Biomaterials 2007;28:4461-8.

[28] Prinzen L, Miserus R-JJHM, Dirksen A, Hackeng TM, Deckers N, Bitsch NJ, et al. Optical and magnetic resonance imaging of cell death and platelet activation using annexin A5-functionalized quantum dots. Nano Lett 2007;7:93-100.

[29] Wiener EC, Konda SD, Wang S, Brechbiel M. Imaging folate binding protein expression with MRI. Acad Radiol 2002;9:316-9.

[30] Domnanich P, Sauer U, Pultar J, Preininger C. Protein microarray for the analysis of human melanoma biomarkers. Sens Actuators B: Chem 2009;139:2-8.

[31] Choi J-W, Kim Y-K, Oh B-K. The development of protein chip using protein $G$ for the simultaneous detection of various pathogens. Ultramicroscopy 2008;108:1396-400.

[32] Scarlett CJ, Smith RC, Saxby A, Nielsen A, Samra JS, Wilson SR, et al. Proteomic classification of pancreatic adenocarcinoma tissue using protein chip technology. Gastroenterology 2006;130:1670-8.

[33] Roh HW, Lee NR, Cho YH, Jung JB, Chung HN, Yang WS, et al. Development of a guideline for protein chip evaluation as medical devices. Curr Appl Phys 2006;6:e261-5

[34] Marconi S, Ferracci G, Berthomieu M, Kozaki S, Miquelis R, Boucraut J, et al. A protein chip membrane-capture assay for botulinum neurotoxin activity. Toxicol Appl Pharm 2008;233:439-46.

[35] Fissell WH, Dubnisheva A, Eldridge AN, Fleischman AJ, Zydney AL, Roy S. High-performance silicon nanopore hemofiltration membranes. J Membr Sci 2009;326:58-63.

[36] Zhang M, Fang S, Zakhidov AA, Lee SB, Aliev AE, Williams CD, et al. Strong, transparent, multifunctional, carbon nanotube sheets. Science 2005;309:1215-9.

[37] Atkinson KR, Hawkins SC, Huynh C, Skourtis C, Dai J, Zhang M, et al. Multifunctional carbon nanotube yarns and transparent sheets: fabrication, properties, and applications. Physica B: Condens Matter 2007;394:33-9.

[38] Flynn ER, Bryant HC, Bergemann C, Larson RS, Lovato D, Sergatskov DA. Use of a SQUID array to detect T-cells with magnetic nanoparticles in determining transplant rejection. J Magn Magn Mater 2007;311:429-35.

[39] Martin R. Peptides as targets of T cell-mediated immune responses. In: Kastin AJ, editor. Handbook of biologically active peptides. Burlington: Academic Press; 2006. p. 585-94. 
[40] Ghasemi-Mobarakeh L, Prabhakaran MP, Morshed M, Nasr-Esfahani M-H, Ramakrishna S. Electrospun poly $(\square-$ caprolactone)/gelatin nanofibrous scaffolds for nerve tissue engineering. Biomaterials 2008;29:4532-9.

[41] Zhang N, Nichols HL, Tylor S, Wen X. Fabrication of nanocrystalline hydroxyapatite doped degradable composite hollow fiber for guided and biomimetic bone tissue engineering. Mater Sci Eng C: Biomim Supramol Syst 2007;27:599-606.

[42] Janjanin S, Li W-J, Morgan MT, Shanti RM, Tuan RS. Mold-shaped, nanofiber scaffold-based cartilage engineering using human mesenchymal stem cells and bioreactor. J Surg Res 2008;149:47-56.

[43] Duan X, McLaughlin C, Griffith M, Sheardown H. Biofunctionalization of collagen for improved biological response: scaffolds for corneal tissue engineering. Biomaterials 2007;28:78-88.

[44] Volcke C, Pirotton S, Grandfils C, Humbert C, Thiry PA, Ydens I, et al. Influence of DNA condensation state on transfection efficiency in DNA/polymer complexes: an AFM and DLS comparative study. J Biotechnol 2006;125:11-21.

[45] Yamagata M, Kawano T, Shiba K, Mori T, Katayama Y, Niidome T. Structural advantage of dendritic poly(l-lysine) for gene delivery into cells. Bioorg Med Chem 2007;15:526-32.

[46] Gómez-Valadés AG, Molas M, Vidal-Alabró A, Bermúdez J, Bartrons $\mathrm{R}$, Perales JC. Copolymers of poly-L-lysine with serine and tryptophan form stable DNA vectors: implications for receptor-mediated gene transfer. J Control Release 2005;102:277-91.

[47] Suzuki R, Takizawa T, Negishi Y, Utoguchi N, Maruyama K. Effective gene delivery with novel liposomal bubbles and ultrasonic destruction technology. Int J Pharm 2008;354:49-55.

[48] De Rosa G, Stefano DD, Laguardia V, Arpicco S, Simeon V, Carnuccio $\mathrm{R}$, et al. Novel cationic liposome formulation for the delivery of an oligonucleotide decoy to NF- $\kappa$ B into activated macrophages. Eur J Pharm Biopharm 2008;70:7-18.

[49] Auguste DT, Furman K, Wong A, Fuller J, Armes SP, Deming TJ, et al. Triggered release of siRNA from poly(ethylene glycol)-protected, pH-dependent liposomes. J Control Release 2008;130:266-74

[50] Yuba E, Kojima C, Sakaguchi N, Harada A, Koiwai K, Kono K. Gene delivery to dendritic cells mediated by complexes of lipoplexes and $\mathrm{pH}$-sensitive fusogenic polymer-modified liposomes. J Control Release 2008;130:77-83.

[51] Pan X, Guan J, Yoo J-W, Epstein AJ, Lee LJ, Lee RJ. Cationic lipidcoated magnetic nanoparticles associated with transferrin for gene delivery. Int J Pharm 2008;358:263-70.

[52] Han S-E, Kang H, Shim GY, Suh MS, Kim SJ, Kim J-S, et al Novel cationic cholesterol derivative-based liposomes for serumenhanced delivery of siRNA. Int J Pharm 2008;353:260-9.

[53] Smith AM, Duan H, Mohs AM, Nie S. Bioconjugated quantum dots for in vivo molecular and cellular imaging. Adv Drug Deliv Rev 2008;60:1226-40.

[54] Courty S, Bouzigues C, Luccardini C, Ehrensperger MV, Bonneau S, Dahan M. Tracking individual proteins in living cells using single quantum dot imaging. Methods Enzymol 2006;414:211-28.

[55] Howarth M, Takao K, Hayashi Y, Ting AY. Targeting quantum dots to surface proteins in living cells with biotin ligase. Proc Natl Acad Sci USA 2005;102:7583-8.

[56] Lagerholm B, Wang M, Ernst L, Ly D, Liu H, Bruchez M, et al. Multicolor coding of cells with cationic peptide coated quantum dots Nano Lett 2004;4:2019-22.

[57] Kolhe P, Khandare J, Pillai O, Kannan S, Lieh-Lai M, Kannan RM. Preparation, cellular transport, and activity of polyamidoaminebased dendritic nanodevices with a high drug payload. Biomaterials 2006;27:660-9.

[58] Thaxton CS, Georganopoulou DG, Mirkin CA. Gold nanoparticle probes for the detection of nucleic acid targets. Clin Chim Acta 2006;363:120-6.

[59] Hien Pham TT, Cao C, Sim SJ. Application of citrate-stabilized gold-coated ferric oxide composite nanoparticles for biological separations. J Magn Magn Mater 2008;320:2049-55.

[60] Gong J-L, Liang Y, Huang Y, Chen J-W, Jiang J-H, Shen G-L, et al. $\mathrm{Ag} / \mathrm{SiO}_{2}$ core-shell nanoparticle-based surface-enhanced Raman probes for immunoassay of cancer marker using silica-coated magnetic nanoparticles as separation tools. Biosens Bioelectron 2007;22:1501-7.

[61] Yun Y, Bange A, Heineman WR, Halsall HB, Shanov VN, Dong Z, et al. A nanotube array immunosensor for direct electrochemical detection of antigen-antibody binding. Sens Actuators B: Chem 2007;123:177-82.

[62] Yoon HC, Lee D, Kim H-S. Reversible affinity interactions of antibody molecules at functionalized dendrimer monolayer: affinity-sensing surface with reusability. Anal Chim Acta 2002;456:209-18.
[63] Lee JH, Yang SS, Kim BW, Sim SJ, Chae H, Yoon HC. Electrochemical immunosensor signaling by employing enzyme-tagged antibody for the determination of antigen or antibody under single competition reaction format. Colloids Surface A 2008;313-314:509-14.

[64] Snejdarkova M, Svobodova L, Evtugyn G, Budnikov H, Karyakin A, Nikolelis DP, et al. Acetylcholinesterase sensors based on gold electrodes modified with dendrimer and polyaniline: a comparative research. Anal Chim Acta 2004;514:79-88.

[65] Yao K, Zhu Y, Yang X, Li C. ENFET glucose biosensor produced with dendrimer encapsulated Pt nanoparticles. Mater Sci Eng C 2008;28:1236-41.

[66] Liu Z-M, Yang Y, Wang H, Liu Y-L, Shen G-L, Yu R-Q. A hydrogen peroxide biosensor based on nano-Au/PAMAM dendrimer/cystamine modified gold electrode. Sens Actuators B: Chem 2005;106:394-400.

[67] Guo F, Zhu Y, Yang X, Li C. Electrostatic layer-by-layer self-assembly of PAMAM-CdS nanocomposites on MF microspheres. Mater Chem Phys 2007;105:315-9.

[68] Hsiao C-Y, Lin C-H, Hung C-H, Su C-J, Lo Y-R, Lee C-C, et al. Novel poly-silicon nanowire field effect transistor for biosensing application. Biosens Bioelectron 2009;24:1223-9.

[69] He B, Morrow TJ, Keating CD. Nanowire sensors for multiplexed detection of biomolecules. Curr Opin Chem Biol 2008;12:522-8.

[70] Bailey SN, Ali SM, Carpenter AE, Higgins CO, Sabatini DM. Microarrays of lentiviruses for gene function screens in immortalized and primary cells. Nat Methods 2006;3:117-22.

[71] Kang L, Chung BG, Langer R, Khademhosseini A. Microfluidics for drug discovery and development: from target selection to product lifecycle management. Drug Discov Today 2008;13:1-13.

[72] Underhill GH, Bhatia SN. High-throughput analysis of signals regulating stem cell fate and function. Curr Opin Chem Biol 2007:11:357-66

[73] Roney C, Kulkarni P, Arora V, Antich P, Bonte F, Wu A, et al. Targeted nanoparticles for drug delivery through the blood-brain barrier for Alzheimer's disease. J Control Release 2005;108:193-214.

[74] Wolinsky JB, Grinstaff MW. Therapeutic and diagnostic applications of dendrimers for cancer treatment. Adv Drug Deliv Rev 2008;60:1037-55.

[75] Vail DM, Amantea MA, Colbern GT, Martin FJ, Hilger RA, Working PK. Pegylated liposomal doxorubicin: Proof of principle using preclinical animal models and pharmacokinetic studies. Semin Oncol 2004;31(6S13):16-35.

[76] Chow T-H, Lin Y-Y, Hwang J-J, Wang H-E, Tseng Y-L, Pang VF, et al. Diagnostic and therapeutic evaluation of ${ }^{111}$ In-vinorelbineliposomes in a human colorectal carcinoma HT-29/luc-bearing animal model. Nucl Med Biol 2008;35:623-34.

[77] Liu J, Ohta S-I, Sonoda A, Yamada M, Yamamoto M, Nitta N, et al. Preparation of PEG-conjugated fullerene containing $\mathrm{Gd}^{3+}$ ions for photodynamic therapy. J Control Release 2007;117:104-10.

[78] Holister P. Nanotech: the tiny revolution. Madrid, Spain: CPM Cientifica; 2002.

[79] Tomalia DA. The dendritic state. Mater Today 2005;8:34-46.

[80] Tomalia DA. Birth of a new macromolecular architecture: dendrimers as quantized building blocks for nanoscale synthetic polymer chemistry. Prog Polym Sci 2005;30:294-324.

[81] D'Emanuele A, Jevprasesphant R, Penny J, Attwood D. The use of a dendrimer-propranolol prodrug to bypass efflux transporters and enhance oral bioavailability. J Control Release 2004;95:5447-53.

[82] Jevprasesphant R, Penny J, Attwood D, D'Emanuele A. Transport of dendrimer nanocarriers through epithelial cells via the transcellular route. J Control Release 2004;97:259-67.

[83] Sashiwa H, Shigemasa Y, Roy R. Chemical modification of chitosan 11: chitosan-dendrimer hybrid as a tree like molecule. Carbohydr Polym 2002;49:195-9.

[84] Domanski DM, Klajnert B, Bryszewska M. Incorporation of fluorescent probes into PAMAM dendrimers. Bioelectrochemistry 2004:63:193-7.

[85] Tomalia DA, Fréchet JMJ. Discovery of dendrimers and dendritic polymers: a brief historical perspective. J Polym Sci Part A: Polym Chem 2002;40:2719-28.

[86] Tomalia DA, Fréchet JMJ. Introduction to “Dendrimers and dendritic polymers". Prog Polym Sci 2005;30:217-9.

[87] Svenson S, Tomalia DA. Dendrimers in biomedical applicationsreflections on the field. Adv Drug Deliv Rev 2005;57:2106-29.

[88] Esfand R, Tomalia DA. Poly(amidoamine) (PAMAM) dendrimers: from biomimicry to drug delivery and biomedical applications. Drug Discov Today 2001;6:427-36.

[89] Sadler K, Tam JP. Peptide dendrimers: applications and synthesis Rev Mol Biotechnol 2002;90:195-229. 
[90] Turnbull WB, Stoddart JF. Design and synthesis of glycodendrimers. Rev Mol Biotechnol 2002;90:231-55.

[91] Cloninger MJ. Biological applications of dendrimers. Curr Opin Chem Biol 2002;6:742-8.

[92] Niederhafner P, Jaroslav S, Jezek J. Peptide dendrimers. J Pept Sci $2005 ; 11: 757-88$

[93] Devarakonda B, Hill RA, de Villiers MM. The effect of PAMAM dendrimer generation size and surface functional group on the aqueous solubility of nifedipine. Int J Pharm 2004;284:133-40.

[94] Fréchet J.M.J., Jiang Y., Hawker C.J., Philippides A.E. Dendritic molecules and method of production US Patent, 5,041,516; 1991: pp. 1-21.

[95] Leu C-M, Shu CF, teng C-F, Shiea J. Dendritic poly(etherimide)s: synthesis, characterization, and modification. Polymer 2001;42:2339-48.

[96] Leon JW, Fréchet JMJ. Analysis of aromatic polyether dendrimers and dendrimer-linear block copolymers by matrix-assisted laser desorption ionization mass spectrometry. Polym Bull 1995;35:449-55.

[97] Hawker CJ, Fréchet JMJ. Preparation of polymers with controlled molecular architecture. A new convergent approach to dendritic macromolecules. J Am Chem Soc 1990;112:7638-47.

[98] Angurell I, Turrin C-O, Laurent R, Maraval V, Servin P, Rossell O, et al. Decorating step-by-step and independently the surface and the core of dendrons. J Org Chem 2007;692:1928-39.

[99] Séverac M, Leclaire J, Sutra P, Caminade A-M, Majoral J-P. A new way for the internal functionalization of dendrimers. Tetrahedron Lett 2004;45:3019-22.

[100] Lee JW, Kim JH, Kim B-K, Shin WS, Jin S-H. Synthesis of Fréchet type dendritic benzyl propargyl ether and Fréchet type triazole dendrimer. Tetrahedron 2006;62:894-900

[101] Lee CC, MacKay JA, Fréchet JM, Szoka FC. Designing dendrimers for biological applications. Nat Biotechnol 2005;23:1517-26.

[102] DNT Inc. Dendritic NanoTechnologies announces new low-cost dendrimers. Focus on Surfactants. 2005; 2005:4.

[103] DNT Inc. DNT Inc announces commercial roll out of Priostar dendrimers. Focus on Surfactants. 2006; 2006:3-4.

[104] Sakharov DV, Jie AFH, Filippov DV, Bekkers MEA, van Boom JH, Rijken DC. Binding and retention of polycationic peptides and dendrimers in the vascular wall. FEBS Lett 2003;573:6-10.

[105] Chauhan AS, Sridevi S, Chalasani KB, Jain AK, Jain SK, Jain NK, et al. Dendrimer-mediated transdermal delivery: enhanced bioavailability of indomethacin. J Control Release 2003;90:33543.

[106] Tam JP. Synthetic peptide vaccine design: synthesis and properties of a high-density multiple antigenic peptide system. Proc Natl Acad Sci USA 1988;85:5409-13.

[107] Roy R. New trends in carbohydrate-based vaccines. Drug Discov Today 2004;1:327-36.

[108] Choi Y, Thomas T, Kotlyar A, Islam MT, Baker Jr JR. Synthesis and functional evaluation of DNA-assembled polyamidoamine dendrimer clusters for cancer cell-specific targeting. Chem Biol 2005; $12: 35-43$

[109] Barrett T, Kobayashi H, Brechbiel M, Choyke PL. Macromolecular MRI contrast agents for imaging tumor angiogenesis. Eur J Radiol 2006;60:353-66.

[110] Ong KK, Jenkins AL, Cheng R, Tomalia DA, Durst HD, Jensen JL, et al. Dendrimer enhanced immunosensors for biological detection. Anal Chim Acta 2001:444:143-8.

[111] Tam JP. Peptide dendrimers as immunogens. In: Kastin AJ, editor. Handbook of biologically active peptides. Burlington: Academic Press; 2006. p. 541-6.

[112] Han S, Baigude H, Hattori K, Yoshida T, Uryu T. Synthesis of new spherical and hemispherical oligosaccharides with polylysine core scaffold. Carbohydr Polym 2007;68:26-34.

[113] Tulu M, Aghatabay NM, Senel M, Dizman C, Parali T, Dulger B. Synthesis, characterization and antimicrobial activity of water soluble dendritic macromolecules. Eur J Med Chem 2009;44:1093-9.

[114] Chen CZ, Cooper SL. Recent advances in antimicrobial dendrimers. Adv Mater 2000;12:843-6.

[115] Gong E, Matthews B, McCarthy T, Chu J, Holan G, Raff J, et al. Evaluation of dendrimer SPL7013, a lead microbicide candidate against herpes simplex viruses. Antiviral Res 2005;68:139-46.

[116] Roy R. Glycodendrimers: novel bacterial adhesion inhibitors. Nanomedicine 2006;2:307

[117] Jiang Y-H, Emau P, Cairns JS, Flanary L, Morton WR, McCarthy TD, et al. SPL7013 gel as a topical microbicide for prevention of vaginal transmission of SHIV $_{89.6} \mathrm{P}$ in Macaques. AIDS Res Hum Retrov 2005;21:207-13.
[118] Helms B, Meijer EW. Dendrimers at work. Science 2006;313:929-30.

[119] Saha UK, Roy R. Glycosylated peptoids as prototypical HIV-1 protease inhibitors. Tetrahedron Lett 1997;38:7697-700.

[120] Dutta T, Garg M, Jain NK. Targeting of efavirenz loaded tuftsin conjugated poly(propyleneimine) dendrimers to HIV infected macrophages in vitro. Eur J Pharm Sci 2008;34:181-9.

[121] Dutta T, Jain NK. Targeting potential and anti-HIV activity of lamivudine loaded mannosylated poly (propyleneimine) dendrimer. Biochim Biophys Acta 2007;1770:681-6.

[122] Klajnert B, Cortijo-Arellano M, Bryszewska M, Cladera J. Influence of heparin and dendrimers on the aggregation of two amyloid peptides related to Alzheimer's and prion diseases. Biochem Biophys Res Commun 2006;339:577-82.

[123] Klajnert B, Cortijo-Arellano M, Cladera J, Majoral J-P, Caminade A-M, Bryszewska M. Influence of phosphorus dendrimers on the aggregation of the prion peptide PrP 185-208. Biochem Biophys Res Commun 2007;364:20-5.

[124] Heegaard PMH, Pedersen HG, Flink J, Boas U. Amyloid aggregates of the prion peptide PrP106-126 are destabilised by oxidation and by the action of dendrimers. FEBS Lett 2004;577:127-33.

[125] Kasai S, Nagasawa H, Shimamura M, Uto Y, Hori H. Design and synthesis of antiangiogenic/heparin-binding arginine dendrimer mimicking the surface of endostatin. Bioorg Med Chem Lett 2002;12:951-4

[126] Shimamura M, Kasai S, Nagasawa H, Ashino H, Yamamoto Y, Uto Y, et al. Angiogenesis inhibition of arginine-rich dendrimers, TX-1943 and TX-1944, which mimic the surface structure of endostatin. Vasc Pharmacol 2006:45:e119.

[127] Astruc D, Blais J-C, Daniel M-C, Gatard S, Nlate S, Ruiz J. Metallodendrimers and dendronized gold colloids as nanocatalysts, nanosensors and nanomaterials for molecular electronics. Comptes Rendus Chimie 2003;6:1117-27.

[128] Auten BJ, Lang H, Chandler BD. Dendrimer templates for heterogeneous catalysts: bimetallic Pt-Au nanoparticles on oxide supports. Appl Catal B: Environ 2008;81:225-35.

[129] Balzani V, Vögtle F. Dendrimers as luminescent hosts for metal cations and organic molecules. Comptes Rendus Chimie 2003;6:867-72.

[130] Beakley LW, Yost SE, Cheng R, Chandler BD. Nanocomposite catalysts: dendrimer encapsulated nanoparticles immobilized in sol-gel silica. Appl Catal A: Gen 2005;292:124-9.

[131] Mazzaglia A, Scolaro LM, Garozzo D, Malvagna P, Romeo R. Synthesis and characterization of poly(amidoamine)-platinum(II) complexes, detailed speciation by matrix-assisted laser desorption ionization mass spectrometry. J Org Chem 2005;690:1978-85.

[132] Mazzitelli CL, Brodbelt JS. Investigation of silver binding to polyamidoamine (PAMAM) dendrimers by ESI tandem mass spectrometry. J Am Soc Mass Spectrom 2006;17:676-84.

[133] Endo T, Yoshimura T, Esumi K. Synthesis and catalytic activity of gold-silver binary nanoparticles stabilized by PAMAM dendrimer. J Colloid Interface Sci 2005;286:602-9.

[134] Chessa G, Canovese L, Visentin F, Santo C, Seraglia R. Synthesis of poly(pyridylthioether) dendrimers incorporating a $\mathrm{Fe}_{2}(\mathrm{CO})_{6}$ cluster core. Tetrahedron 2005;61:1755-63.

[135] Martinovic J, Chiorcea-Paquim A-M, Diculescu VC, Van Wyk J, Iwuoha E, Baker P, et al. Metallo-functionalized first-generation salicylaldimine poly(propylenimine) tetraamine dendrimers: electrochemical study and atomic force microscopy imaging. Electrochim Acta 2008;53:4907-19.

[136] Newkome GR, Soo Yoo K, Hwang S-H, Moorefield CN. Metallodendrimers: homo- and heterogeneous tier construction by $\operatorname{bis}\left(2,2^{\prime}: 6^{\prime}, 2^{\prime \prime}\right.$-terpyridinyl $) \mathrm{Ru}(\mathrm{II})$ complex connectivity. Tetrahedron 2003:59:3955-64.

[137] Bronstein L, Shifrina Z. Nanoparticles in dendrimers: from synthesis to application. Nanotechnol Russ 2009;4:576-608.

[138] Diederich F, Felber B. Supramolecular chemistry of dendrimers with functional cores. Proc Natl Acad Sci USA 2002;99:4778-81.

[139] Caminade A-M, Laurent R, Majoral J-P. Characterization of dendrimers. Adv Drug Deliv Rev 2005;57:2130-46.

[140] Furer VL, Vandyukova II, Vandyukov AE, Fuchs S, Majoral JP, Caminade AM, et al. DFT analysis of vibrational spectra of phosphorus-containing dendrons built from cyclotriphosphazene core. J Mol Struct 2009;932:97-104.

[141] Caminade A-M, Turrin C-O, Sutra P, Majoral J-P. Fluorinated dendrimers. Curr Opin Colloid Interface Sci 2003;8:282-95.

[142] Caminade A-M, Maraval V, Laurent R, Turrin C-O, Sutra P, Leclaire $\mathrm{J}$, et al. Phosphorus dendrimers: from synthesis to applications. Comptes Rendus Chimie 2003;6:791-801. 
[143] Caminade A-M, Majoral J-P. Phosphorus dendrimers possessing metallic groups in their internal structure (core or branches): syntheses and properties. Coord Chem Rev 2005;249:1917-26.

[144] Caminade A-M, Maraval A, Majoral J-P. Phosphorus-containing dendrons: synthesis, reactivity, properties, and use as building blocks for various dendritic architectures. Eur J Inorg Chem 2006;2006:887-901.

[145] Bakshi MS, Kaura A. Poly(amidoamine) dendrimer interactions with sodium dodecyl sulfate studied by viscosity measurements. Colloids Surface A 2004;244:45-51.

[146] Alvarez-Venicio V, Jiménez-Nava B, Carreón-Castro MdP, Rivera E, Méndez IA, Huerta AA, et al. Synthesis and incorporation in Langmuir films of oligophenylenevinylene dendrimers bearing a polar head group and different dendritic poly(benzyl ether) branches. Polymer 2008;49:3911-22.

[147] Bao C, Jin M, Lu R, Zhang T, Zhao YY. Preparation of Au nanoparticles in the presence of low generational poly(amidoamine) dendrimer with surface hydroxyl groups. Mater Chem Phys 2003;81:160-5.

[148] Cho MY, Kang HS, Kim K, Kim SJ, Joo J, Kim KH, et al. Fabrication and electrical characteristics of organic thin film transistor using $\pi$-conjugated dendrimer. Colloids Surface A 2008;313-314:431-4.

[149] Arrington D, Curry M, Street S, Pattanaik G, Zangari G. Copper electrodeposition onto the dendrimer-modified native oxide of silicon substrates. Electrochim Acta 2008;53:2644-9.

[150] Alonso B, Armada PG, Losada J, Cuadrado I, González B, Casado $\mathrm{CM}$. Amperometric enzyme electrodes for aerobic and anaerobic glucose monitoring prepared by glucose oxidase immobilized in mixed ferrocene-cobaltocenium dendrimers. Biosens Bioelectron 2004;19:1617-25.

[151] Armada MPG, Losada J, Zamora M, Alonso B, Cuadrado I, Casado CM. Electrocatalytical properties of polymethylferrocenyl dendrimers and their applications in biosensing. Bioelectrochemistry 2006;69:65-73.

[152] Buschbeck R, Lang H. Triethylene glycol ether end-grafted carbosilane dendrimers: synthesis and complexation behaviour. Inorg Chem Commun 2004; 7:1213-6.

[153] Klajnert B, Sadowska M, Bryszewska M. The effect of polyamidoamine dendrimers on human erythrocyte membrane acetylcholinesterase activity. Bioelectrochemistry 2004;65:23-6.

[154] Shcharbin D, Jokiel M, Klajnert B, Bryszewska M. Effect of dendrimers on pure acetylcholinesterase activity and structure. Bioelectrochemistry 2006;68:56-9.

[155] Kubát P, Lang K, Zelinger Z. Interaction of porphyrins with PAMAM dendrimers in aqueous solution. $\mathrm{J}$ Mol Liquids 2007;131-132:200-5.

[156] Shcharbin D, Janicka M, Wasiak M, Palecz B, Przybyszewska M, Zaborski $M$, et al. Serum albumins have five sites for binding of cationic dendrimers. BBA-Proteins Proteom 2007;1774 946-51.

[157] Shcharbin D, Ottaviani MF, Cangiotti M, Przybyszewska M, Zaborski M, Bryszewska M. Impact of PAMAM G2 and G6 dendrimers on bovine serum albumin (fatty acids free and loaded with different fatty acids). Colloids Surface B 2008;63:27-33.

[158] Bakshi MS, Kaura A, Miller JD, Paruchuri VK. Sodium dodecyl sulfate-poly(amidoamine) interactions studied by AFM imaging, conductivity, and Krafft temperature measurements. J Colloids Interface Sci 2004;278:472-7.

[159] Beezer AE, King ASH, Martin IK, Mitchel JC, Twyman LJ, Wain $\mathrm{CF}$. Dendrimers as potential drug carriers; encapsulation of acidic hydrophobes within water soluble PAMAM derivatives. Tetrahedron 2003:59:3873-80.

[160] Abdelhady HG, Allen S, Davies MC, Roberts CJ, Tendler SJB Williams PM. Atomic force microscopy studies of generation 4 poly(amidoamine) (PAMAM) dendrimers on functionalized surfaces. Surf Sci 2004;558:99-110.

[161] Allabashi R, Arkas M, Hörmann G, Tsiourvas D. Removal of some organic pollutants in water employing ceramic membranes impregnated with cross-linked silylated dendritic and cyclodextrin polymers. Water Res 2007:41:476-86.

[162] Cromer JR, Wood SJ, Miller KA, Nguyen T, David SA. Functionalized dendrimers as endotoxin sponges. Bioorg Med Chem Lett 2005; $15: 1295-8$

[163] Labieniec M, Ulicna O, Vancova O, Glowacki R, Sebekova K, Bald E, et al. PAMAM G4 dendrimers lower high glucose but do not improve reduced survival in diabetic rats. Int J Pharm 2008;364:1429.

[164] Krishna TR, Jain S, Tatu US, Jayaraman N. Synthesis and biological evaluation of 3-amino-propan-1-ol based poly(ether imine) dendrimers. Tetrahedron 2005;61:4281-8.
[165] Jayamurugan G, Jayaraman N. Synthesis of large generation poly(propyl ether imine) (PETIM) dendrimers. Tetrahedron 2006;62:9582-8

[166] Kofoed J, Reymond J-L. Dendrimers as artificial enzymes. Curr Opin Chem Biol 2005;9:656-64.

[167] Jiang D-L, Aida T. A dendritic iron porphyrin as a novel hemoprotein mimic: effects of the dendrimer cage on dioxygen-binding activity. Chem Commun 1996;13:1523-4.

[168] Jiang D-L, Aida T. Bioinspired molecular design of functional dendrimers. Prog Polym Sci 2005;30:403-22.

[169] Bezouska K. Design, functional evaluation and biomedical applications of carbohydrate dendrimers (glycodendrimers). Rev Mol Biotechnol 2002;90:269-90.

[170] Pavlov GM, Errington N, Harding SE, Korneeva EV, Roy R. Dilute solution properties of lactosylated polyamidoamine dendrimers and their structural characteristics. Polymer 2001;42:3671-8.

[171] Kobayashi K, Akaike T, Usui T. Synthesis of poly (N-acetyl-blactosaminide-carrying acrylamide): chemical-enzymatic hybrid process. Methods Enzymol 1994;242:226-35.

[172] de Paz JL, Noti C, Böhm F, Werner S, Seeberger PH. Potentiation of fibroblast growth factor activity by synthetic heparin oligosaccharide glycodendrimers. Chem Biol 2007;14:879-87.

[173] Malik N, Wiwattanapatapee R, Klopsch R, Lorenz K, Frey H, Weener JW, et al. Dendrimers: relationship between structure and biocompatibility in vitro, and preliminary studies on the biodistribution of ${ }^{125}$ I-labelled polyamidoamine dendrimers in vivo. J Control Release 2000;65:133-48.

[174] Domanski DM, Klajnert B, Bryszewska M. Influence of PAMAM dendrimers on human red blood cells. Bioelectrochemistry 2004;63:189-91.

[175] Jevprasesphant R, Penny J, Jalal R, Attwood D, McKeown NB, D'Emanuele A. The influence of surface modification on the cytotoxicity of PAMAM dendrimers. Int J Pharm 2003;252:263-6.

[176] King Heiden TC, Dengler E, Kao WJ, Heideman W, Peterson RE. Developmental toxicity of low generation PAMAM dendrimers in zebrafish. Toxicol Appl Pharm 2007;225:70-9.

[177] Dutta T, Agashe HB, Garg M, Balakrishnan P, Kabra M, Jain NK Poly(propyleneimine)dendrimer based nanocontainers for targeting of efavirenz to human monocytes/macrophages in vitro. J Drug Target 2007;15:89-98.

[178] Neerman MF, Zhang W, Parrish AR, Simanek EE. In vitro and in vivo evaluation of a melamine dendrimer as a vehicle for drug delivery. Int J Pharm 2004;281:129-32.

[179] Göller R, Vors J-P, Caminade A-M, Majoral J-P. Phosphorus dendrimers as new tools to deliver active substances. Tetrahedron Lett 2001;42:3587-90.

[180] Sashiwa H, Shigemasa Y, Roy R. Chemical modification of chitosan, part 9: reaction of $\mathrm{N}$-carboxyethylchitosan methyl ester with diamines of acetal ending PAMAM dendrimers. Carbohydr Polym 2002;47:201-8

[181] Sashiwa H, Shigemasa Y, Roy R. Chemical modification of chitosan 8: preparation of chitosan-dendrimer hybrids via short spacer. Carbohydr Polym 2002;47:191-9.

[182] Sashiwa H, Aiba S-I. Chemically modified chitin and chitosan as biomaterials. Prog Polym Sci 2004;29:887-908.

[183] Oliveira JM, Kotobuki N, Marques AP, Pirraco RP, Benesch J, Hirose M, et al. Surface engineered carboxymethylchitosan/poly (amidoamine) dendrimer nanoparticles for intracellular targeting. Adv Funct Mater 2008;18:1840-53.

[184] Dubber M, Lindhorst TK. Treahalose-based octopus glycosides for the synthesis of carbohydrate-centered PAMAM dendrimers and thiourea-bridged glycoclusters. Org Lett 2001;3:401922.

[185] Domanski DM, Bryszewska M, Salamonczyk G. Preliminary evaluation of the behavior of fifth-generation thiophosphate dendrimer in biological systems. Biomacromolecules 2004;5:2007-12.

[186] Dutta T, Garg M, Dubey V, Mishra D, Singh K, Pandita D, et al. Toxicological investigation of surface engineered fifth generation poly(propyleneimine) dendrimers in vivo. Nanotoxicology 2008;2:62-70.

[187] Makimura Y, Zhonghong G, Roy R. Synthesis of novel sialic acid-containing polymers as inhibitors of hemagglutination. Int Congress Ser 2001;1223:45-8.

[188] Jevprasesphant R, Penny J, Attwood D, McKeown NB, D'Emanuele A. Engineering of dendrimer surfaces to enhance transepithelial transport and reduce cytotoxicity. Pharm Res 2003;20: 1543-50.

[189] Kono K, Fukui T, Takagishi T, Sakurai S, Kojima C. Preparation of poly(ethylene glycol)-modified poly(amidoamine) dendrimers 
with a shell of hydrophobic amino acid residues and their function as a nanocontainer. Polymer 2008;49:2832-8.

[190] Cheng Y, Li M, Xu T. Potential of poly(amidoamine) dendrimers as drug carriers of camptothecin based on encapsulation studies. Eur J Med Chem 2008;43:1791-5.

[191] Cheng Y, Qu H, Ma M, Xu Z, Xu P, Fang Y, et al. Polyamidoamine (PAMAM) dendrimers as biocompatible carriers of quinolone antimicrobials: an in vitro study. Eur J Med Chem 2007;42:10328.

[192] Yiyun C, Tongwen X. Dendrimers as potential drug carriers. Part I. Solubilization of non-steroidal anti-inflammatory drugs in the presence of polyamidoamine dendrimers. Eur J Med Chem 2005;40:1188-92.

[193] Yiyun C, Tongwen X, Rongqiang F. Polyamidoamine dendrimers used as solubility enhancers of ketoprofen. Eur J Med Chem 2005;40:1390-3.

[194] Dhanikula RS, Hildgen P. Influence of molecular architecture of polyether-co-polyester dendrimers on the encapsulation and release of methotrexate. Biomaterials 2007;28:3140-52.

[195] Canetta E, Maino G. Molecular dynamic analysis of the structure of dendrimers. Nucl Instrum Methods B 2004;213:71-4.

[196] Cheng Y, Li Y, Wu Q Zhang J, Xu T. Generation-dependent encapsulation/electrostatic attachment of phenobarbital molecules by poly(amidoamine) dendrimers: evidence from 2D-NOESY investigations. Eur J Med Chem 2008;43:2291-7.

[197] Devarakonda B, Otto DP, Judefeind A, Hill RA, de Villiers MM. Effect of $\mathrm{pH}$ on the solubility and release of furosemide from polyamidoamine (PAMAM) dendrimer complexes. Int $\mathrm{J}$ Pharm 2007;345:142-53.

[198] Aulenta F, Hayes W, Rannard S. Dendrimers: a new class of nanoscopic containers and delivery devices. Eur Polym J 2003;39:1741-71.

[199] Agashe HB, Babbar AK, Jain S, Sharma RK, Mishra AK, Asthana $A$, et al. Investigations on biodistribution of technetium-99mlabeled carbohydrate-coated poly(propylene imine) dendrimers. Nanomedicine 2007;3:120-7.

[200] Mano JF. Stimuli-responsive polymeric systems for biomedical applications. Adv Eng Mater 2008;10:515-27.

[201] Lee J-K, Suh Y-W, Kung MC, Downing CM, Kung HH. Efficient synthesis of immolative carbamate dendrimer with olefinic periphery. Tetrahedron Lett 2007;48:4919-23.

[202] Li S, Szalai ML, Kevwitch RM, McGrath DV. Dendrimer disassembly by benzyl ether depolymerization. J Am Chem Soc 2003;125:10516-7.

[203] Szalai ML, Kevwitch RM, McGrath DV. Geometric disassembly of dendrimers: dendritic amplification. J Am Chem Soc 2003;125:15688-9.

[204] Szalai ML, McGrath DV. Phototriggering of geometric dendrimer disassembly: an improved synthesis of 2,4-bis(hydroxymethyl) phenol based dendrimers. Tetrahedron 2004;60:7261-6.

[205] Hui H, Xiao-dong F, Zhong-lin C. Thermo- and pH-sensitive dendrimer derivatives with a shell of poly(N,N-dimethylaminoethyl methacrylate) and study of their controlled drug release behavior. Polymer 2005;46:9514-22.

[206] Pistolis G, Malliaris A, Tsiourvas D, Paleos CM. Poly(propyleneimine) dendrimers as $\mathrm{pH}$-sensitive controlledrelease systems. Chem Eur J 1999;5:1440-4.

[207] Zheng Q Pan C-Y. Preparation and characterization of dendrimerstar PNIPAAM using dithiobenzoate-terminated PPI dendrimer via RAFT polymerization. Eur Polym J 2006;42:807-14.

[208] Lai P-S, Lou P-J, Peng C-L, Pai C-L, Yen W-N, Huang M-Y, et al. Doxorubicin delivery by polyamidoamine dendrimer conjugation and photochemical internalization for cancer therapy. J Control Release 2007:122:39-46.

[209] Papagiannaros A, Dimas K, Papaioannou GT, Demetzos C. Doxorubicin-PAMAM dendrimer complex attached to liposomes: cytotoxic studies against human cancer cell lines. Int J Pharm 2005;302:29-38.

[210] Wiwattanapatapee R, Lomlim L, Saramunee K. Dendrimers conjugates for colonic delivery of 5-aminosalicylic acid. J Control Release 2003;88:1-9.

[211] Ghorai S, Bhattacharyya D, Bhattacharjya A. The first examples of anthracene capped chiral carbohydrate derived dendrimers: synthesis, fluorescence and chiroptical properties. Tetrahedron Lett 2004:45:6191-4.

[212] Yamada A, Hatano K, Koyama T, Matsuoka K, Takahashi N, Hidari KIPJ, et al. Lactotriaose-containing carbosilane dendrimers: syntheses and lectin-binding activities. Bioorg Med Chem 2007;15:1606-14.
[213] Yamada A, Hatano K, Koyama T, Matsuoka K, Esumi Y, Terunuma D. Syntheses of a series of lacto-N-neotetraose clusters using a carbosilane dendrimer scaffold. Carbohydr Res 2006;341: 467-73.

[214] Yamada A, Hatano K, Matsuoka K, Koyama T, Esumi Y, Koshino $\mathrm{H}$, et al. Vero toxin-binding activities of carbosilane dendrimers periphery-functionalized with galabiose. Tetrahedron 2006;62:5074-83.

[215] Bhadra D, Yadav AK, Bhadra S, Jain NK. Glycodendrimeric nanoparticulate carriers of primaquine phosphate for liver targeting. Int J Pharm 2005;295:221-33.

[216] Agrawal P, Gupta U, Jain NK. Glycoconjugated peptide dendrimersbased nanoparticulate system for the delivery of chloroquine phosphate. Biomaterials 2007;28:3349-59.

[217] Matsuoka K, Terabatake M, Esumi Y, Terunuma D, Kuzuhara H. Synthetic assembly of trisaccharide moieties of globotriaosyl ceramide using carbosilane dendrimers as cores. A new type of functional glyco-material. Tetrahedron Lett 1999;40:7839-42.

[218] Boysen MMK, Lindhorst TK. 'Sugaring' carbosilane dendrimers via hydrosilylation. Tetrahedron 2003;59:3895-8.

[219] Prieto MJ, Schilrreff P, Tesoriero MVD, Morilla MJ, Romero EL. Brain and muscle of Wistar rats are the main targets of intravenous dendrimeric sulfadiazine. Int J Pharm 2008;360:204-12.

[220] Bhadra D, Bhadra S, Jain S, Jain NK. A PEGylated dendritic nanoparticulate carrier of fluorouracil. Int J Pharm 2003;257:111-24.

[221] Gajbhiye V, Vijayaraj Kumar P, Tekade RK, Jain NK. PEGylated PPI dendritic architectures for sustained delivery of $\mathrm{H} 2$ receptor antagonist. Eur J Med Chem 2009;44:1155-66.

[222] Haba Y, Harada A, Takagishi T, Kono K. Synthesis of biocompatible dendrimers with a peripheral network formed by linking of polymerizable groups. Polymer 2005;46:1813-20.

[223] Kono K, Kojima C, Hayashi N, Nishisaka E, Kiura K, Watarai $\mathrm{S}$, et al. Preparation and cytotoxic activity of poly(ethylene glycol)-modified poly(amidoamine) dendrimers bearing adriamycin. Biomaterials 2008;29:1664-75.

[224] Dodziuk H, Demchuk OM, Schilf W, Dolgonos G, Synthesis. NMR study of a first generation dendrimer having four branches involving four glycine and one carbomoyl-(3,7-dimethoxy-2naphthalene) groups and attempts to complex it with $\alpha-, \beta-$ or $\gamma$-cyclodextrins. J Mol Struct 2004;693:145-51.

[225] Muhanna AMA, Ortiz-Salmerón E, Garcla-Fuentes L, GiménezMartInez JJ, Vargas-Berenguel A. Synthesis of peptide dendrimers based on a $\beta$-cyclodextrin core with guest binding ability. Tetrahedron Lett 2003;44:6125-8.

[226] Imae $T$, Hirota $T$, Funayama $K$, Aoi K, Okada M. Binding of poly(amido amine) dendrimer to sodium hyaluronate in aqueous $\mathrm{NaCl}$ solution. J Colloids Interface Sci 2003;263:306-11.

[227] Kitchens KM, El-Sayed MEH, Ghandehari H. Transepithelial and endothelial transport of poly(amidoamine) dendrimers. Adv Drug Deliv Rev 2005;57:2163-76

[228] Perumal OP, Inapagolla R, Kannan S, Kannan RM. The effect of surface functionality on cellular trafficking of dendrimers. Biomaterials 2008;29:3469-76.

[229] Pisal DS, Yellepeddi VK, Kumar A, Kaushik RS, Hildreth MB, Guan X, et al. Permeability of surface-modified polyamidoamine (PAMAM) dendrimers across Caco-2 cell monolayers. Int J Pharm 2008;350:113-21.

[230] Seib FP, Jones AT, Duncan R. Comparison of the endocytic properties of linear and branched PEIs, and cationic PAMAM dendrimers in B16f10 melanoma cells. J Control Release 2007;117:291-300.

[231] Langer R, Vacanti JP. Tissue engineering. Science 1993;260:920-6.

[232] Griffith LG, Naughton G. Tissue engineering-current challenges and expanding opportunities. Science 2002;295:1009-14.

[233] Heyes CD, Groll J, Moller M, Nienhaus GU. Synthesis, patterning and applications of star-shaped poly(ethylene glycol) biofunctionalized surfaces. Mol Biosyst 2007;3:419-30.

[234] Kawase M, Kurikawa N, Higashiyama S, Miura N, Shiomi T, Ozawa C, et al. Effectiveness of polyamidoamine dendrimers modified with tripeptide growth factor, glycyl-L-histidyl-L-lysine, for enhancement of function of hepatoma cells. J Biosci Bioeng 1999;88:4337.

[235] Tomalia DA, Huang B, Swanson DR, Brothers II HM, Klimash JW. Structure control within poly(amidoamine) dendrimers: Size, shape and regio-chemical mimicry of globular proteins. Tetrahedron 2003:59:3799-813.

[236] Tomalia DA, Brothers HM, Piehler LT, Durst HD, Swanson DR. Partial shell-filled core-shell tecto(dendrimers): a strategy to surface differentiated nano-clefts and cusps. Proc Natl Acad Sci USA 2002;99:5081-7. 
[237] Gabellieri E, Strambini GB, Shcharbin D, Klajnert B, Bryszewska M. Dendrimer-protein interactions studied by tryptophan room temperature phosphorescence. BBA-Proteins Proteom 2006;1764:1750-6.

[238] Klajnert B, Stanislawska L, Bryszewska M, Palecz B. Interactions between PAMAM dendrimers and bovine serum albumin. BBAProteins Proteom 2003;1648:115-26.

[239] Kim M-H, Kino-Oka M, Kawase M, Yagi K, Taya M. Response of human epithelial cells to culture surfaces with varied roughnesses prepared by immobilizing dendrimers with/without d-glucose display. J Biosci Bioeng 2007;103:192-9.

[240] Benhabbour SR, Sheardown H, Adronov A. Cell adhesion and proliferation on hydrophilic dendritically modified surfaces. Biomaterials 2008;29:4177-86.

[241] Abukawa H, Shin M, Williams WB, Vacanti JP, Kaban LB, Troulis MJ. Reconstruction of mandibular defects with autologous tissueengineered bone. J Oral Maxillofac Surg 2004;62:601-6.

[242] Petite H, Viateau V, Bensaid W, Meunier A, de Pollak C, Bourguignon $\mathrm{M}$, et al. Tissue-engineered bone regeneration. Nat Biotechnol 2000;18:959-63.

[243] Saint-Cyr M, Miranda D, Gonzalez R, Gupta A. Immediate corticocancellous bone autografting in segmental bone defects of the hand. J Hand Surg-Brit Eur 2006;31:168-77.

[244] Merkx MAW, Maltha JC, Freihofer H-PM, Kuijpers-Jagtman AM Incorporation of three types of bone block implants in the facial skeleton. Biomaterials 1999;20:639-45.

[245] Su-Gwan K, Hak-Kyun K, Sung-Chul L. Combined implantation of particulate dentine, plaster of Paris, and a bone xenograft $\left(\right.$ Bio-Oss ${ }^{\circledR}$ ) for bone regeneration in rats. J Cranio Maxill Surg 2001;29:282-8

[246] Babensee JE, Anderson JM, McIntire LV, Mikos AG. Host response to tissue engineered devices. Adv Drug Deliv Rev 1998;33:111-39.

[247] Kahan BD. Immunosupressive therapy. Curr Opin Immunol 1992;4:553-60.

[248] Srouji S, Livne E. Bone marrow stem cells and biological scaffold for bone repair in aging and disease. Mech Ageing Dev 2005;126:281-7.

[249] Ohgushi H, Kotobuki N, Funaoka H, Machida H, Hirose M, Tanaka Y, et al. Tissue engineered ceramic artificial joint-ex vivo osteogenic differentiation of patient mesenchymal cells on total ankle joints for treatment of osteoarthritis. Biomaterials 2005;26:465461.

[250] Uemura T, Dong J, Wang Y, Kojima H, Saito T, Iejima D, et al. Transplantation of cultured bone cells using combinations of scaffolds and culture techniques. Biomaterials 2003;24:2277-86.

[251] Oliveira JM, Sousa RA, Kotobuki N, Tadokoro M, Hirose M, Mano $\mathrm{JF}$, et al. The osteogenic differentiation of rat bone marrow stromal cells with dexamethasone-loaded carboxymethylchitosan/poly(amidoamine) dendrimer nanoparticles. Biomaterials 2009;30:804-13.

[252] Oliveira JM, Sousa RA, Kotobuki N, Malafaya PB, Tadokoro M, Hirose M, et al. Dexamethasone-loaded carboxymethylchitosan/poly(amidoamine) dendrimer nanoparticles enhances bone formation in vivo. Tissue Eng, Part A 2008;14:721.

[253] Lygre $H$. Prosthodontic biomaterials and adverse reactions: a critical review of the clinical and research literature. Acta Odontol Scand 2002;60:1-9.

[254] Viljanen EK, Skrifvars M, Vallittu PK. Dendritic copolymers and particulate filler composites for dental applications: degree of conversion and thermal properties. Dent Mater 2007;23:1420-7.

[255] Temenoff JS, Mikos AG. Review: tissue engineering for regeneration of articular cartilage. Biomaterials 2000;21:431-40.

[256] Aigner T, Stove J. Collagens- major component of the physiological cartilage matrix, major target of cartilage degeneration, major tool in the cartilage repair. Adv Drug Deliv Rev 2003;55:1569-93.

[257] Buckwalter JA. Articular cartilage: injuries and potential for healing. J Orthop Sports Phys Ther 1998;28:192-202.

[258] Redman SN, Oldfield SF, Archer CW. Current strategies for articular cartilage repair. Eur Cell Mater 2005;9:23-32.

[259] Glowacki J. In vitro engineering of cartilage. J Rehabil Res Dev 2000;37:171-7.

[260] Miller BS, Steadman JR, Briggs KK, Rodrigo JJ, Rodkey WG. Patient satisfaction and outcome after microfracture of degenerative knee. J Knee Surg 2004;17:13-7.

[261] Krishnan SP, Skinner JA. (i) Novel treatments for early osteoarthritis of the knee. Curr Orthopaed 2005;19:407-14.

[262] Akizuki S, Yasukawa Y, Takizawa T. Does arthroscopic abrasion arthroplasty promote cartilage regeneration in osteoarthritic knees with eburnation? A prospective study of high tibial osteotomy with abrasion arthroplasty versus high tibial osteotomy alone. Arthroscopy 1997;13:9-17.

[263] Shapiro F, Koide S, Glimcher MJ. Cell origin and differentiation in the repair of full-thickness defects of articular cartilage. J Bone Joint Surg Am 1993;75:532-53.

[264] Tibesku CO, Szuwart T, Kleffner TO, Schlegel PM, Jahn UR, Van Aken $\mathrm{H}$, et al. Hyaline cartilage degenerates after autologous osteochondral transplantation. J Orthop Res 2004;22:1210-4.

[265] Sontjens SHM, Nettles DL, Carnahan MA, Setton LA, Grinstaff MW. Biodendrimer-based hydrogel scaffolds for cartilge tissue repair. Biomacromolecules 2006; 7:310-6.

[266] Khew ST, Yang QJ, Tong YW. Enzymatically crosslinked collagenmimetic dendrimers that promote integrin-targeted cell adhesion. Biomaterials 2008;29:3034-45.

[267] Duan X, Sheardown H. Dendrimer crosslinked collagen as a corneal tissue engineering scaffold: mechanical properties and corneal epithelial cell interactions. Biomaterials 2006;27:4608-17.

[268] Grinstaff MW. Designing hydrogel adhesives for corneal wound repair. Biomaterials 2007;28:5205-14.

[269] Hata N, Kim M-H, Isoda K, Kino-Oka M, Kawase M, Yagi K, et al. Dendrimer-immobilized culture surface as a tool to evaluate formation of cellular cytoskeleton of anchorage-dependent cells. J Biosci Bioeng 2004;97:233-8.

[270] Mellado M, Carrasco YR. Imaging techniques: new insights into chemokine/chemokine receptor biology at the immune system. Pharmacol Therap 2008;119:24-32.

[271] Hamann I, Zipp F, Infante-Duarte C. Therapeutic targeting of chemokine signaling in multiple sclerosis. J Neurol Sci 2008;274:31-8.

[272] Silva TA, Garlet GP, Fukada SY, Silva JS, Cunha FQ. Chemokines in oral inflammatory diseases: apical periodontitis and periodontal disease. J Dent Res 2007;86:306-19.

[273] Cascieri MA, Springer MS. The chemokine/chemokine-receptor family: potential and progress for therapeutic intervention. Curr Opin Chem Biol 2000;4:420-7.

[274] Neel NF, Schutyser E, Sai J, Fan G-H, Richmond A. Chemokine receptor internalization and intracellular trafficking. Cytokine Growth F R 2005;16:637-58.

[275] Cartier L, Hartley O, Dubois-Dauphin M, Krause K-H. Chemokine receptors in the central nervous system: role in brain inflammation and neurodegenerative diseases. Brain Res Rev 2005;48:16-42.

[276] Grainger DJ, Reckless J. Broad-spectrum chemokine inhibitors (BSCIs) and their anti-inflammatory effects in vivo. Biochem Pharmacol 2003;65:1027-34

[277] Honczarenko M, Le Y, Swierkowski M, Ghiran I, Glodek AM, Silberstein LE. Human bone marrow stromal cells express a distinct set of biologically functional chemokine receptors. Stem Cells 2006;24:1030-41.

[278] Kabanov AV, Gendelman HE. Nanomedicine in the diagnosis and therapy of neurodegenerative disorders. Prog Polym Sci 2007;32:1054-82.

[279] Partdrige W. The blood-brain barrier: bottlneck in brain drug development. NeuroRx 2005;2:3-14.

[280] Mayhan W. Regulation of blood-brain barrier permeability. Microcirculation 2001;8:90-104.

[281] Smith MW, Gumbleton M. Endocytosis at the blood brain barrier: from basic understanding to drug delivery strategies. J Drug Target 2006;14:191-214.

[282] da Cruz MT, Cardoso AL, de Almeida LP, Simões S, de Lima MC Tf-lipoplex-mediated NGF gene transfer to the CNS: neuronal protection and recovery in an excitotoxic model of brain injury. Gene Ther 2005; $12: 1242-52$.

[283] da Cruz MT, Simões S, de Lima MC. Improving lipoplex-mediated gene transfer into C6 glioma cells and primary neurons. Exp Neurol 2004;187:65-75.

[284] Rao KS, Reddy MK, Horning JL, Labhasetwar V. TAT-conjugated nanoparticles for the CNS delivery of anti-HIV drugs. Biomaterials 2008;29:4429-38.

[285] Pulkkinen M, Pikkarainen J, Wirth T, Tarvainen T, Haapa-aho V, Korhonen $\mathrm{H}$, et al. Three-step tumor targeting of paclitaxel using biotinylated PLA-PEG nanoparticles and avidin-biotin technology: formulation development and in vitro anticancer activity. Eur Pharm Biopharm 2008;70:66-74.

[286] Vinogradov SV, Batrakova EV, Kabanov AV. Nanogels for oligonucletide delivery to the brain. Bioconjug Chem 2004;15:50-60.

[287] Dhanikula RS, Argaw A, Bouchard JF, Hildgen P. Methotrexate loaded polyether-copolyester dendrimers for the treatment of gliomas: enhanced efficacy and intratumoral transport capability. Mol Pharm 2008;5:105-16. 
[288] Supattapone S, Nguyen H-OB, Cohen FE, Prusiner SB, Scott MR. Elimination of prions by branched polyamines and implications for therapeutics. Proc Natl Acad Sci USA 1999;96:14529-34.

[289] Supattapone S, Wille H, Uyechi L, Safar J, Tremblay P, Szoka FC, et al. Branched polyamines cure prion-infected neuroblastoma cells. J Virol 2001;75:3453-61.

[290] Klajnert B, Cortijo-Arellano M, Cladera J, Bryszewska M. Influence of dendrimer's structure on its activity against amyloid fibril formation. Biochem Biophys Res Commun 2006;345:21-8.

[291] Patel DA, Henry JE, Good TA. Attenuation of $\beta$-amyloid-induced toxicity by sialic-acid-conjugated dendrimers: role of sialic acid attachment. Brain Res 2007;1161:95-105.

[292] Klajnert B, Cangiotti M, Calici S, Majoral JP, Caminade A-M, Cladera J, et al. EPR study of the interactions between dendrimers and peptides involved in Alzheimer's and prion diseases. Macromol Biosci 2007;7:1065-74.

[293] Kim JB, Choi JS, Nam K, Lee M, Park JS, Lee JK. Enhanced transfection of primary cortical cultures using arginine-grafted PAMAM dendrimer, PAMAM-Arg. J Control Release 2006;114:110-7.

[294] Choi JS, Nam K, Park J-Y, Kim J-B, Lee J-K, Park J-S. Enhanced transfection efficiency of PAMAM dendrimer by surface modification with L-arginine. J Control Release 2004;99:445-56.

[295] Wu G, Yang W, Barth RF, Kawabata S, Swindall M, Bandyopadhyaya AK, et al. Molecular targeting and treatment of an epidermal growth factor receptor-positive glioma using boronated cetuximab. Clin Cancer Res 2007;13:1260-8.

[296] Morgan MT, Nakanishi Y, Kroll DJ, Griset AP, Carnahan MA, Wathier $M$, et al. Dendrimer-encapsulated camptothecins: increased solubility, cellular uptake, and cellular retention affords enhanced anticancer activity in vitro. Cancer Res 2006;66:1191321.

[297] Salgado A.J., Oliveira J.M., Fraga J.S., Pereira V.H., Pirraco R.P., Neves N.M., Mano J.F., Reis R.L., Sousa N. Carboxymethylchitosan/poly(amidoamine) dendrimer nanoparticles in central nervous system regenerative medicine: effects on neurons/glial cells viability and internalization efficiency. Macromol Biosci; accepted for publication.

[298] Kay MA, Glorioso JC, Naldini L. Viral vectors for gene therapy: the art of turning infectious agents into vehicles of therapeutics. Nat Med 2001;7:33-40.

[299] Merdan T, Kopecek J, Kissel T. Prospects for cationic polymers in gene and oligonucleotide therapy against cancer. Adv Drug Deliv Rev 2002;54:715-58.

[300] Toub N, Malvy C, Fattal E, Couvreur P. Innovative nanotechnologies for the delivery of oligonucleotides and siRNA. Biomed Pharmacother 2006;60:607-20.

[301] de Martimprey H, Vauthier C, Malvy C, Couvreur P. Polymer nanocarriers for the delivery of small fragments of nucleic acids: oligonucleotides and siRNA. Eur J Pharm Biopharm 2009;71:490-504.

[302] Dufès C, Uchegbu IF, Schätzlein AG. Dendrimers in gene delivery. Adv Drug Deliv Rev 2005;57:2177-202.

[303] Haensler J, Szoka Jr FC. Polyamidoamine cascade polymers mediate efficient transfection of cells in culture. Bioconjug Chem 1993;4:372-9.

[304] Kim HJ, Kwon MS, Choi JS, Kim BH, Yoon JK, Kim K, et al. Synthesis and characterization of poly(amino ester) for slow biodegradable gene delivery vector. Bioorg Med Chem 2007;15:1708-15.

[305] Galletti R, Masciarelli S, Conti C, Matusali G, Di Renzo L, Meschini $\mathrm{S}$, et al. Inhibition of Epstein Barr Virus LMP1 gene expression in B lymphocytes by antisense oligonucleotides: uptake and efficacy of lipid-based and receptor-mediated delivery systems. Antiviral Res 2007;74:102-10.

[306] Caminade A-M, Majoral J-P. Water-soluble phosphorus-containing dendrimers. Prog Polym Sci 2005;30:491-505.

[307] Rolland O, Turrin C-O, Bacquet G, Poupot R, Poupot M, Caminade A$\mathrm{M}$, et al. Efficient synthesis of phosphorus-containing dendrimers capped with isosteric functions of amino-bismethylene phosphonic acids. Tetrahedron Lett 2009;50:2078-82.

[308] Loup C, Zanta M-A, Caminade A-M, Majoral J-P, Meunier B. Preparation of water-soluble cationic phosphorus-containing dendrimers as DNA transfecting agents. Chem- Eur J 1999;5:3644-50.

[309] Arima H, Chihara Y, Arizono M, Yamashita S, Wada K, Hirayama $\mathrm{F}$, et al. Enhancement of gene transfer activity mediated by mannosylated dendrimer $/ \alpha$-cyclodextrin conjugate (generation $3, \mathrm{G} 3$ ). J Control Release 2006;116:64-74.

[310] Joester D, Losson M, Pugin R, Heinzelmann H, Walter E, Merkle HP, et al. Amphiphilic dendrimers: novel self-assembling vectors for efficient gene delivery13. Angew Chem, Int Ed 2003;42:1486-90.
[311] Luo D, Haverstick K, Belcheva N, Han E, Saltzman WM. Poly(ethylene glycol)-Conjugated PAMAM dendrimer for biocompatible, high-efficiency DNA delivery. Macromolecules 2002;35:3456-62.

312] Zhang X-Q, Wang X-L, Huang S-W, Zhuo R-X, Liu Z-L, Mao H-Q, et al. In vitro gene delivery using polyamidoamine dendrimers with a trimesyl core. Biomacromolecules 2005;6:341-50.

[313] Boussif O, Lezoualc'h F, Zanta MA, Mergny MD, Scherman D, Demeneix B, et al. A versatile vector for gene and oligonucleotide transfer into cells in culture and in vivo: polyethylenimine. Proc Natl Acad Sci USA 1995;92:7297-301.

[314] Dung TH, Kim JS, Juliano RL, Yoo H. Preparation and evaluation of cholesteryl PAMAM dendrimers as nano delivery agents for antisense oligonucleotides. Colloids Surface A 2008;313-314:273-7.

[315] Russ V, Günther M, Halama A, Ogris M, Wagner E. Oligoethylenimine-grafted polypropylenimine dendrimers as degradable and biocompatible synthetic vectors for gene delivery. J Control Release 2008;132:131-40.

[316] Tziveleka L-A, Psarra A-MG, Tsiourvas D, Paleos CM. Synthesis and characterization of guanidinylated poly(propylene imine) dendrimers as gene transfection agents. J Control Release 2007; 117:137-46.

[317] Tziveleka L-A, Psarra A-MG, Tsiourvas D, Paleos CM. Synthesis and evaluation of functional hyperbranched polyether polyols as prospected gene carriers. Int J Pharm 2008;356:31424.

[318] Choi JS, Ko KS, Park JS, Kim Y-H, Kim SW, Lee M. Dexamethsone conjugated poly(amidoamine) dendrimer as a gene carrier for efficient nuclear translocation. Int J Pharm 2006;320:171-8.

[319] Manunta M, Nichols B, Hong Tan P, Sagoo P, Harper J, George AJT. Gene delivery by dendrimers operates via different pathways in different cells, but is enhanced by the presence of caveolin. J Immunol Methods 2006;314:134-46.

[320] Ruponen M, Honkakoski P, Rönkkö S, Pelkonen J, Tammi M, Urtti A Extracellular and intracellular barriers in non-viral gene delivery. J Control Release 2003;93:213-7.

[321] Diaz-Mochon JJ, Fara MA, Sanchez-Martin RM, Bradley M. Peptoid dendrimers-microwave-assisted solid-phase synthesis and transfection agent evaluation. Tetrahedron Lett 2008;49:923-6.

[322] Herrmann A, Mihov G, Vandermeulen GWM, Klok H-A, Müllen K. Peptide-functionalized polyphenylene dendrimers. Tetrahedron 2003;59:3925-35.

[323] Mannisto M, Vanderkerken S, Toncheva V, Elomaa M, Ruponen M, Schacht E, et al. Structure-activity relationships of poly(-lysines): effects of pegylation and molecular shape on physicochemical and biological properties in gene delivery. J Control Release 2002;83:169-82

[324] Higashi N, Uchino A, Mizuguchi Y, Niwa M. Chain length effects of oligo(L-lysine)-shelled dendrimers on interaction with DNA. Int J Biol Macromol 2006;38:120-5.

[325] Okuda T, Sugiyama A, Niidome T, Aoyag H. Characters of dendritic poly(-lysine) analogues with the terminal lysines replaced with arginines and histidines as gene carriers in vitro. Biomaterials 2004;25:537-44.

[326] Hussain M, Shchepinov MS, Sohail M, Benter IF, Hollins AJ, Southern EM, et al. A novel anionic dendrimer for improved cellular delivery of antisense oligonucleotides. J Control Release 2004;99:13955.

[327] Vincent L, Varet J, Pille J-Y, Bompais H, Opolon P, Maksimenko A, et al. Efficacy of dendrimer-mediated angiostatin and TIMP-2 gene delivery on inhibition of tumor growth and angiogenesis: in vitro and in vivo studies. Int J Cancer 2003;105:419-29.

[328] Kuo J-HS, Lin Y-L. Remnant cationic dendrimers block RNA migration in electrophoresis after monophasic lysis. J Biotechnol 2007; 129:383-90.

[329] Nishiyama N, Iriyama A, Jang W-D, Miyata K, Itaka K, Inoue $Y$, et al. Light-induced gene transfer from packaged DNA enveloped in a dendrimeric photosensitizer. Nat Mater 2005;4: 934-41.

[330] Shieh M-J, Peng C-L, Lou P-J, Chiu C-H, Tsai T-Y, Hsu C-Y, et al. Non-toxic phototriggered gene transfection by PAMAM-porphyrin conjugates. J Control Release 2008;129:200-6.

[331] Kuo J-HS, Jan M-S, Lin Y-L. Interactions between U-937 human macrophages and poly(propyleneimine) dendrimers. J Control Release 2007;120:51-9.

[332] Kobayashi H, Kawamoto S, Jo S-K, Sato N, Saga T, Hiraga A, et al. Renal tubular damage detected by dynamic micro-MRI with a dendrimer-based magnetic resonance contrast agent. Kidney Int 2002;61:1980-5. 
[333] Rietveld IB, Kim E, Vinogradov SA. Dendrimers with tetrabenzoporphyrin cores: near infrared phosphors for in vivo oxygen imaging. Tetrahedron 2003;59:3821-31.

[334] Thomas TP, Patri AK, Myc A, Myaing MT, Ye JY, Norris TB, et al In vitro targeting of synthesized antibody-conjugated dendrimer nanoparticles. Biomacromolecules 2004;5:2269-74.

[335] Shukla R, Thomas TP, Peters JL, Desai AM, Kukowska-Latallo J, Patri AK, et al. HER2 specific tumor targeting with dendrimer conjugated anti-HER2 mAb. Bioconjug Chem 2006;17:1109-15.

[336] Baek M-G, Roy R. Synthesis and protein binding properties of Tantigen containing GlycoPAMAM dendrimers. Bioorg Med Chem 2002;10:11-7.

[337] Baek M-G, Roy R. Simultaneous binding of mouse monoclonal antibody and streptavidin to heterobifunctional dendritic -lysine core bearing $\mathrm{T}$-antigen tumor marker and biotin. Bioorg Med Chem 2001;9:3005-11.

[338] Kolhe P, Misra E, Kannan RM, Kannan S, Lieh-Lai M. Drug complexation, in vitro release and cellular entry of dendrimers and hyperbranched polymers. Int J Pharm 2003;259:143-60.

[339] Agarwal A, Saraf S, Asthana A, Gupta U, Gajbhiye V, Jain NK Ligand based dendritic systems for tumor targeting. Int J Pharm 2008;350:3-13.

[340] Pun SH, Tack F, Bellocq NC, Cheng J, Grubbs BH, Jensen GS, et al. Targeted delivery of RNA cleaving DNA-enzyme (DNAzyme) to tumor tissue by transferrin-modified, cyclodextrin-based particles. Cancer Biol Ther 2004;7:31-41.
[341] Citro G, Perrotti D, Cucco C, D’Agnano I, Sacchi A, Zupi G, et al. Inhibition of leukemia cell proliferation by receptor-mediated uptake of cmyb antisense oligodeoxynucleotides. Proc Natl Acad Sci USA 1992;89:7031-5.

[342] Majoros IJ, Myc A, Thomas T, Mehta CB, Baker Jr JR. PAMAM dendrimer-based multifunctional conjugate for cancer therapy: synthesis, characterization, and functionality. Biomacromolecules 2006;7:572-9.

[343] Islam MT, Majoros IJ, Baker Jr JR. HPLC analysis of PAMAM dendrimer based multifunctional devices. J Chromatogr B 2005;822:21-6.

[344] Yang W, Cheng Y, Xu T, Wang X, Wen L-P. Targeting cancer cells with biotin-dendrimer conjugates. Eur J Med Chem 2009;44:862-8.

[345] Artemov D, Mori N, Ravi R, Bhujwalla ZM. Magnetic resonance molecular imaging of the HER-2/neu receptor. Cancer Res 2003;63:2723-7.

[346] Tomalia DA. Dendrimers as multi-purpose nanodevices for oncology drug delivery and diagnostic imaging. Nanomedicine 2006;2:309.

[347] Saad M, Garbuzenko OB, Ber E, Chandna P, Khandare JJ, Pozharov VP, et al. Receptor targeted polymers, dendrimers, liposomes: which nanocarrier is the most efficient for tumor-specific treatment and imaging? J Control Release 2008;130:107-14. 